\title{
5. Ergebnisse der Untersuchung
}

\subsection{Die Bedeutung des Publikums aus journalistischer Sicht}

Im Mittelpunkt dieser Untersuchung steht die Frage, was aus journalistischer Sicht die Fernsehberichterstattung über Gewaltkriminalität beim Publikum bewirkt und wie Wirkungsannahmen und Wirkungsabsichten das journalistische Handeln in diesem Themenfeld leiten. Die Analyse stützt sich im Folgenden auf die Befragung von 33 Journalistinnen und Journalisten sowie die Auswertung von 264 Beiträgen zu Gewaltkriminalität im Inland aus 344 Nachrichten- und Boulevardmagazinsendungen. Dabei folgt diese Untersuchung dem dynamisch-transaktionalen Ansatz, wie er in Kapitel 2.2.1 beschrieben wird (vgl. Früh und Schönbach 1982, 1984, 2005, Früh 1991). Aufgrund der Bedeutung, welche die Befragten ihrem Publikum als zentraler Bezugsgröße journalistischen Handelns zusschreiben, bietet sich dieser Ansatz in modifizierter Form an: Im überarbeiteten Schaubild wird deutlich, dass es primär die Medienseite ist, die Botschaften aussendet, während das wesentliche Para-Feedbach von der Publikumsseite ausgeht. Die Publikumsseite ist grau markiert, da diese Prozesse aus journalistischen Mutmaßungen rekonstruiert werden. Das Aktivationsniveau umfasst nicht nur Wissen, sondern auch Annahmen und Empfindungen.

Abb. 10: Publikum und Medienschaffende: Intra- und Inter-Transaktionen aus journalistischer Sicht

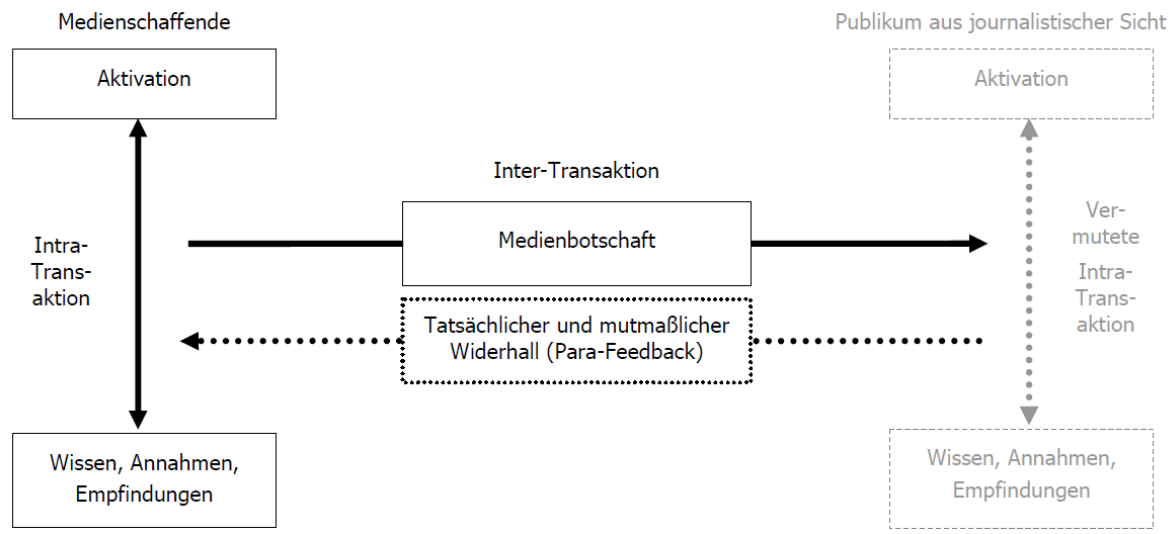

Überarbeitetes Schema nach Früh (1991: 53). 
Im folgenden Kapitel geht es um die Interaktion, die Schönbach und Früh InterTransaktion nennen, und die im Schaubild unten in der mittleren Spalte steht. Um deren Bedeutung zu erfassen, ist zunächst zu fragen: Inwiefern nehmen die Befragten den Widerhall auf ihre Berichterstattung überhaupt wahr? Welche Bedeutung messen sie ihrem Publikum bei? Dabei werden jeweils zunächst die Positionen beleuchtet, die einhellig vertreten werden, und im Anschluss relevante Unterschiede nach Sendergruppen und Formaten. ${ }^{15}$

\subsubsection{Publikumsbedürfnisse als Angelpunkt journalistischen Handelns}

Die Publikumsbedürfnisse zu befriedigen ist das zentrale Handlungsmotiv der Befragten. Das Publikum in seiner Entscheidungsmacht steht im Mittelpunkt. Weil das Bemühen um die Publikumsgunst Angelpunkt journalistischen Handelns ist, wird hier von Publikumszentrierung gesprochen. Alle der Befragten, die für die untersuchten Magazine sowie die Nachrichten von Privatsendern tätig sind, arbeiten ihrem Bekunden nach publikumszentriert.

Magazinredakteurin, Privatsender: „Wir senden das, was der Zuschauer sehen möchte.“

Nachrichtenredakteur, öffentlich-rechtlicher Sender: „Das Publikum spielt eine große Rolle, (...) dafür sind wir da. Sonst wären wir keine Medien.“

Publikumszentrierung bedeutet, sowohl Themenauswahl wie Machart nach dem vermuteten Publikumsinteresse auszurichten. Dazu bedarf es aus journalistischer Sicht unentwegter Feinabstimmung, um den sich ständig wandelnden Publikumsbedürfnissen gerecht zu werden. Dabei ist die Bereitschaft, die Medienbotschaft mundgerecht zu servieren, sehr hoch. Auch wie sie sich inhaltlich positionieren, leiten die Befragten weitgehend von ihrer Kundschaft ab.

Magazinredakteur, Privatsender: „Fernsehen neigt dazu, vielleicht auch weil man feige ist, sich immer auf die vermeintlich richtige Seite zu stellen. Man stellt sich auf die Seite des Opfers, man macht sich zum Anwalt der kleinen Leute. (...) Interessant wird es erst dann, wenn Sie sich mal trauen, gegen den Strich zu bürsten. Aber das wird selten gemacht.“

Mit dem Unterfangen, sich die Publikumssicht zu Eigen zu machen, geht die bekundete Hochachtung vor dem Publikum einher. Dessen Missachtung taucht in den Interviews allein aus der angeblichen Sicht anderer auf. Auch wenn den Zuschauenden tendenziell geringe Bildung und niedrige Einkommen zugerechnet dass alle Befragten zur gleichen Aussage kommen bzw. keiner der Befragten eine gegensätzliche Aussage macht (vgl. Kap. 4.1.4). 
werden, sprechen die Befragten von der Dummheit des Publikums allenfalls als Irrtum vergangener Tage.

Nachrichtenredakteur, Privatsender: „Ich glaube, dass die Wettbewerber begriffen haben, dass der Zuschauer nicht so blöd ist, wie man vielleicht mal irgendwann dachte.“

Magazinredakteur, Privatsender: „Der Zuschauer ist nicht doof, der Zuschauer hat immer Recht!“

Die Befragten nennen eine andauernde Publikumsbindung als ihr Ziel. Es gilt, das Publikum nicht nur kurzzeitig zu gewinnen, sondern zum Ausharren möglichst über die gesamte Sendungslänge und darüber hinaus zu bewegen. Den Strom der Zuschauenden (,audience flow“) zu leiten, erhöht die Chancen jedes einzelnen Beitrags und jeder weiteren Sendung, die Gunst des Publikums zu gewinnen. Wer also mit seinem Beitrag sein Publikum vergrault, erschwert auch anderen in der Redaktion, Zugang zum Publikum zu gewinnen. So wird die Publikumszentrierung als wechselseitige Abhängigkeit innerhalb des Senders verstärkt. Unter allen Umständen soll das Publikum so stark gebunden werden, dass es nicht zur Konkurrenz wechselt oder den Fernseher ausschaltet - besonders in den kritischen Momenten, wenn Beiträge und Sendungen enden.

Letztlich streben die Befragten an, über den Tag hinaus Publikumsbindung zu verfestigen. Dies spielt eine besondere Rolle für die Berichterstattung über Gewaltkriminalität. Danach geht es nicht allein darum, jene Themen möglichst hoch zu dosieren, die als publikumsträchtig gelten, sondern ein Programm so zu gestalten, dass es in seiner Mischung auf nachhaltige und konstante Resonanz stößt. Dabei ist es nach Bekunden der Interviewten strategisch sinnvoll, punktuell auf Emotionalisierung zu verzichten, um als Informationsquelle glaubwürdig zu wirken und damit langfristig akzeptiert zu werden. Einer solchen langfristigen Strategie unterliegt beispielsweise die Platzierung von Nachrichtenblöcken in Boulevardmagazinen. Sie führt zwar Befragten zufolge unmittelbar zu Quotenverlusten, dient aber dazu, den Anspruch der Magazine zu unterstreichen, keineswegs nur emotionale Bedürfnisse zu befriedigen, sondern aktuell und seriös zu berichten.

Magazinredakteur, Privatsender: „Da ist der Aktualitätsanspruch, den die Nachrichtenkollegen genauso haben wie wir, einfach wichtig. Da setzen wir uns sogar über Quotenaspekte hinweg. (...) Es ist ein paradoxes Geschäft, in dem wir uns bewegen. Es ist eine breite Straße, auf dieser Straße gibt es mehrere Fahrspuren. Die Richtung muss stimmen, aber Sie haben mehrere Spuren, auf der Sie sich bewegen können.“

Die Logik der Programmplanung zu verstehen, bedeutet also, diese mäandernden Entscheidungen einzubeziehen. Sie stellen die Publikumszentrierung nicht in Frage, sondern sind Teil einer auf nachhaltigen Erfolg angelegten Strategie. 
Die herausragende Bedeutung der Publikumsorientierung wird von den befragten Beschäftigten der öffentlich-rechtlichen Nachrichten auffällig relativiert. Sie beschreiben eine eigenständige Bedeutung der Nachrichten in den gebührenfinanzierten Programmen und bilden damit unter den Befragten eine sich vom restlichen Untersuchungsfeld unterscheidende Subgruppe.

\begin{abstract}
Nachrichtenredakteurin, öffentlich-rechtlicher Sender: „Wenn der [Zuschauer] uns nicht guckt, habe ich keine Berechtigung mehr. Aber ich kann leider keine Sendung machen, die nur dem Zuschauer gefällt, weil ich gleichzeitig die Verpflichtung habe, nach meinem Staatsvertrag Nachrichten zu gestalten. Kleiner Spagat.“

Nachrichtenredakteur, öffentlich-rechtlicher Sender: „Wir versuchen schon, uns in das absehbare Publikumsinteresse hinein zu versetzen. Dies ist ein Faktor, aber nicht der alleinige.“
\end{abstract}

Ganz offensichtlich wird auch bei öffentlich-rechtlichen Nachrichten intensiv abgewogen, welche Art von Nachrichten das Publikum vermutlich wünscht. Abgelehnt wird aber eine zentrale Orientierung an diesen Wünschen. Diese eigenständige Haltung ist anderen Befragten zufolge auch innerhalb der öffentlich-rechtlichen Sender umstritten. Eine gesunkene Sehbeteiligung an klassischen Nachrichtenformaten gilt als eine neue Herausforderung, die eigenen Prioritäten neu zu bestimmen und die Publikumsorientierung der öffentlich-rechtlichen Nachrichten zu verstärken.

Magazinredakteur, öffentlich-rechtlicher Sender: „Man darf sich nicht gleichzeitig hinstellen und jammern, dass einem die Zuschauer weglaufen. (...) Und wenn ein Boulevardmagazin mehr Zuschauer zieht als ein Nachrichtenjournal, muss man vielleicht mal überlegen, ob man ein bisschen was falsch macht."

Damit ist denkbar, dass eigenständige, aus journalistischen Kriterien und nicht aus Publikumsbedürfnissen entwickelte Qualitätsmaßstäbe in den Sendern selbst in Bezug auf die öffentlich-rechtlichen Nachrichten an Bedeutung verlieren, sobald die Programmverantwortlichen durch sinkende Quoten unter Legitimationsdruck geraten.

\title{
5.1.2 Begründung der Publikumszentrierung
}

Die interviewten Fernsehjournalistinnen und Fernsehjournalisten erörtern die Ursachen einer gewachsenen Publikumszentrierung und deren Auswirkungen auf ihre Themenauswahl und die Machart ihrer Beiträge. Die Befragten begründen die gewachsene Macht des Publikums mit einem veränderten Fernsehmarkt. Mit dem Aufkommen kommerzieller Fernsehsender seit 1984 und der Gründung öffentlichrechtlicher Spartenkanäle hat sich aus ihrer Sicht die Konkurrenz auf dem Markt 
verschärft. Zuschauende können unter immer mehr Programmalternativen wählen. Befürchtungen um Einbußen in der Sehbeteiligung werden vielfach so drastisch beschrieben, als drohe der einzelnen Sendung tatsächlich der Totalverlust des Publikums.

Magazinredakteur, Privatsender: „Wenn man unter Ausschluss der Öffentlichkeit berichtet, dann braucht man gar nicht mehr zu berichten.“

Die zunehmend wahrgenommene Abhängigkeit vom Publikum führt dazu, die Logik des Marktes zu verinnerlichen und die eigene Arbeit als eine Dienstleistung zu betrachten, die in erster Linie von der Kundschaft definiert wird. Darin sehen sich vor allem die in öffentlich-rechtlichen Sendern Beschäftigten unter gewachsenem Druck, sich der Entscheidungsmacht des Publikums zu beugen.

Magazinredakteur, öffentlich-rechtlicher Sender: „Mir ist eine hohe Zuschauerakzeptanz wichtig. Ich bin weg von dieser öffentlich-rechtlichen Philosophie: Wir senden etwas, wir haben etwas zu sagen, und der Zuschauer muss es einfach sehen. Diese Zeiten sind vorbei. Es gibt genügend Sender, wo man hinswitchen kann, und dieses Sendungsbewusstsein und diese Sendemoral, die funktionieren nicht mehr.“

Die Befragten vergleichen die Wahlentscheidungen ihrer Zielgruppe mit einem Kaufverhalten, und das unabhängig davon, ob sie für öffentlich-rechtliche oder private Sender arbeiten. Aus der Verinnerlichung der Marktlogik heraus gehen Befragte in Führungsverantwortung mit Begriffen um, die dem Marketing entstammen. Ein Programmverantwortlicher beispielsweise spricht synonym von Zuschauenden als dem „Zuschauermarkt“, andere charakterisieren den unverwechselbaren Stil der eigenen Sendung als Marktfaktor, als Alleinstellungsmerkmal (unique selling proposition, USP).

Magazinredakteur, Privatsender: „Im Fernsehen wird mittlerweile viel mit Marketing-Begriffen operiert. Ein Beitrag hat plötzlich einen ,USP' zu haben. (...) Da wird dann gesprochen von , approach' und von ,target groups' und von Tonalität. (...) Das ist klar, weil die entscheidenden Leute, die an den Hebeln sitzen, mehr und mehr aus dem Management kommen. Die haben keinen journalistischen Hintergrund, sondern einen betriebswirtschaftlichen Hintergrund."

Damit steigt der Takt, in dem publikumsgerechte Reize gesetzt werden müssen. Vor allem Befragte über 40 Jahren beobachten, dass das Publikum wählerischer geworden ist und infolgedessen der Stellenwert der Sehbeteiligung für die Programmverantwortlichen zugenommen hat. Danach führt die erhöhte Programmvielfalt zu kürzeren Zyklen der Zuwendung und zu deutlich nachlassender Programmtreue. Die Hand an der Fernbedienung ist nervöser geworden. Dies erschwert beispielsweise den Aufbau längerer Spannungsbögen. Dieser höhere Takt von Auswahlentscheidungen führt zu einer größeren Bedeutung der Quote. So werden gleichsam immer 
häufiger Prüfsteine einer Publikumszentrierung gesetzt. Dadurch erhöht sich der Druck, die flatterhafte Publikumsgunst immer wieder neu zu erringen.

\subsubsection{Wirkungsabsichten jenseits der Publikumszentrierung}

Die Befragten schildern, inwieweit sie Wirkungsabsichten verfolgen, die sich nicht aus Publikumsbedürfnissen ableiten lassen. Um die Erklärkraft der Publikumszentrierung als Leitmotiv der Befragten zu überprüfen, wurden in den Interviews gleichsam als Gegenprobe Motive erörtert, aus persönlichen Bedürfnissen heraus zu handeln. Angesprochen wurden dabei sowohl emotionale wie ideologische Motive mit Blick auf die Berichterstattung über Gewaltkriminalität: Inwieweit legen es die Befragten darauf an, womöglich aus persönlicher Straflust Tatverdächtige zu stigmatisieren? Inwieweit versuchen sie, mit ihrer Berichterstattung auf Polizei und Justiz einzuwirken und eigene politische Ansichten zu forcieren? Inwieweit schließlich sehen sie sich in erzieherischer Funktion gegenüber ihrem Publikum, um beispielsweise zur Verbrechensverhütung beizutragen?

Nachrichtenredakteurin, Privatsender: „Ich bin nicht die Frau Oberlehrerin, die alle Zuschauer umerziehen kann.“

Magazinredakteurin, öffentlich-rechtlicher Sender: „Wir sind keine Erziehungsanstalt und auch keine Besserungsanstalt.“

Einhellig äußern die Befragten aller Sender und Formate, dass eine Einflussnahme auf ihr Publikum und die Gesellschaft für sie kein vorrangiges Ziel ist. Erzieherische Absichten gelten als unjournalistisch.

Straflust: das Fernsehen als Pranger

In den Interviews wurde versucht zu erkunden, inwieweit die Befragten darauf zielen, Tatverdächtige bzw. Verurteilte zu stigmatisieren und ob dabei ein Strafbedürfnis der Befragten handlungsrelevant ist. Zur Diskussion gestellt wurde, ob das Fernsehen als Pranger wirken solle. Keiner der Befragten bejaht diese Frage grundsätzlich. Insofern besteht Einhelligkeit. Aufgrund der intensiven Debatten, die um eine Prangerrolle der Medien geführt wurden, sollen hier auch die vereinzelt abweichenden Aussagen dargestellt werden. Einige Befragte fordern ein Anprangern vor allem beim Verdacht der Gewalt an Kindern oder auch bei ausländerfeindlicher Gewalt.

Agenturreporter: „Dass man diesem Monster, diesem Kindergärtner, der sich an Kindern vergreift, auch ein Gesicht geben kann. (...) Ihm gegenüber empfinde ich kein Mitleid, der soll mal an den Pranger gestellt werden." 
Nachrichtenredakteur, Privatsender: „Wenn fünf Schläger einen Afrikaner zusammentreten, ohne Grund, dann (...) will ich die Gesichter von diesen Arschlöchern sehen, da wird auch nichts gepixelt."

Einige - allesamt männliche - Befragte äußern sich drastisch, wenn es um kindliche Opfer geht. Wer sich an Kindern vergreift bzw. dessen verdächtigt wird, gilt als „Schwein“ oder „echter Dreck“. In solchen, eher als Ausnahmen betrachteten Fällen, wird für gut geheißen, im Wortsinne anzuprangern - also die Beschuldigten zu bestrafen, indem sie bloßgestellt und öffentlichen Angriffen ausgesetzt werden. Die Phantasien reichen so weit, Verdächtige erheblich unter Druck zu setzen.

Magazinredakteur, Privatsender: „Dann hoffe ich, dass der sich ein Schrittchen gen Selbstmord bewegt. (lacht) Ja, nicht ganz so, aber dass der schon Reue empfindet, dass der schon sagt: ,Mein Gott, was habe ich denn da gemacht?’“

Freier Reporter, öffentlich-rechtlicher und Privatsender: „Das sind für mich Schweine. (...) Die Leute, die so was machen, sollen sich nie sicher sein.“"

Befragte in Leitungsfunktion dagegen halten die Realisierung von Straflust bzw. aktiver Intervention für unakzeptabel - auch wenn sich Reporter und Reporterinnen aus ihrer Sicht verständlicherweise empören, wenn sie beispielsweise mit Personen konfrontiert sind, die der Gewalt an Kindern bezichtigt werden oder überführt sind. Offene Angriffe und eine sichtbare Bloßstellung gelten als Tabu. Wird gelegentlich journalistische Straflust sichtbar, tilgen Interviewte in Leitungsfunktion dies ihrem Bekunden nach aus dem Sendematerial.

Magazinredakteur, Privatsender: „Das nehmen wir alles raus, weil ich das total unangenehm finde. Weil wir da plötzlich in der Rolle eines Scharfrichters sind - und das wollen wir nicht sein."

Nachrichtenredakteurin, öffentlich-rechtlicher Sender: „Wir würden eher eine Story rausschmeißen, bevor wir das Gefühl haben, da hat eine persönliche Vorliebe, eine persönliche Antipathie oder eine persönliche Regung im Wesentlichen die Machart oder das Sein dieses Stückes in der Sendung bestimmt.“

Magazinredakteur, öffentlich-rechtlicher Sender: „So sehr, wie einen manchmal selber vielleicht die Wut packt oder die Fassungslosigkeit, das muss man unterdrücken.“

\section{Einfluss auf Polizei und Justiz}

Mit ihrer Berichterstattung auf die Arbeit der Polizei einzuwirken, wird von den Befragten durchweg als abwegig bezeichnet. Zwar gibt es einzelne Stimmen zu Ermittlungspannen oder sonstigen Versäumnissen der Polizei. Dennoch wird eine kritische Begleitung der Polizei oder gar eine Einflussnahme für praktisch unmöglich gehalten. 
Magazinredakteur, Privatsender: „Auf die Arbeit der Ermittler haben wir keine Wirkung. Da machen wir uns überhaupt keine Illusion."

Auch zu einer gezielten Einflussnahme auf die Justiz bekennt sich keiner der Befragten. Analog zur Zurückhaltung gegenüber der Polizei betonen Journalistinnen und Journalisten, dass sie nicht über ausreichendes Recherchewissen verfügen, um Verfahrens- oder Rechtsmängel erkennen und daraus eine Kritik ableiten zu können.

\section{Einfluss auf die Politik}

Ebensowenig wollen die Befragten ihrem Bekunden nach mit der Fernsehberichterstattung über Gewaltkriminalität auf die Politik im Allgemeinen oder auf Gesetzgebungsverfahren im Besonderen Einfluss zu nehmen. Strategien, mit bestimmten Inhalten und Formen politisch etwas zu verändern, gelten als aussichtslos.

Magazinredakteur, öffentlich-rechtlicher Sender: „Ich kann mit so einer Sendung Menschen erreichen. Aber ich kann politisch nichts erreichen."

Zwar halten die Befragten unbeabsichtigte politische Wirkungen für möglich, dass etwa aufgrund öffentlichen Drucks beispielsweise Gesetze verschärft werden. Allerdings berichten sie keinen Fall, in dem sie von einer publikumszentrierten Berichterstattung Abstand genommen hätten, um bestimmte Folgen zu vermeiden und damit einem politischen Kalkül Rechnung zu tragen.

\section{Einfluss auf die Bevölkerung}

Als weiteres mögliches Handlungsmotiv jenseits einer Publikumszentrierung wurde erfragt, inwieweit Journalistinnen und Journalisten aus eigenen Beweggründen heraus das Ziel verfolgen, auf die Bevölkerung einzuwirken, um Einstellungen und Verhalten zu verändern und damit Gewalttaten zu verhindern. Ob dies möglich ist, wird skeptisch gesehen. Gleichwohl gilt die Verbrechensverhütung als willkommener Nebenbei-Effekt. In diesem Zusammenhang ist beispielsweise vom Gebrauchswert von Nachrichten als „news to use“ die Rede. Ein möglicher Gebrauchswert kann darin liegen, dass Zuschauende sich selbst und andere aufgrund der Berichterstattung besser schützen und Risikoverhalten vermeiden. Die Befragten räumen allerdings ein, dass dieser Nutzen in der Kriminalitätsberichterstattung kaum eine Rolle spielt.

Magazinredakteur, Privatsender: „Der Gebrauchswert rückt immer in den Hintergrund. (...) Das ist mit Sicherheit immer ein Teil, aber ich glaube, das ist eher ein Feigenblättchen. Also de facto ist es einfach die Geschichte, wo die Leute stehen bleiben, hingucken und sagen, huch, um Himmelswillen. Das ist der einzige Zweck.“ 


\subsubsection{Zusammenfassung}

Die Publikumsbedürfnisse werden als zentrale Leitgröße journalistischen Handelns beschrieben. Ziel ist es, kurzfristig eine hohe Sehbeteiligung und vor allem langfristig eine hohe Akzeptanz zu erfahren. Publikumszentriert arbeiten ihrem Bekunden nach alle der Befragten bis auf die für öffentlich-rechtliche Nachrichten Tätigen sie sehen sich in einem besonderen Spannungsfeld, sowohl die Ansprüche des Publikums wie staatsvertragliche Verpflichtungen zu erfüllen. Die Befragten schildern, dass mit der Öffnung und Verbreiterung des Fernsehmarktes die Konkurrenz der Sender sich verschärft und der Wankelmut des Publikums zugenommen hat. Damit begründen sie eine weitgehende Anpassung an die Bedürfnisse des Publikums.

Emotionale oder ideologische Motive, jenseits der Publikumszentrierung mit der Fernsehberichterstattung über Gewaltkriminalität Einfluss zu nehmen, sind für die Befragten ohne Belang. Erzieherisch zu wirken, ist verpönt. Die Abscheu insbesondere vor der Gewalt an Kindern äußert sich zwar bei einigen Befragten in deutlicher Straflust. Interviewte in Leitungsfunktion dagegen beschreiben, dass sie eine von persönlichen Gefühlen geleitete Berichterstattung verhindern. Keiner der Befragten formuliert den Anspruch, auf Polizei, Justiz oder die Politik einzuwirken. Lediglich die Absicht, auf die Öffentlichkeit zur Verbrechensverhütung einzuwirken, wird als Nebenbei-Effekt begrüßt, nicht aber planvoll verfolgt.

\subsection{Die Formung des Publikumsbildes}

Im folgenden Kapitel geht es darum, den Prozess der Interaktion zwischen Publikum und Medienschaffenden zu beleuchten. Woraus speisen sich die Wirkungsannahmen der Befragten, wie entsteht ihr Bild vom Publikum?

\subsubsection{Die Einschaltquote als Leitgröße}

Zu fragen ist, welche Rolle die im Redaktionsalltag „Quoten“ genannten Daten der Sehbeteiligung für die Steuerung journalistischen Handelns und die Bildung von Wirkungsannahmen und Wirkungsabsichten spielen. Für wie zuverlässig werden sie gehalten? Wie werden sie gedeutet, um Wirkungen auf das Publikum zu erklären? Diese Fragen werden fokussiert auf die Berichterstattung über Gewaltkriminalität. Quer durch verschiedene Redaktionen werden die Quoten als Messwert von Publikumsaffinität betrachtet, und was sich als publikumsaffin erwiesen hat, wird reproduziert, bis sich im dynamischen Wechselspiel zwischen Publikum und Medien neue Bedürfnisse zeigen.

Nachrichtenredakteur, Privatsender: „Es gibt die Quoten. Und wir wissen einfach, dass solche Geschichten funktionieren.“ 
Redakteurin für Magazine und Nachrichten, öffentlich-rechtlicher Sender: „Es ist sicher ein verstärkender Effekt, dass man immer wieder auf einen fahrenden Zug aufspringt. Wenn es einmal gut gelaufen ist, macht man weiter damit.“

An der Validität dieser quantitativen Publikumsforschung äußert keiner der Befragten grundsätzliche Zweifel. Alle Befragten in Leitungsfunktionen schildern, wie intensiv sie die Daten der Sehbeteiligung wahrnehmen. Eine besondere Rolle spielen dabei die Verläufe innerhalb der Sendungen und die Daten über die Zusammensetzung des jeweiligen Publikums, um sich ein detailliertes Bild vom eigenen Wirkungserfolg - und dem der Konkurrenz - zu machen. Steigt die Sehbeteiligung eines Beitrags deutlich an, so wird davon ausgegangen, dass die Bedürfnisse des Publikums erfüllt wurden und ein publikumszentriertes Handeln damit erfolgreich war. Dabei weisen die Interviewten darauf hin, dass auch beitragsunabhängige Faktoren bedeutsam sind - beispielsweise der Sendeplatz, das Programmumfeld des eigenen Hauses und das Gegenprogramm der konkurrierenden Sender. Quotenausschläge von Dauer allerdings werden durchweg als starker Indikator genommen. Auch in den öffentlich-rechtlichen Sendern ist den Befragten zufolge die Bereitschaft deutlich gesunken, Quoteneinbußen hinzunehmen.

Magazinredakteur, öffentlich-rechtlicher Sender: „Wenn ein Thema zwei-, dreimal nicht läuft, dann sagt man, lass' jetzt mal die Finger davon."

In Nuancen unterscheidet sich, wie Befragte ihre Abhängigkeit von der Sehbeteiligung deuten. Angestellte ohne Führungsverantwortung und freiberuflich Tätige skizzieren sich tendenziell als Getriebene, Angestellte in Leitungsfunktion beschreiben sich eher als aktiv.

Magazinredakteur, öffentlich-rechtlicher Sender: „Meine Lieblingsbeschäftigung, das gebe ich offen zu, ist die Analyse des Quotenminutenverlaufs am nächsten Tag.“

Freier Autor, öffentlich-rechtlicher Sender: „Es ist schon so gewesen, dass man nach den einzelnen Dokumentationen wie ein Schuljunge am nächsten Morgen auf den Anruf wartete, hat man nun das Klassenziel erreicht oder nicht. Das ist bitter, dieses Gefühl. Es macht einen als Dokumentarfilmer klein, von diesen Zahlen letztlich abhängig zu sein.“

Unabhängig von der individuellen Verortung im redaktionellen Gefüge aber berichten die Befragten einmütig von einem umfassenden Quotendruck und werden die Daten der Sehbeteiligung als Leitgröße redaktionellen Handelns nicht grundsätzlich in Frage gestellt.

\section{Unterschiede nach Sendern und Formaten}

Die Bedeutung der Quote wird in öffentlich-rechtlichen Sendern als ähnlich groß wie in den Privatsendern beschrieben. Damit zeigt sich eine Konvergenz zwischen den Sendern, die vor allem Befragte des öffentlich-rechtlichen Fernsehens über 
einem Alter von 40 Jahren im Rückblick auf ihre berufliche Entwicklung und die Veränderungen in den Redaktionen beobachten.

Magazinredakteurin, öffentlich-rechtlicher Sender: „Ein anderer Aspekt ist die Quote, weil die auch im Öffentlich-Rechtlichen zunehmend zählt. Und wer etwas anderes behauptet, weiß es vielleicht nicht besser, ich möchte nicht sagen, lügt.“

Vom unmittelbaren Druck der Quote sehen sich lediglich diejenigen ausgenommen, die Beiträge für die Hauptnachrichten der öffentlich-rechtlichen Sender produzieren. Eine Verknüpfung des Publikumsinteresses mit einzelnen Beiträgen ist dort unmöglich, da den Befragten zufolge das Publikum diese Nachrichtensendungen gewöhnlich als Ganzes betrachtet.

Nachrichtenredakteurin, öffentlich-rechtlicher Sender: „Nachrichten sind wie Zähne putzen. Sie hören nicht mitten drin auf. Die Leute gehen raus, sie machen leise, telefonieren mit ihrer Mutter, schmieren sich ein Bütterchen. Sie gucken bis zu dem Moment, wo ihnen die Nachrichtenmacher selbst signalisieren, das ist nicht so wichtig: Lotto, Wetter, Sport. Ansonsten wird bis zum bitteren Ende geguckt.“

Dies bedeutet, dass sich in diesem Segment des Fernsehprogramms der Quotendruck nicht auf den einzelnen Beitrag, sondern die gesamte Sendung auswirkt, sich also gleichsam großflächiger verteilt.

\subsubsection{Geringer Widerhall des Publikums}

Die Befragten beschreiben, inwieweit sie unmittelbar Resonanz von ihrem Publikum erfahren. Auch wenn Fernsehjournalisten und Fernsehjournalistinnen ein Millionenpublikum erreichen und sich eigenem Bekunden zufolge ihr Berufsalltag vor allem darum dreht, ihrer Kundschaft gerecht zu werden, befinden sie sich in einem Dilemma: das Publikum regt sich per Fernbedienung, aber es schweigt sich über seine Motive aus.

Nachrichtenredakteurin, öffentlich-rechtlicher Sender: „Von den Zuschauern kriege ich praktisch keine Reaktion. Ich habe in meinem ganzen Journalistenleben vielleicht fünf, sechs Zuschriften gekriegt."

Magazinredakteur, Privatsender: „Da kommt vielleicht einmal im Jahr eine Mail, die einen persönlich betrifft.“

Die Befragten schildern ein solch spärliches unmittelbares Echo auf kurze, aktuelle Beiträge, aber auch auf längere Dokumentationen. Befragte mit größerer Berufserfahrung nehmen einen drastischen Rückgang der Publikumsresonanz wahr. 
Dokumentarfilmerin, öffentlich-rechtlicher Sender: „Am Tag nach Dokumentationen standen die Telefone nicht mehr still. Die Sekretärinnen konnten ihre gesamte andere Arbeit ruhen lassen, weil sich so viele Zuschauer gemeldet haben. Wir haben bergeweise Post bekommen, die beantwortet werden musste. Heute, selbst bei sehr kritischen Filmen, sind es in der Regel drei, vier Anrufe, zwei, drei Briefe oder Emails, mehr ist das nicht mehr.“

Ein anderes Bild ergibt sich lediglich, wenn ein konkretes, inhaltliches Interesse geweckt wird. Eine Redakteurin berichtet beispielsweise von einer hohen Resonanz auf einen Beitrag über Betrug im Internet, der zu konkreten Nachfragen anderer Betroffener führt. Einen unmittelbaren Dialog mit ihrem Publikum schildern vor allem die Reporterinnen und Reporter, die während Dreharbeiten ins Gespräch kommen oder im Alltag wieder erkannt werden, weil sie selber vor der Kamera stehen. Ein Korrektiv journalistischer Arbeit erwächst aus diesen Begegnungen kaum. Bestenfalls können Befragte aus diesen zufälligen Gesprächen ziehen, dass ihre Art zu berichten den Menschen, die sie zufällig treffen, auf irgendeine Weise gefallen hat. Über eine freundliche Vagheit gehen diese Reaktionen nicht hinaus.

Reporterin, öffentlich-rechtlicher Sender: „Das ist oft rührend unkritisch. Da gibt es keine journalistischen Hinweise, sondern das ist Gefallen oder Nichtgefallen.“

Die Befragten kommen überdies zu dem Schluss, dass das Echo, das die Redaktionen spärlich, unbestimmt und zufällig erreicht, wenig über die Gesamtheit des Publikums aussagt. Aus ihrer Sicht sind Publikumsreaktionen kaum ernst zu nehmen, weil sich hier nicht die Zuschauenden, sondern meist nur die empörten Zuschauenden zu Wort melden.

Dokumentarfilmerin, öffentlich-rechtlicher Sender: „Es gibt Zuschauer, die sagen, sie mögen die Musik nicht und fragen: Warum muss man das so dramatisch machen? Die fordern, dass das Ganze noch nüchterner erzählt werden sollte. Allerdings sind das ja auch Zuschauer, die den Film geguckt haben. Ob sie ihn geguckt hätten, wenn er sehr viel nüchterner erzählt worden wäre, weiß ich nicht."

Möglicherweise also spiegeln aus journalistischer Sicht die Publikumsreaktionen nicht einmal das Verhalten jener wider, die sich äußern. So mutmaßen die Befragten, dass bei den Reaktionen soziale Erwünschtheit eine größere Rolle spielt als tatsächliche Fernsehbedürfnisse - dass also selbst jene, die bestimmte Inhalte oder Formen als zu gewalttätig kritisieren, sie dennoch einschalten und interessant finden. 
Im Spannungsfeld zwischen dem täglichen Datenstrom zur Sehbeteiligung des Publikums und dessen spärlichem unmittelbarem Echo beschreiben die Befragten ihre Unsicherheit über die Folgen ihres Handelns.

Magazinredakteur, öffentlich-rechtlicher Sender: „Manchmal möchte man Mäuschen spielen und einfach mal in die Wohnstuben reingucken."

Nachrichtenredakteur, Privatsender: „Ich sehe nur in die Kamera, nicht in die Wohnzimmer.“

Die täglich einlaufenden quantitativen Daten zur Höhe und vor allem dem Verlauf der Sehbeteiligung innerhalb von Sendungen und Beiträgen und das spärliche Publikumsecho erfordern ständige Interpretationsarbeit, betonen die Befragten. So zeigen sich die Interviewten davon überzeugt, dass Zuschauende zwar ein feines Gespür für Beitragsmängel haben, aber ihren Griff zur Fernbedienung schlecht begründen können. Damit liefern die quantitativen Daten zur Sehbeteiligung und die qualitativen Daten in Form der unmittelbaren Resonanz einzelner keine Gebrauchsanweisung für die Redaktion, sondern stets nur Rohmaterial, das kluger Analyse und zielsicherer Strategien bedarf. Ein Image des Publikums als fiktiver Zielperson schildert keiner der Befragten, die Zielgruppe wird allenfalls grob definiert.

Nachrichtenredakteurin, öffentlich-rechtlicher Sender: „Ich versuche es so gut zu machen, dass die Gescheiten noch Interesse daran haben und die Dummen es verstehen. Aber das ist auch das einzige Kriterium, unter dem ich an meinen Zuschauer denke.“

Beispielhaft ist in den Interviews mal vom „kleinen Mann“ oder vom „Bildzeitungsleser“ oder vom „Dachdecker, der um 18 Uhr nach Hause kommt und müde ist“ die Rede. Doch ein dauerhaftes Konstrukt, also die Vorstellung einer konkreten Zielperson journalistischen Handelns wird nicht geschildert. So wird die Ermittlung von Publikumsbedürfnissen als außerordentlich dynamisch beschrieben. Entscheidend ist aus Sicht der Verantwortlichen, die Erfolge und Misserfolge von gestern zu begreifen, um heute ein Programm zu erstellen, das sie morgen als Erfolg verbuchen können. Selbst wenn sie also präzise analysieren können, wer an einem Tag eingeschaltet hat und eingeschaltet bleibt, ist damit noch nicht beantwortet, mit welchem Programm sie am folgenden Tag ihr Publikum erreichen, interessieren und berühren. Die Befragten sprechen von „Küchenpsychologie“ und von ständigen Überraschungen.

Nachrichtenredakteur, Privatsender: „Was erwarten die Zuschauer, kennen wir unsere Zuschauer, was denken unsere Zuschauer? Wir sind jeden Tag aufs Neue überrascht, wenn sie nicht das denken, was wir vermuten, was sie denken.“

Magazinredakteur, Privatsender: „Ich halte mein Gewerbe für ein höchst unpräzises, diffuses, sehr mäanderndes Handeln." 
Um die Bedürfnisse ihres Publikums zu befriedigen, plädieren die Befragten dafür, dessen Perspektive anzunehmen. Da es unmöglich ist, sich in jemanden hineinzuversetzen, den man kaum kennt, bedarf es eines Konstrukts. Eine Form dieser Annäherung beschreiben die Befragten darin, sich selbst als Ebenbild des Publikums zu betrachten - und damit dessen Interessen und Empfindungen aus den eigenen $\mathrm{zu}$ erschließen. Diese Annahme impliziert eine Seelenverwandtschaft zwischen Medienschaffenden und Zuschauenden. Dass sie sich als Seismographen der Publikumsbedürfnisse begreifen, begründen die Befragten damit, dass sie in derselben Welt leben wie ihr Publikum.

Nachrichtenredakteurin, öffentlich-rechtlicher Sender: „Sie können nicht immer von sich auf alle anderen schließen. Aber wir stehen ja mitten im Leben, wir sind ganz normale Menschen und ganz normale Familien."

Damit wird eine Art doppelter Wahrnehmung gezeichnet: der professionelle Blick, der beispielsweise technische Mängel wie Schnittfehler, überstrahlte Bilder oder falsche Einblendungen erfasst. Daneben wird ein Empfinden der Profis für die emotionale Substanz eines Beitrags angenommen, das von handwerklichem Fachwissen unbelastet ist und dem Empfinden des Publikums ähnelt. Darüber hinaus beschreiben Befragte in Leitungsposition Strategien, einer drohenden Entfremdung entgegenzuwirken. Diese zielen beispielsweise darauf, die Redaktion so zusammenzusetzen, dass sie zumindest in einigen Aspekten der Zielgruppe entspricht. Damit halten sie für möglich, sich auf sich selbst zu beziehen und damit zugleich das Publikum in großer Breite abzubilden.

Nachrichtenredakteurin, öffentlich-rechtlicher Sender: „Meine Aufgabe ist es, dafür zu sorgen, dass es eine gute Mischung in dieser Redaktion gibt von Menschen, die aus allen Teilen Deutschlands kommen, ich habe Ausländer hier, (...) Menschen, die Singles sind, Kinder haben, älter sind, jünger sind, Männchen, Weibchen.“”

Um sich über die Wirkungen auf das Publikum klar zu werden, spielen die Diskussionen innerhalb der Redaktion eine Schlüsselrolle für die Befragten. Sie betreffen die Arbeit am Beitrag vor der Ausstrahlung ebenso wie die Analyse des Beitrags danach. Zwar zeigt sich keiner der Befragten überzeugt, dass sich ein Resonanztest in der Redaktion eins zu eins auf die erwartbare Resonanz im Publikum übertragen lässt, gleichwohl gilt er als ein wichtiger Gradmesser. Beschrieben wird beispielsweise die Stille nach dem Betrachten eines Beitrags in der Redaktion als Indiz für dessen Potenzial, das Publikum zu berühren.

Magazinredakteur, öffentlich-rechtlicher Sender: „Daran merkt man, dass es besonders emotionale O-Töne waren, dass die Geschichte spannend ist, außergewöhnlich ist, dass so was einem natürlich nah geht: Da redet dann keiner mehr. (...) Wenn wir da mit zehn Leuten sitzen, und alle sind ruhig im Raum, würde ich schon sagen, dass das dann bei vielen Zuschauern zu Hause auch so ist.“ 
Soweit die redaktionell Beschäftigten unsicher sind über den publikumsgerechten Aufbau eines Beitrags, die ansprechende Montage von Bild und Text oder die Auswahl von Originaltönen, suchen sie in redaktionsinternen Diskussionen ein Echo. Diese sollen ihnen mehr Sicherheit über die zu erwartenden Reaktionen des Publikums gewähren, das selbst zum Dialog kaum zur Verfügung steht. Eine wichtige Rolle bei der Validierung in der Redaktion spielen Professionelle anderer Berufe, vor allem Cutterinnen und Cutter.

Nachrichtenredakteurin, Privatsender: „Ganz oft, wenn ich einen Beitrag schneide und texte, frage ich den Cutter: ,Was sagst du dazu? Bewegt dich das? Welcher O-Ton würde dich eher interessieren?' Weil das mein erster Zuschauer ist."

Nicht immer können Journalistinnen und Journalisten in Entscheidungsunsicherheit auf Erfahrungen zurückgreifen. Im tagesaktuellen Medienbetrieb müssen sie sich unter hohem Zeitdruck von Wirkungserwartungen leiten lassen. Beachten konkurrierende Medien - die gleichermaßen ein möglichst hohes Publikum zu erreichen versuchen - ein Thema besonders stark, veranlasst dies publikumszentriert agierende Medienschaffende, es gleichermaßen zu tun.

Magazinredakteur, Privatsender: „Es gibt keine Strategie im Sinne, wir müssen mehr über Sexualmorde an Kindern berichten'. Die haben wir nicht, sondern wir sind schlicht und einfach ein Teil der allgemeinen Aufgeregtheit. Wir befördern die Aufgeregtheit durch unsere Berichterstattung. Wir sind aber genauso Getriebene, sobald es im Ticker drin ist oder in der Regional-Zeitung oder manchmal die Bild es vor uns hat.“

Die Beobachtung der Konkurrenz ist hier bedeutsam als Weg der Vermittlung zentrales Handlungsmotiv ist es, aufzugreifen, was die Menschen bewegt. Offenbar beschränkt sich das Konkurrenzverhalten auf die Übernahme erfolgreicher Vorgehensweisen, ohne dass senderübergreifende konzeptionelle Debatten zu beobachten sind. Darauf deutet, dass Befragte vielfach ähnlich handeln, dafür aber ganz verschiedene Begriffe verwenden. So spricht eine Magazinredakteurin davon, dass in ihrer Redaktion zunehmend verlangt wird, ,den Zuschauer damit zu kriegen, dass es ihn berührt, und das ist eben die Emo-Ebene“. Andere beschreiben das gleiche Phänomen und berichten, dass ihnen der Begriff „Emo-Ebene“ unbekannt ist. Befragte in zwei Sendern sprechen vom „Spooky-Faktor“, ein Ausdruck, der wiederum von keinem weiteren Gesprächspartner verwendet wird.

\subsubsection{Wissenschaftliche Interpretation: Skepsis gegenüber der Medienforschung}

Die Befragten erläutern, welche Rolle die Marktforschung der Sender und der Hochschulen für sie spielt. Konkrete Ergebnisse aus der sendereigenen Marktforschung sind den Befragten, soweit sie nicht Führungsverantwortung tragen, weitgehend unbekannt. Soweit sie von Marktforschung sprechen, beziehen sie sich allein auf die tagesaktuelle Auswertung der Sehbeteiligung. Damit ist keineswegs ausge- 
schlossen, dass Ergebnisse der Marktforschung indirekt journalistische Routinen beeinflussen. Über die Quoten hinausgehende Erkenntnisse aus quantitativen oder qualitativen Publikumsbefragungen werden nur von Interviewten mit Führungsverantwortung erwähnt. Allerdings beschreiben sie die Bedeutung der Marktforschung vor allem als Bestätigung der eigenen Intuition.

Magazinredakteur, Privatsender: „Für mich haben sich die Krawall-Formate überholt. Ich habe letzte Woche eine nagelneue Marktforschung bekommen, und dort wird es mir vom Zuschauermarkt bestätigt. Also ist es jetzt nicht nur meine Wahrnehmung, was ich mir einbilde, was ich hoffe, sondern es wird mir definitiv vom Zuschauermarkt so bestätigt.“

Soweit die Marktforschung aber unerwartete, kontraintuitive Ergebnisse liefert, werden diese vielfach skeptisch aufgenommen oder abgelehnt. So wird beispielsweise vermutet, dass befragte Zuschauerinnen und Zuschauer ihre wirklichen Motive nicht offen legen oder sozial erwünscht antworten, sich aber anders verhalten - beispielsweise ein höheres Informationsbedürfnis angeben, als es ihrem tatsächlichen Fernsehverhalten entspricht. Universitäre Medienforschung spielt in den Interviews nur insofern eine Rolle, als sie sich konkret auf die Formate bezieht, für welche die Befragten selbst tätig sind. So berichten unmittelbar Betroffene von einer Untersuchung, wonach junge Leute Boulevardmagazine ähnlich wie Fernsehnachrichten als Informationssendungen einordnen (Hajok 2004: 123f.). Die Tageszeitung „Die Welt" titelte daraufhin: „,taff” statt ,Tagesschau': Wie Jugendliche fernsehen" (Welt 2004). So erlangte die Studie einige Publizität. Eine systematische Beachtung der aktuellen Medienforschung an den Hochschulen lässt sich aus den Interviews heraus nicht erkennen.

\subsubsection{Zusammenfassung}

Die quantitativen Messwerte zur Sehbeteiligung („Quoten“) gelten als Leitgröße journalistischen Handelns. Lediglich bei den öffentlich-rechtlichen Nachrichten weicht die Bedeutung der Quoten deutlich ab, zumal die Sehbeteiligung innerhalb dieses Formates den Befragten zufolge nur gering schwankt. Die Befragten erhalten kaum Resonanz von ihrem Publikum, und die Reaktionen sind spärlicher als vor ein paar Jahren. Direkte Kontakte mit ihrem Publikum empfinden die Befragten als wenig aussagestark. Die Interviewten beschreiben ihre große Unsicherheit darüber, was ihre Beiträge auslösen. Sie schildern ihre Annahme, aus eigenen Emotionen bzw. der Resonanz in der Redaktion oder dem Handeln anderer Medien schließen zu können, ob ein Thema publikumsaffin zu werden verspricht oder nicht. Befragte ohne Führungsverantwortung schildern, dass ihnen Ergebnisse der sendereigenen Marktforschung, die über die Messung der Sehbeteiligung hinausgehen, unbekannt sind. Interviewte in Leitungsfunktionen verfügen über derartiges Wissen, beschreiben entsprechende Studien aber eher skeptisch und beziehen sich auf sie vor allem als Bestätigung der eigenen Befunde. Die universitäre Medienforschung wird insofern erwähnt, als sie sich konkret auf einzelne Fernsehformate bezieht. 
Die Erkenntnisse und Annahmen von Fernsehjournalistinnen und Fernsehjournalisten darüber, was ihr Publikum an Gewaltkriminalität interessiert, welche Rolle Emotionen spielen und welche Faktoren das Publikumsinteresse bestimmen, werden in diesem Kapitel analysiert. Damit wird die in Abb. 10 auf der rechten Seite gezeigte und in Anlehnung an Früh (1991) sowie Früh und Schönbach (1982, 1984, 2005) Intra-Transaktion genannte Aktivation des Publikums beschrieben (s. Kap. 2.2.1). Die zentrale Frage also ist: Welche Faktoren bestimmen aus journalistischer Sicht, wie sich das Publikum den angebotenen Medieninhalten zuwendet und was diese beim Publikum auslösen? Damit also wird der dynamisch-transaktionale Ansatz nicht empirisch und theoretisch umfassend fundiert, sondern wird das Publikum allein aus dem Wissen, den Annahmen und den Empfindungen der Befragten modelliert. Dafür steht in der überarbeiteten Darstellung (s. Abb.10, rechte Spalte) der Begriff ,vermutete Intra-Transaktionen“.

\subsubsection{Der Nachrichtenwert von Kriminalität}

Die befragten Fernsehjournalistinnen und Fernsehjournalisten schildern aus ihrer Sicht, wie stark und unter welchen Bedingungen ihr Publikum an Gewaltkriminalität interessiert ist. Zur Diskussion gestellt wurde, ob die These „Rotlicht und Blaulicht gehen immer" tatsächlich eine Faustregel in Fernsehredaktionen ist, wie Mayr (2006) behauptet, insbesondere ob Kriminalitätsberichterstattung („Blaulicht") als generell erfolgsträchtig gilt, um das Publikum zu erreichen. Ob körperliche Verletzung regelhaft zu starker Beachtung führt, wurde mit Blick auf die These „If it bleeds it leads“ (Kapuscinski 1999: III, Patterson 2000: 5, Kerbel 2000, Karl 2006: 66) erfragt. Die Befragten widersprechen einhellig den beiden zuvor genannten Thesen. Einen Automatismus sehen sie nicht. Danach ist die Berichterstattung über Gewaltkriminalität nicht stets und unbedingt publikumsaffin. Vielmehr beschreiben die Befragten die Erfahrung, dass das Publikum nur ein begrenztes Maß an Berichterstattung über Gewaltkriminalität wünscht. Eine Häufung berichteter Fälle stößt auf Ablehnung.

Nachrichtenredakteurin, öffentlich-rechtlicher Sender: „Der Zuschauer goutiert sie, wenn sie nicht im Übermaß sind. Sonst wäre es imageschädigend für uns.“

Magazinredakteur, Privatsender: „Irgendwann ist dem Zuschauer genug Verbrechen, genug Gewalt, genug Schlechtes, also ab und zu muss man auch einfach mal durchatmen. Permanentes Penetrieren mit furchtbaren Geschichten tut der Quote nicht gut.“

Nach diesen Annahmen also ist das Publikumsinteresse an Gewaltkriminaliät bedingt. In Ausmaß und Qualität unterliegt es Grenzen. Werden diese Grenzen überschritten, gilt das Publikum als erschöpft und nicht mehr empfänglich für eine weitere Berichterstattung. 
Die Befragten, die für öffentlich-rechtliche Nachrichten arbeiten, gehen davon aus, dass ihr Publikum konstant eine zurückhaltende Gewichtung von Gewaltkriminalität in den Nachrichten erwartet. Die Interviewten, die für die Nachrichten von Privatsendern tätig sind, gehen von einem stärkeren Publikumsinteresse aus, sehen aber zugleich eine abgeflaute Neugier auf spektakuläre Einzelfälle. Damit verwerfen sie eine Steigerungslogik, der zufolge Fernsehnachrichten immer stärkere Reize setzen müssten, um Aufmerksamkeit zu gewinnen.

\begin{abstract}
Nachrichtenredakteurin, Privatsender: „Die Zuschauer sind gesättigt, die wollen nicht immer (...) noch grausamere Verbrechen im Detail. Der Trend geht zur Normalität. Man hat Außergewöhnliches, Exorbitantes, Verrücktes, man hat in den vergangenen Jahren alles gesehen, und der Wunsch ist wieder ein bisschen mehr Normalität, sich vergleichen können, sich selbst einschätzen können, sich wieder finden in Programmen.“
\end{abstract}

Im Vergleich von öffentlich-rechtlichem und privatem Magazinjournalismus zeigt sich eine jeweils entgegengesetzte Entwicklung: Während die für öffentlich-rechtliche Boulevardmagazine arbeitenden Befragten im Verlauf der letzten Jahre einen Anstieg der Nachfrage sehen, geht ihre private Konkurrenz von einem Abflauen aus. In den Privatsendern wird beobachtet, dass die Affinität der Zuschauenden zu Gewaltthemen zeitweise überschätzt und ein breites Publikum durch ein zu hohes $\mathrm{Maß}$ an Berichterstattung ermüdet wurde.

Magazinredakteur, Privatsender: „Das erträgt ja kein Mensch, jeden Abend Gewalt, Mord, Brutalität, heulende Menschen. Das ist eine Weile der Neugierfaktor, weil man das zuvor nicht gesehen hatte und nichts davon in der Realität kannte, sondern nur aus Filmen, aber nach zwei, drei, vier Jahren hat bei den Menschen eine unglaubliche Übersättigung eingesetzt.“

Anders äußern sich diejenigen, die für öffentlich-rechtliche Boulevardmagazine arbeiten. Sie sehen eine weiterhin starke Emotionalisierung durch Gewalt und eine konstante Nachfrage.

\title{
5.3.2 Die Bedeutung von Gefühlen
}

Die befragten Journalistinnen und Journalisten skizzieren aus ihrer Sicht, welche Rolle Gefühle für die Betrachtung von Kriminalitätsberichterstattung spielen, welche Gefühle dies sind und wann im Rezeptionsverlauf sie besonders wichtig sind. Sie beschreiben, inwiefern es darum geht, Gefühle zu zeigen, um sie auszulösen, und zu welchen Folgewirkungen es dabei kommt. Untersucht wird auch, wie sich diese Annahmen vom Publikum nach Programmen und Sendern unterscheiden. 
Gefühle auszulösen gilt als Schlüssel, um zu einem breiten Publikum vorzudringen. Einhellig vertreten dies die Befragten, ungeachtet gradueller Unterschiede zwischen den verschiedenen Fernsehformaten.

Magazinredakteur, Privatsender: „Wenn Geschichten emotional berühren, haben Sie ein besonderes Zuschauerinteresse. Das sehen Sie dann auch in der Kurve.“

Agenturreporter: „Gefühle bei der Berichterstattung bringen unheimlich viel, weil sie für den Sender die Zuschauer fesseln. Die Zuschauer wollen gefesselt werden, und die Zuschauer werden nicht gefesselt durch eine blanke Berichterstattung, dass etwas passiert ist.“

Emotionalisierung als Erfolgskonzept des Fernsehens stützt sich auch auf die Einschätzung, dass es fernsehtypische Wirkungsmechanismen gibt. Danach vermag das Fernsehen, in besonderer Weise Gefühle zu vermitteln und auszulösen.

Dokumentarfilmerin, öffentlich-rechtlicher Sender: „Mit jedem Film müssen wir Gefühle auslösen, weil es sonst nicht funktioniert. Film ist kein intellektuelles Medium, es wirkt über Bilder, und Bilder lösen unmittelbar zunächst mal Gefühle aus. (...) Und wenn Sie es nicht schaffen, bei Zuschauern Gefühle zu erzeugen, dann wird der Film nicht geschaut.“

Im Zeitverlauf der Rezeption gilt eine Emotionalisierung besonders am Anfang eines Beitrags als wirksam. Somit werden die emotionalisierende Anteile als eher beschleunigend für den Wirkungsprozess, informierende Anteile als eher verlangsamend gesehen: Hat ein Beitrag seine emotionale Bindungskraft erst entfaltet, sind damit Informationsbedürfnisse aufgeladen. In diesem Sinne gilt aus journalistischer Sicht das Bedürfnis, emotional erreicht zu werden, als Primärbedürfnis des Fernsehpublikums. Daher rückt Gewalt vor allem in seiner emotionalen Tragweite in den Mittelpunkt des Interesses. Gewalt ist das Ursprungsereignis, und ihre emotionalen Folgen sind das eigentliche Thema. Dabei geht es nicht um die Verletzung an sich, sondern um die Verletzten, um ihr Leid und ihre Hoffnung auf Heilung. Das Publikum, so die Annahme der Befragten, wird vor allem über die Reaktionen der Gewaltopfer emotionalisiert.

Freier Autor, öffentlich-rechtlicher Sender: „Blutig muss es nicht sein. Blut sieht man gar nicht so oft. Das Kriterium, ob man Kriminalstücke macht, ist immer das persönliche Schicksal.“

Agenturreporter: „Die Zuschauer wollen sehen, welche Folgen diese Tragik hat.“

Das Ausmaß der emotionalen Erschütterung ist der entscheidende Gradmesser, ob ein Bericht über eine Gewalttat sein Publikum findet oder nicht. Der Reiz von Fernsehberichterstattung über Gewaltkriminalität für die Zuschauenden beruht den Befragten zufolge auf einer Gleichgewichtsstörung: Der Bericht über ein Gewaltverbrechen irritiert die Zuschauenden emotional. Damit schafft der Beitrag einen Spannungszustand, der schließlich aufzulösen ist. Mit dieser Verarbeitung der Irritation wird das Publikum an die Berichterstattung gebunden. Diese Wirkungs- 
annahme schließt ein, dass das Publikum einen Selbstbezug herstellt. Die Befragten beschreiben diesen Prozess vor allem Furcht und Mitgefühl. Danach gründet Furcht darauf, dass die Zuschauenden in ihrer Angst um sich selbst oder um Menschen, die ihnen nahe stehen, berührt werden. Mitgefühl basiert darauf, dass Zuschauende, die selbst nicht betroffen sind, sich betroffen fühlen und gleichsam emotional teilnehmen.

Magazinreporter, Privatsender: „Eine Tat ist immer dann groß und interessant für uns, wenn sie erschrocken hat. Wenn die Brutalität erschrocken hat. Und dann schließt sich der Kreis zu den Opfern. Am nächsten Tag sehe ich, dass die Mutter des toten Mädchens ihr Leiden erzählt und während des Interviews weint. (...) Mitleid zu erwecken ist nicht schwierig.“

Während die Furcht auf das eigene Sicherheitsbedürfnis verweist und sich ohne jede Empathie mit den von Kriminalität tatsächlich Betroffenen äußern kann, ist Mitleid unabhängig davon möglich, ob sich die Betrachtenden selbst für gefährdet halten. Furcht und Mitleid sind von eigenständiger Bedeutung, doch vielfach miteinander verbunden.

\section{Unterschiede nach Sendern und Formaten}

Die befragten Redakteurinnen und Redakteure von Boulevardmagazinen und den Nachrichten der Privatsender skizzieren Emotionalisierung als einen wesentlichen Zweck ihrer Formate, der durch das Publikumsinteresse legitimiert ist. Abzugrenzen sind die vermuteten Bedürfnisse des Publikums von öffentlich-rechtlichen Nachrichten.

Redakteurin für Nachrichten und Magazine, öffentlich-rechtlicher Sender: „Es hat viel mit dem Format zu tun. Das Boulevardmagazin ist sicherlich die Spielfläche für das größte Maß an Emotionalität.“

Für die öffentlich-rechtlichen Nachrichten heben die Befragten einen geringeren Stellenwert von Emotionalität hervor, während für das Publikum der Privatsender ähnliche Bedürfnisse an Nachrichten wie an Boulevardmagazine vermutet werden.

\subsubsection{Die Bedeutung von Furcht}

Das Publikumsbild der Interviewten wird mit Blick darauf beschrieben, welche Rolle Verbrechensfurcht für das Publikum spielt, worauf sie sich bezieht und was sie speist, wie sie sich auf die Bindung zum Programm auswirkt und wie bedeutsam ihre Auflösung ist. Die Angst der Zuschauenden, ihnen oder ihrem Umfeld könne Schreckliches widerfahren, ist aus Sicht der Befragten eines der zentralen Publikumsmotive, sich der Berichterstattung über Gewaltkriminalität zuzuwenden. Diese Furcht wird bestimmt durch die Wahrnehmung des Ereignisses und deren subjekti- 
ven Bezug auf die Betrachtenden selbst. Die Furcht wird auf zwei Gefährdungsszenarien bezogen: Zum einen wird der unmittelbare Selbstbezug der Berichterstattung dadurch gespeist, sich selbst als gefährdet zu empfinden. Die Befragten betrachten als ein Grundmotiv der von ihnen erreichten Menschen, sich selbst an Stelle des Opfers zu betrachten.

Magazinreporter, Privatsender: „Dass Menschen sich in die Situation hineinversetzen können, die diese Menschen durchmachen, durchlebt haben. Identifizierung wäre Quatsch, aber wenn sie sagen würden: ,Das könnte mir auch passieren.'““

Eng verwandt mit der Furcht um die eigene Person ist die Furcht um das nächste Umfeld. Als besonders stark wird die Furcht beschrieben, das eigene Kind könne zum Gewaltopfer werden. Hier ist die Rede von „Urängsten“. Sie werden verknüpft mit dem latenten Empfinden, dass Kinder verletzlich und die Eltern - wie auch die Gesellschaft insgesamt - machtlos sind, Kinder vor allen denkbaren Gefahren zu bewahren.

Nachrichtenredakteurin, öffentlich-rechtlicher Sender: „Die noch viel unverständlichere Gewalt gegen Kinder, vor der alle Eltern Angst haben, was immer als Standard gesehen wird, nämlich die Gewalt von Fremden, berührt unglaubliche Urängste.“

Das diesen Ängsten um sich selbst und seine Nächsten zu Grunde liegende Muster ist die Auflösung von Grenzen - zwischen Vertrautem und Fremdem, zwischen Sicherheit und Gefahr, zwischen Fürsorge und Zerstörung. Je unbegreiflicher der gezeigte Schrecken ist, soweit er noch verknüpft zu sein scheint mit der Erlebniswelt des Publikums, desto stärker ist die mutmaßliche Wirkung eines Fernsehbeitrags über Gewaltkriminalität. Dabei geht es nicht allein um das Geschehen, die Brutalität einer Tat an sich. Der äußerste Tabubruch, etwa die Ermordung eines Kindes, zeigt, dass menschliches Verhalten grenzenlos ist und keine Haltung, kein Empfinden und kein Verhalten verlässlich sind. Diese tiefe Verunsicherung wird mit Begriffen wie Mysterium dargestellt.

Freier Autor, öffentlich-rechtlicher Sender: „Dass es ein Duell gibt zwischen Erwachsenen, dass auch Affekttaten zwischen Erwachsenen passieren, da kann ich mich hineindenken, da gibt es innewohnende Kräfte, die mir nur zu gut bekannt sind. Aber das andere ist ein Mysterium, wie so etwas passieren kann, und das gilt es in einer Gesellschaft, die doch so sozial oder auch so kinderfreundlich sein will, besonders zu untersuchen."

Das Gefühl von Gefährdung stützt sich den Befragten zufolge in der Regel nicht auf eine rational begründete Risikoeinschätzung, sondern auf eine subjektiv konstruierte Furcht. Um diese Furcht zu empfinden, müssen die Zuschauenden eine Verbindung zwischen dem berichteten Geschehen und ihrem eigenen Alltag sehen. Seine größtmögliche Wirkung, so vermuten die Befragten, entfaltet der Fernseher nicht als ein Guckkasten, der den fernen Schrecken zeigt, sondern als Spiegel eines Grauens, das, subjektiv gesehen, die Lebenswelt des Publikums erfasst. 
Als Ziel der Auseinandersetzung mit der eigenen Furcht beschreiben Medienschaffende in den Forschungsinterviews die Auflösung der Furcht. So, wie sie annehmen, dass es ein Publikumsbedürfnis nach dem Durchleben von Furcht gibt, vermuten sie ein Bedürfnis nach Erleichterung. Wird die Furcht als Irritation über entgrenzte Gefahr verstanden, führt die Verarbeitung dieser Irritation zu einer Vergewisserung, selbst im sicheren Diesseits zu stehen. Damit wird ein Mechanismus skizziert, der zwei Bewegungen enthält - das Eintauchen in das fremde Grauen und das Wiederauftauchen im eigenen Alltag.

Magazinredakteurin, öffentlich-rechtlicher Sender: „Die Rolle des Opfers hat oft zwei Seiten. Die Leute gucken das und sagen entweder, ,oh, wie furchtbar, ist das schlimm'. Das berührt sie in dem Moment. Oder sie sagen auch, ,gut, dass mir das nicht passiert ist'.“

Die Furcht bedarf ihrer Auflösung, um das Publikum nicht nachhaltig zu belasten. Dafür genügt nicht allein die Selbstvergewisserung der Zuschauenden, selber noch einmal der machtvollen Gewalt entronnen zu sein. Furcht in diesem Sinne ist also keine nachhaltige Furchtsamkeit, sondern der eher kurze Schrecken, der kurzzeitig Aufmerksamkeit schafft. Wichtig ist, dass der Täter oder die Täterin aus dem Dunkel vertrieben und schließlich gefasst werden. Eine gewichtige Rolle spielt dabei, Polizei und Justiz als letztlich machtvoller als die Gewalt zu erleben.

Freier Agenturreporter: „Es fasziniert die Menschen, wozu andere Menschen im Stande sind, und es interessiert auch die Leute, wie so was aufgeklärt wird, welche Möglichkeiten die Polizei hat, und wie man solche Leute überhaupt bestraft.“

Der Erlösung kann ebenso dienen, das Opfer nicht als traumatisiert und psychisch zerstört zu erleben, sondern an der Bewältigung eines Gewaltverbrechens teilzuhaben. Die Befragten beschreiben ein starkes Bedürfnis ihres Publikums, in der Dramaturgie der jeweiligen Sendung die Irritation zu verarbeiten und damit aus der Furcht zur Erleichterung zu gelangen.

\subsubsection{Die Bedeutung von Mitgefühl}

Fernsehjournalisten und Fernsehjournalistinnen umreißen, wie bedeutsam aus ihrer Sicht das Mitgefühl des Publikums mit den Betroffenen von Gewaltkriminalität ist, wem es in besonderem Maße gilt und wem nicht, was es beeinflusst und was es für die Betrachtenden angenehm macht. Neben der Angst um sich selbst und andere ist das Bedürfnis, Mitgefühl mit leidenden Menschen zu empfinden, ein wichtiges Motiv des Publikums, Fernsehbeiträge zur Gewaltkriminalität zu betrachten, so vermuten die Macherinnen und Macher. Die Befragten sprechen dabei von Mitgefühl und weitgehend synonym von Empathie als einem subjektiven Mitfühlen mit den gezeigten Akteuren der Kriminalitätsberichterstattung, vor allem mit den Ver- 
brechensopfern und ihren Angehörigen. Die emotionale Haltung gegenüber den unmittelbaren und mittelbaren Betroffenen von Gewalt ist für alle Befragten unstrittig. Danach gilt den Opfern und den ihnen nahe stehenden Menschen das Mitgefühl des Publikums gleichsam automatisch.

Nachrichtenredakteur, Privatsender: „Mit Opfern hat man immer Mitgefühl, ganz normal menschlich.“

Begründet wird diese Annahme damit, dass das Mitleid mit dem Opfer in eine eindeutige Haltung einzupassen ist. Mit der Ablehnung von Verbrechen und Brutalität scheint die Solidarisierung mit dem Opfer am ehesten zu verkoppeln zu sein, und das Mitgefühl mit der positiv bewerteten Figur deutlich einfacher als das Mitgefühl mit einer Person, die auf Ablehnung oder auch nur ambivalente Gefühle stößt. Dieser Annahme zufolge ist das Mitgefühl des Publikums gleichsam unteilbar und klar auf die Anteilnahme mit den Verbrechensopfern und seinen Angehörigen gerichtet, soweit sie sich für eine eindeutige Haltung anbieten und nicht in schuldhaftes Verhalten verstrickt sind. Die Befragten vermuten einen emotionalen Nutzwert. Dieser Annahme zufolge ist es dem Publikum angenehm, mit leidenden Verbrechensopfern bzw. ihren Angehörigen mitzutrauern, ohne tatsächlich vom Grund der Trauer belastet zu sein. So begründet eine Redakteurin, warum sie in einem Magazinbeitrag über die Beerdigung einer ermordeten jungen Frau trauernde junge Menschen zeigt und auf deren Tränen fokussiert. Damit, so ihre Annahme, wird das Publikum gleichsam in die Trauergemeinde einbezogen und an das Programm gebunden.

Magazinredakteurin, öffentlich-rechtlicher Sender: „Das mache ich sehr bewusst, weil es, zynisch gesprochen, ganz schön ist, so traurig zu sein, wenn man so einen Beitrag sieht. (...) Wenn Leute einen solchen Film sehen, wollen sie keinen zynischen Unterton und keine distanzierte Darstellung hören. Da wollen sie auch keine Erörterung gesellschaftspolitischer Ursachen für männliche Sexualtäter hören. Da wollen sie einfach diesen Moment der Trauer jetzt erleben. Schluss, aus, Feierabend. Das andere kann man alles mal thematisieren, aber in einem anderen Kontext.“

Der Begriff der schönen Traurigkeit belegt die Annahme, dass sich die Emotionen der real Betroffenen von denen des mitfühlenden Publikums fundamental unterscheiden: Was für die einen Ausdruck eines großen Verlustes ist, ist für die Menschen am Bildschirm ein eher angenehmes Gefühl, dem sie sich hingeben können, ohne wirklich zu leiden.

Nachrichtenredakteur, Privatsender: ,Leute in extremen Situationen berühren einen. Aber kein Mensch ist in der Lage, wirklich nachzuempfinden, was in Menschen vorgeht, die gerade ein kleines Kind verloren haben. Das ist dieses ,Uah!', ich gucke halb hin, weil es mir ansatzweise gelingt, das nachzuvollziehen, aber nicht wirklich." 
Damit wird bereits auf den Zusammenhang zwischen der Folgenschwere eines Verbrechens und der Bildung von Empathie verwiesen sowie die Frage, welche Rolle es spielt, Leidende und Leid zu zeigen, um Mitgefühl zu wecken.

\subsubsection{Wirkungsrelevante Nachrichtenfaktoren}

Untersucht wird, welche Faktoren aus Sicht der befragten Journalistinnen und Journalisten beeinflussen, wie sich die Fernsehberichterstattung über Gewaltkriminalität auf ihr Publikum auswirkt. Im Mittelpunkt stehen damit die vermuteten Einflüsse auf die Bildung von Furcht und Mitgefühl im Publikum, die als zentral befunden werden, um eine größtmögliche Zahl von Zuschauenden zu gewinnen und zu halten. Aus diesen journalistischen Deutungen kristallisieren sich fünf wirkungsrelevante Nachrichtenfaktoren als besonders gewichtig heraus. Sie werden in Anlehnung an die Nachrichtenwerttheorie als Folgenschwere, Reichweite, Personalität ${ }^{16}$, Polarität und Visualität bezeichnet. Sie beziehen sich zunächst auf Merkmale der Delikte, der beteiligten Personen und deren Interaktion und gründen sich damit auf das Geschehen selbst, wie es aus journalistischer Perspektive wahrgenommen wird. Diese fünf Faktoren werden aus Sicht der Befragten insoweit wirksam, als sie sich journalistisch ausschöpfen lassen. So lässt sich beispielsweise die Personalität eines Konflikts zwischen Täter und Opfer nur entfalten, wenn er sich durch Bilder und Töne möglichst intensiv vermitteln lässt und die Recherche nicht an Hausfassaden endet. Letztlich also beziehen sich die benannten Wirkungsfaktoren auf Merkmale der Berichterstattung.

\subsubsection{Folgenschwere}

Der Nachrichtenfaktor Folgenschwere umreißt, wie stark sich aus Sicht der Befragten ein Gewaltereignis unmittelbar im Einzelfall auswirkt, gelegentlich auch, was es mittelbar für die Gesellschaft bedeutet. Die Folgenschwere einer Tat wird von den Befragten einhellig als einer der wichtigsten Wirkungsfaktoren genannt.

Magazinredakteur, Privatsender: „Es gibt immer wieder Konstellationen, die interessant sind: (...) Die spektakuläre Geschichte, an der man nicht vorbei kommen kann, oder eine MetaEbene, die ein gesellschaftsrelevantes Phänomen aufdeckt.“

Geht es um die „spektakuläre Geschichte“, wird die Gewalttat für sich betrachtet. Sie mag einzigartig sein oder ohne jeden Bezug zu anderen Ereignissen wahr-

16 Abweichend von der Terminologie der Nachrichtenwerttheorie ist hier von Personalität und nicht von Personalisierung die Rede, um journalistische Deutungsmuster von Handlungsmustern sprachlich klar abzugrenzen (vgl. Visualität und Visualisierung). 
genommen werden. Geht es um die „Meta-Ebene“, wird die Gewalttat für einen Umstand oder eine Entwicklung gedeutet, die mit der Tat ausgedrückt oder durch sie erst ausgelöst werden. Das angenommene Publikumsinteresse an Gewaltkriminalität wird eng verknüpft mit drastischen Formen der Gewalt, vor allem dem Bruch des Tötungstabus. Vielfach wird „Mord und Totschlag“ synonym für besonders interessierende Gewaltkriminalität genannt.

Nachrichtenredakteurin, öffentlich-rechtlicher Sender: „Mord ist einfach ein Thema für alle.“

Freier Autor, öffentlich-rechtlicher Sender: „Tötungsverbrechen als ein extremer psychologischer Zustand: (...) Da liegt so eine Neugier.“

Zum anderen spielt eine Rolle, ob der Einzelfall im größeren Zusammenhang etwas auslöst - sei es, dass dies bereits geschehen ist oder noch erwartet wird. So beschreibt eine Nachrichtenredakteurin, dass bei der Berichterstattung über den Sexualmord an einem Jungen durch einen vorbestraften Sexualstraftäter bereits die Antizipation politischer Reaktionen bedacht wurde.

Nachrichtenredakteurin, öffentlich-rechtlicher Sender: „Also davon auszugehen, dass dieser Fall möglicherweise eine politische Diskussion auslösen könnte und damit pars pro toto für etwas steht. Die Diskussion, die sich ja dann auch sofort angeschlossen hat. (...) Also Sicherheitsverwahrung, härtere Strafen gegen Sexualstraftäter, Kenntlichmachen von Sexualstraftätern, Fußfesseln, Internetveröffentlichung.“

Im Zuge einer Berichterstattung unter hohem Zeitdruck spielt diese Vorausschau von Diskussionen, die noch gar nicht begonnen haben, eine große Rolle. Ist zu erwarten, dass die Politik ein spektakuläres Verbrechen als Vignette gesellschaftlicher Missstände oder politischer Versäumnisse aufgreift, sehen sich Journalistinnen und Journalisten unter dem Erwartungsdruck ihres Publikums, über die Gewalttat als Auslöser und Symptom zu berichten. Dies wird insbesondere als Erklärung für die stark gestiegene Aufmerksamkeit für Gewalt an Kindern angeführt, welche die Befragten als weiteren Grund für die geradezu explosionsartige Verstärkung der Berichterstattung über Sexualmorde an Kindern vermuten.

Freier Autor, öffentlich-rechtlicher Sender: „Warum so viele unschuldigste Wesen, die vielleicht einige Tage alt nur sind, nicht länger leben durften: Das ist ein Thema, wo auch soziale und politische Ebenen mit hineinkommen, Hintergründe - und dann wird es natürlich noch eine Spur spannender.“

Explizit stützen sich Befragte auf eine Äußerung des früheren Bundeskanzlers Gerhard Schröder. Der hatte 2001 in einem Interview mit der Bild am Sonntag gesagt: „Was allerdings die Behandlung von Sexualstraftätern betrifft, komme ich mehr und mehr zu der Auffassung, dass erwachsene Männer, die sich an kleinen Mädchen vergehen, nicht therapierbar sind. Deswegen kann es da nur eine Lösung geben: 
wegschließen - und zwar für immer!“ (Kleine und Quoos 2001: 8f.) Diese Äußerung war aufgeladen durch die Berichterstattung im Sommer desselben Jahres über den Sexualmord an einem achtjährigen Mädchen. Damit wurde dieses Thema quasi zum Regierungsgegenstand erhoben. In der Folge, so die Befragten, stieg die wahrgenommene Bedeutung.

\begin{abstract}
Nachrichtenredakteurin, öffentlich-rechtlicher Sender: „Wenn Themen einmal, aus welchen Gründen auch immer, eine Hürde übersprungen haben, besitzen sie über eine lange Zeit eine entsprechende Virulenz. Ich erinnere mich, dass es mal einen Bundeskanzler gab, der sich sehr dezidiert zu Kinderstraftätern geäußert hat. Und damit hat das Thema natürlich eine Schwelle übersprungen."
\end{abstract}

So ist Folgenschwere ein Konstrukt, das sich nur bedingt auf den sichtbaren Grad der Zerstörung und vor allem auf deren Deutung bezieht. Dies wird vor allem insoweit sichtbar, als sich diese Deutung im Zeitverlauf ändert.

\title{
5.3.3.2 Reichweite
}

Die Reichweite ist das Maß, auf wie viele Menschen sich ein Ereignis bezieht bzw. beziehen lässt. $\mathrm{Zu}$ unterscheiden ist die statistische Reichweite, also wie viele Menschen nach gesicherten, intersubjektiv überprüfbaren Befunden betroffen sind, von der gefühlten Reichweite, also wie viele Menschen sich aus ihrer subjektiven Einschätzung von Wahrscheinlichkeiten heraus betroffen fühlen. Der Nachrichtenfaktor Reichweite stellt damit die Verknüpfung von Ereignissen mit der Lebenswirklichkeit des Publikums her.

Statistische Reichweite lässt sich in absoluten Zahlen als Zahl der Betroffenen sowie in prozentualen Anteilen als Wahrscheinlichkeit darstellen, von einem Ereignis erfasst zu werden. Die statistische Reichweite von Gewalttaten ist zum einen ein Maß der Rückschau, wie sich ein Risiko bislang abgebildet hat. Sie ist zum anderen ein Maß der Vorausschau, wie hoch die Gefahr ist, künftig Opfer einer Gewalttat zu werden. Nach Einschätzung der Befragten wenden sich die Zuschauenden der Berichterstattung über Gewaltkriminalität nicht deshalb zu, weil sie aus objektivierbaren Befunden ableiten, dass sie selbst oder das nahe Umfeld tatsächlich gefährdet sind. Von daher beeinflussen aus journalistischer Sicht allgemeine Erkenntnisse über das Kriminalitätsgeschehen, beispielsweise Eckdaten aus der Polizeilichen Kriminalitätsstatistik, kaum das Publikumsinteresse.

Nachrichtenredakteur, Privatsender: „Sie können die Entscheidung, ob Sie eine Nachricht vermelden, nicht mit Statistik begründen. Wir sind diejenigen, die abbilden sollen. (...) Da kann man nicht sagen, aber statistisch gesehen ist es so, dass es eigentlich gar keine Kriminalität mehr gibt, also brauchen wir darüber nicht zu berichten." 
Danach bestimmt vor allem die Wucht des Beispielhaften, wie stark Zuschauende eine Anbindung der gezeigten Gewaltdelikte an ihre eigene Lebenswirklichkeit sehen. Gefühlte Reichweite ist das Empfinden, von Ereignissen betroffen zu sein. Sie wird daraus gespeist, Ereignisse rückblickend in der eigenen Lebenswirklichkeit zu verorten bzw. sie vorausschauend im eigenen Umkreis zu erwarten. Gefühlte Reichweite kann völlig unabhängig von begründeten Erkenntnissen entstehen. Die befragten Journalisten und Journalistinnen vermuten, dass die Kriminalitätsberichterstattung auf einen je nach Publikumssegment unterschiedlichen Resonanzboden stößt. Danach dringt sie insoweit durch, als sie bereits latent vorhandene Ängste berührt. Dabei findet der Abgleich weniger mit realen Erfahrungen statt, die die Zuschauenden selber machen, als eher mit ihren Empfindungen.

Magazinredakteur, öffentlich-rechtlicher Sender: „Die Menschen, die vor irgendetwas Angst haben, ob zu Hause eingebrochen wird, ob die Handtasche geraubt wird, was auch immer, lassen sich natürlich gerne von so etwas inspirieren oder schauen das gerne."

Gefühlte Reichweite nimmt aus Sicht der Befragten zu, wenn das Abseitige auf der Folie des Vertrauten geschieht. Erkennen sich Zuschauerinnen und Zuschauer im Ambiente einer Straftat wieder, verknüpft sich die eigene Normalität mit dem Ungeheuerlichen, das in eine ähnliche Normalität eingebrochen ist. So erscheint es eher vorstellbar, selbst von Gewalt erfasst zu werden. Damit verlieren bizarre Gewaltdelikte wie eine kannibalistische Bluttat an Reiz gegenüber einem Eifersuchtsmord, der nicht in einer fernen Welt, sondern hinter gewohnten Hausfassaden zu spielen scheint.

Magazinreporter, öffentlich-rechtlicher Sender: „Familiendramen sind spannend, weil man denkt, das könnte möglicherweise in meiner Familie passieren, möglicherweise bei meinem Nachbarn direkt um die Ecke. Das ist vielleicht alläglich. Da sind wir eher auf einer Ebene des Zuschauers als beim Kannibalen, was ja so abstrus und abnorm ist, dass man nicht damit rechnet, dass so etwas in der Nachbarschaft passieren könnte.“

Magazinredakteur, Privatsender: „Eine Relevanz, eine Daseinsberechtigung hat eine Geschichte dann, wenn sie bei Dir und mir spielen könnte.“

So wird der Tatort zur Chiffre eines ganz normalen Heims, in dem dennoch Schreckliches geschieht. Die Ähnlichkeit der äußeren Umstände nährt die Angst, dass damit auch die Grenzen verwischen zwischen der eigenen, sicheren Zone und dem gefährlichen Ort, der im Fernsehen gezeigt wird. Diese Verbindung von Vertrautem und Beängstigendem, von Konsonanz und Überraschung, wird von den Befragten als „Gruseleffekt“ oder „Spooky-Faktor“ beschrieben. Damit beschreiben sie explizit subjektive Reichweite als Faktor, um Verbrechensfurcht zu erregen und zu steigern. Gleichsam erweist sich subjektive Reichweite als Faktor dafür, Mitgefühl mit Gewaltopfern zu entwickeln. 
Magazinredakteur, öffentlich-rechtlicher Sender: „Ich kann mich mit dem Mädchen von nebenan identifizieren, weil ich auch von nebenan bin. Der Begriff passt nicht hundertprozentig, aber es geht in die Richtung, dass man als Zuschauer mitfiebern kann, dass man sich damit identifiziert, dass man sich eine Meinung bilden kann.“

Scheint die Gewalttat in einer sozial fernen Welt zu geschehen - beispielsweise in einem kriminellen Milieu - wird eine geringe subjektive Reichweite angenommen. Dabei spielen auch kulturelle Nähe oder Ferne eine Rolle. Die Menschen, die zuschauen, sind den Befragten zufolge vorrangig interessiert an Berichterstattung über Menschen derselben Ethnie. Als je fremder sie die Ethnie der Menschen betrachten, über die berichtet wird, desto geringer ist ihr Interesse. Eine Berichterstattung über Delikte, in die ausschließlich Menschen ausländischer Herkunft verwickelt sind, stößt danach auf geringe Anteilnahme.

Agenturreporter: „Wenn zum Beispiel ein Vietnamese seinen chinesischen Nachbarn im Studentenwohnheim umbringt, hört man [von den Redaktionen] oft die Antwort: ,keine deutschen Interessen'. Wenn Opfer und Täter nicht deutsch sind, fällt es heraus. (...) Es spielt, glaube ich, keine Rolle, dass man Angst hat, jemanden zu diskriminieren. Man denkt immer an den Fernsehzuschauer, und der scheint sich dafür nicht ganz so zu interessieren.“

Magazinredakteur, öffentlich-rechtlicher Sender: „Deutscher Täter, deutsches Opfer ist am besten, wenn ich das so sagen darf.“

Also wird selbst die in Deutschland geschehende, also räumlich nahe Gewalt unter Nichtdeutschen als Konflikt einer subjektiv fernen Welt betrachtet, die dem Publikum nicht nahe geht. Maßgeblich ist also nicht, wo ein Delikt geschieht, sondern wen es betrifft. Ob die Protagonisten eines Ereignisses als nah empfunden werden und so der Faktor subjektiver Reichweite gespeist wird, ist wiederum subjektiv begründet - also nicht allein dadurch, dass Personen einem fremden Kulturkreis entstammen, sondern dass sie fremd wirken. Diese Annahme impliziert, dass die Zielgruppe in großer Mehrheit deutsch ist und die kulturell definierte Ethnie als entscheidende Eigenschaft erachtet.

Dieses weitgehende Desinteresse an Nichtdeutschen bezieht sich auf Alltagskriminalität, die man als folgenlos für die deutsche Mehrheitsgesellschaft einschätzt, nicht aber auf ideologisch motivierte Gewalt, seien es so genannte Ehrenmorde oder ausländerfeindliche Gewalt. In diesen Fällen führt die Deutung gesellschaftlicher Folgenschwere wiederum zu stärkerer Beachtung.

\subsubsection{Personalität}

Personalität umreißt, wie stark ein wahrgenommenes Geschehen konkret durch Menschen geprägt ist. Das Interesse des Publikums an Gewaltkriminalität ist im Kern ein Interesse an den Menschen, die von ihr unmittelbar betroffen sind, so vermuten die Befragten: Menschen werden durch Menschen erreicht. Die Bericht- 
erstattung berührt ihr Publikum vor allem dann, wenn sie Personen und deren Gewalterfahrungen in großer Schärfe sichtbar macht ${ }^{17}$. Damit gehört Personalität zu den zentralen Bedingungen für eine Wirkung der Kriminalitätsberichterstattung. Die Fokussierung auf Personen gilt als geradezu zwingend.

\begin{abstract}
Magazinredakteur, öffentlich-rechtlicher Sender: „Ob es eine Kriminalgeschichte oder eine Promi-Geschichte ist, sie muss spannend und personalisierbar sein. (...) Der Zuschauer muss das Gefühl haben, dass wir wissen, wie die Unterwäsche von den Menschen aussieht, die uns beim Interview gegenübersitzen. Natürlich wissen wir das nicht. Aber das Gefühl, dass du so dicht dran bist, den könntest du selbst das fragen."
\end{abstract}

Damit wird die Thematisierung von Gewaltkriminalität in aller Regel als Beschreibung des Einzelfalls und seiner Folgen aufgefasst, nicht etwa als ausschließlich abstrakte Beschreibung von gesellschaftlichen Zuständen und Entwicklungen. Aus journalistischer Sicht gilt es, zu den Personen vorzudringen, die am stärksten und möglichst unmittelbar von der Gewalt erfasst sind, und dies sind die Verbrechensopfer und ihre Angehörigen. Als eigentliches Thema wird betrachtet, die emotionalen Folgen von Gewalt zu beleuchten, weil sich in ihr die Wucht von Gewaltkriminalität am deutlichsten zeigt. Und darüber kann im Idealfall niemand ausdrucksstärker Auskunft geben als die Gewaltopfer selbst und ihr nächstes Umfeld. Angenommen wird, dass das Publikum grundsätzlich parteilich mit dem Opfer empfindet und daher eine Berichterstattung erwartet, die vorrangig die Emotionen der Opferseite vermittelt und eine Anteilnahme mit den unmittelbar und mittelbar Gewaltbetroffenen ermöglicht.

Magazinredakteur, öffentlich-rechtlicher Sender: „Opfer interessieren mich mehr, weil man sich damit ja als Zuschauer identifiziert. (...) Das geht ja viel schneller, so einen emotionalen Kontakt oder so eine emotionale Brücke zwischen einem Opferkreis und den Zuschauern herzustellen, als zwischen dem Täterkreis [und den Zuschauern].“

Dem liegt die Erwartung zu Grunde, dass eine Emotionalisierung - sei es, um die Furcht der zuschauenden Personen um sich selbst und ihr Umfeld oder ihr Mitgefühl mit den Protagonisten eines Beitrags zu wecken - primär an das Opfer geknüpft ist: Die Empathie mit dem Opfer ist entscheidend, nicht die Aversion gegen den Täter oder die Täterin. Eine Empathie mit dem Täter oder der Täterin gilt als verfehlt und mindert die Wirkung der Berichterstattung. Auch um Furcht zu erregen, taugt den Befragten eine Fokussierung auf Verdächtigte und Verurteilte nur bedingt. Vielmehr gelten Unschärfen in der Betrachtung als spannungssteigernd: Die gespenstische Gewalt bleibt unfassbar und von allumfassender Bedrohlichkeit.

Magazinredakteurin, Privatsender: „Damit ich eine Geschichte spannend finde, sollte sie spooky sein, also so einen Mystery-Faktor haben, der sie nicht zum 08/15-Fall macht. Wenn

17 Personalität ist in der Berichterstattung über Gewaltkriminalität eng mit der Polarität der dargestellten Personen verknüpft, siehe dazu auch Kap. 5.3.3.4. 
man keinen Täter hat, macht es das allein schon spooky, wenn also jemand gestorben ist, wahrscheinlich durch Gewalteinwirkung, aber der Täter irgendwo hier herumläuft und vielleicht unser Nachbar ist. Dann hat das auch schon einen Spooky-Faktor.“

Überdies spiegeln sich monströse Taten in aller Regel nicht in den Gesichtern der Beschuldigten wider. Es sind nicht Frankensteins Monster, die auf der Anklagebank sitzen, sondern meist unscheinbare Gestalten - sie taugen also kaum als Sinnbilder des Grauens. Um Furcht und Mitgefühl zu erregen, stehen daher vor allem die Opfer und ihr Umfeld im Mittelpunkt des Interesses.

\subsubsection{Polarität}

Polarität wird hier verstanden als die besondere Ausprägung von Merkmalen. Vielfach, aber nicht zwingend, zeigt sie sich bipolar in stark gegensätzlichen Merkmalen. Das Publikum ist den Befragten zufolge umso eher für eine Berichterstattung zu gewinnen, je stärker sich in ihr Polarität abbildet, sei es in Zuständen als latente Polarität (zum Beispiel machtvoll vs. ohnmächtig) oder im Handeln als manifeste Polarität (vor allem Täter vs. Opfer). Das Publikum ist nach Ansicht der Interviewten in der Regel fokussiert auf einen aktuell sichtbar gewordenen Gewaltakt, der definiert wird durch Urheber und Adressat der Gewalt, durch Zerstören und Zerstörtwerden. Die Befragten skizzieren die Gewalttat per se als bipolares Ereignis und folgern, dass sich daraus eine polarisierte Betrachtung gleichsam von selbst anbietet.

Magazinredakteurin, öffentlich-rechtlicher Sender: „Das haben die Menschen gerne, Schwarz und Weiß, Gut und Böse. Zumal die Rollen verteilt sind.“

Magazinredakteur, öffentlich-rechtlicher Sender: „Meistens ergeben sich die Rollen. Meistens habe ich ja schon mal einen Täter und ein Opfer. Das sind zwei verschiedene Rollen.“

Diese Deutung wird als unverfügbar betrachtet: Es darf keine Verwirrung darüber geben, wer etwas getan hat und wer Opfer ist, und damit auch, wem positive und wem negative Eigenschaften zugeordnet werden. Entscheidend sind dabei aus Sicht der Befragten vor allem Eigenschaften der Opfer. Bei der Betrachtung des Verbrechensopfers als der zentralen Figur von Emotionalisierung spielt Polarität vor allem in drei Aspekten eine Rolle: Das ideale Opfer ist unschuldig, schwach und sympathisch. In ihren Äußerungen zur Rolle des Opfers für die Kriminalitätsberichterstattung heben Fernsehjournalistinnen und Fernsehjournalisten einhellig hervor, dass Opfern die Rolle zukommt, Mitgefühl zu wecken. Eine nachhaltige Wirkung der dem Publikum unterstellten grundsätzlichen Parteilichkeit für das Opfer wird allerdings nur dann angenommen, wenn es gelingt, über Empathie hinaus Sympathie zu erregen. 
Magazinredakteur, öffentlich-rechtlicher Sender: „Das ist Sympathie in diesem ursprünglichen Sinne. Nicht nur mitfühlen im Sinne von Mitleid, oh Gott, dem ist etwas Schreckliches passiert, sondern dass der Zuschauer zu dem Protagonisten eine Nähe herstellen kann.“

Im Sinne starker Polarität fällt den Opfern bzw. deren nahen Angehörigen die Rolle der personifizierten Unschuld zu. Ihnen darf keinerlei Mitschuld am Gewaltgeschehen angelastet werden, um ihre klar konturierte Rolle zu spielen. Sie sollen gleichsam widerspruchsfrei auftreten, um sich als Kristallisationspunkte der Publikumsemotionen anzubieten. Damit werden zweideutige Konstellationen als ungeeignet betrachtet, um dem Publikum einen emotionalen Zugang zu ebnen. Die Emotionalisierung durch eine klare Polarisierung wird als eine Voraussetzung für das Publikumsinteresse und in der Folge für Anteilnahme verstanden. Verbrechensopfer dürfen sich nicht mit den Beschuldigten gemein machen, sondern müssen ihnen unterworfen sein, sie dürfen durch ihren Lebenswandel oder ihr der Tat vorangehendes Verhalten nicht mitschuldig geworden sein. Sind Opfer offenbar konflikthaft mit den Beschuldigten verstrickt und wird das Opferverhalten als riskant und schuldbeladen betrachtet, gelingt die Verknüpfung zum Publikum nicht.

Dokumentarfilmerin, öffentlich-rechtlicher Sender: „Es hat einen gewissen Automatismus passiert ein Mord im Drogenmilieu, ist die Geschichte damit im Grunde journalistisch tot. Weil sich kein Mensch mehr für eine Geschichte interessiert, die letztlich ein Drogenkonflikt ist. (...) Da wird das Opfer automatisch mitschuldig gesprochen. Es ist nicht das hilflose, unschuldige Opfer wie ein Kind, wo von vorneherein eine Empörung gewährleistet ist.“

Das Mitgefühl des Fernsehpublikums, so wie es die Befragten konstruieren, gilt dem Verbrechensopfer im Allgemeinen, bei näherer Sicht aber vorrangig dem Opfer, das bestimmte Rollenerwartungen erfüllt. Niemand scheint diesem Muster besser zu entsprechen als das Kind, das zum Verbrechensopfer wird.

Magazinredakteur, öffentlich-rechtlicher Sender: „Wenn es um Kinder geht, gerät man sofort in eine Haltung, nahezu jeder Mensch. Man muss schon sehr abgebrüht sein, um nicht Mitleid zu empfinden."

Magazinredakteur, Privatsender: „Wenn man das Thema Gewalt an Kindern als Ware, als Verkaufsware sieht, verkauft es sich sehr gut, da es immer einen gewissen Gesprächsstoff liefert, einen emotionalen Stoff und einfach Drama.“

Die Befragten liefern für die Fokussierung auf das kindliche Opfer und die Annahme, dass es in besonderer Weise die Emotionen des Fernsehpublikums erregt, im Kern drei Gründe:

1. Das kindliche Opfer gilt als das unschuldige Opfer. Das Opfer soll in seiner Reinheit ein Gegenbild zur dunklen Tätergestalt liefern. Als extremer Ausdruck der Verletzung Unschuldiger wird beispielsweise die Entführung und Misshandlung eines Mädchens durch einen ihm fremden Täter beschrieben. 
Magazinredakteur, Privatsender: „Das ist eindeutig, eine relativ schwarz-weiße Geschichte. Weil sicherlich niemand auf die Idee kommen würde, dass jemand vom Schulweg entführt wird und das wollte oder unterstützt hat, insofern sind da die Fronten klar.“

2. Das kindliche Opfer gilt als das schwache Opfer. Daher wird das Mitleid mit einem Kind, das der Gewalt Erwachsener ausgeliefert ist, als geradezu zwangsläufig angenommen.

Freier Autor, öffentlich-rechtlicher Sender: „Dass ein Opfer so klein ist und ein Täter so groß in dem Augenblick, in dem sie zusammentreffen, halte ich für besonders eklatant.“

3. Das kindliche Opfer gilt als das sympathische Opfer. Dies schließt ein, dass jede Form der Berichterstattung über Kinder das Publikum berührt, erst recht in der Zuspitzung auf Leid, das Kindern angetan wird. Damit ist die Sehbeteiligung deutlich zu steigern.

Magazinredakteur, Privatsender: „Es hat zu tun mit so schlichten Dingen, die der Psychologe ,Kindchenschema' nennt. Da geht es um große Kinderaugen.“

Im Mittelpunkt des Publikumsinteresses steht damit nicht allein, was geschehen ist und was es in der Folge auslöst, sondern welche besonderen Eigenschaften der zentralen Personen - vor allem der Opfer - sich erkennen lassen. Im Umkehrschluss werden alte Menschen als besonders ungeeignet gesehen, vom Publikum als Figuren der Emotionalisierung betrachtet zu werden.

Agenturjournalist: „Bei Kindern ist die Betroffenheit des Zuschauers ist am größten, das Mitleid für die Eltern, für die Angehörigen. Bei einem 78-Jährigen ist das nicht da.“

Freier Reporter, private und öffentlich-rechtliche Sender: „Bei Redaktionskonferenzen heißt es dann: ,Nee, gute Geschichte, aber zu alt.' (...) Es gibt Themen, die werden nicht mehr gemacht, weil sie beim Zuschauer in der Quote nicht so ankommen."

Die Tatverdächtigen selbst gelten als weniger geeignet, um zu polarisieren. Die Befragten halten die Fokussierung auf Tatverdächtige für riskant, weil sie eine unerwünschte Nähe schaffen und damit eine klare Polarität gerade antasten kann. Die Befragten stellen Polarität, vor allem wenn sie sich am Konstrukt des idealen Opfers orientiert, explizit meist in den Zusammenhang mit der Schaffung von Empathie. Sie wird funktional auch mit der Erregung von Furcht verknüpft: mit dem gleichsam reinen Opfer kontrastiert die Wucht der Gewalt besonders stark. So wird Polarität vor allem über Opfereigenschaften definiert und als wichtiger Faktor gesehen, das Publikum emotional anzusprechen. 
Visualität wird verstanden als die Vermittelbarkeit mittels Bildern. Die Befragten beschreiben sie als zentral, um Wirkungen beim Fernsehpublikum zu erzielen. Schaulust gilt als ein zentrales Einschaltmotiv. Das Fernsehen, das diesem Bedürfnis folgt, wird als ,bildgetrieben“ gekennzeichnet.

Magazinredakteur, öffentlich-rechtlicher Sender: „Die Macht der Bilder im Fernsehen ist nicht zu unterschätzen.“

Magazinredakteurin, öffentlich-rechtlicher Sender: „Beim Fernsehen sprechen die Bilder sehr viel. Wenn die entsprechend gedreht sind, kommt man den Leuten ganz nah oder eben auch nicht. Und das macht gefühlsmäßig viel aus, weil sich oft Gefühle einfach durch Bilder vermitteln.“

Die von Gewalt betroffenen Menschen zu zeigen, wird für bedeutsam gehalten, um eine Emotionalisierung des Publikums zu erreichen. Das Ausmaß der Gewalt aus ihren emotionalen Folgen ermessen zu können, wird sowohl als wichtig erachtet, um Furcht zu erregen, wie auch um Mitleid mit den Gewaltopfern zu wecken. Letztlich wird die Wucht einer Gewalttat erst an Folgephänomenen deutlich, an der Verstörung des Opfers oder der Trauer der Angehörigen. Die Befragten beschreiben die Erwartungshaltung des Publikums, dass die psychischen Folgen dem physischen Ausmaß der Zerstörung entsprechen, das heißt, dass die Protagonisten der Berichterstattung ihr Leid ausdrucksstark vermitteln.

Magazinredakteur, öffentlich-rechtlicher Sender: „Bei einem Beitrag spielt es eine große Rolle, wie nah ich dem Zuschauer die Geschichte bringen kann. Fotos von Betroffenen spielen eine Rolle. Oder Interviews mit Betroffenen, natürlich noch besser. Die sprechen mit uns über ihre Geschichte. Die bindet natürlich viel stärker, weil mir dann wirklich Menschen begegnen und nicht nur Hausfassaden.“

Magazinredakteur, öffentlich-rechtlicher Sender: „Wir versuchen, eine menschelnde Geschichte hinzukriegen. Das Blut finde ich nicht so interessant.“

Die Frage, worauf die Schaulust zielt, führt zu der möglicherweise verblüffenden Antwort, dass sie die Gewalttat selbst weitgehend ausnimmt. Die These „If it bleeds it leads" (Kapuscinski 1999: III, Patterson 2000: 5, Kerbel 2000, Karl 2006: 66) bestätigen die Befragten nicht im wörtlichen Sinne. Danach entsprechen Bilder, die Gewalt unmittelbar und womöglich blutig zeigen, nicht dem Bedürfnis eines breiten Publikums. Das Interesse des Fernsehpublikums an einer Berichterstattung über Gewaltkriminalität ist gebrochen, meinen die Interviewten. Danach geht die vermutete Neugier einher mit einer Abwehr dagegen, zu viel zu sehen und zu viele Details zu erfahren. Entscheidend ist die feine Balance zwischen Nähe und Distanz. Einhellig vertreten die Befragten die Einschätzung, dass eine Visualisierung der unmittelbaren Tatfolgen vom breiten Publikum abgelehnt wird: Wer zuschaut, will vom 
Abseitigen erfahren, ohne sinnlich teilzuhaben. Es ist offenbar nicht die kriminelle Gewalt in ihrer Eigenheit, ihrem genauen Ablauf und in ihrer Brutalität, die das Publikum anzieht. Diese Annahme wird unmittelbar durch Befunde zur Sehbeteiligung gestützt.

Nachrichtenredakteur, Privatsender: „Blut ist ein Abschalter. Die Leute wollen auch nicht verstümmelte Leichen sehen. Abends, beim Abendessen, bei den Nachrichten, da will man das Grauen nicht so sehen. Man will immer nur eine Ahnung davon haben.“

Magazinredakteur, öffentlich-rechtlicher Sender: „Eine Tat näher zu beschreiben, wird von unseren Zuschauern, nach allem, was wir wissen, nicht gewünscht. Die interessieren sich für Kriminalität, aber nicht für die Details, weil die einen emotional nicht binden. Vor Jahren, als wir damit anfingen, sind wir vom Gegenteil ausgegangen."

Dieser Erfahrung zufolge führt die Abscheu vor dem Grauen auch zu einer Abwehr gegen deren mediale Darstellung und damit zu einem Einbruch in der Sehbeteiligung. Das zentrale Ziel der Programmanbieter, die Bindung des Publikums an die Programminhalte, lässt sich mit der detaillierten Darstellung von Gewaltkriminalität nicht erreichen.

\subsubsection{Zusammenfassung}

Nach den Erfahrungen von Fernsehjournalistinnen und Fernsehjournalisten ist das Publikum an Berichterstattung über Gewaltkriminalität nur bedingt interessiert. Die für private Sender Tätigen sehen eine Überreizung durch Gewalt, während die Befragten öffentlich-rechtlicher Sender eine konstante Nachfrage beschreiben. Emotionalisierung gilt als Schlüssel zum Publikumserfolg.

Die Befragten beschreiben die Furcht des Publikums vor Gewalt als ein zentrales Motiv, sich Fernsehberichten über Gewaltkriminalität zuzuwenden. Gefürchtet wird Gewalt gegen die eigene Person oder das nahe Umfeld, vor allem Kinder. Für bedeutsam wird nicht nur gehalten, Furcht zu erregen, sondern sie abschließend wieder aufzulösen. Als gleichfalls wichtig gilt es, Mitgefühl mit Verbrechensopfern und ihren Angehörigen zu wecken. Das Publikum ist, so vermuten die Befragten, emotional auf der Seite der Opfer. Aus den geschilderten Wirkungsannahmen lassen sich fünf wirkungsrelevante Nachrichtenfaktoren verdichten:

1. Folgenschwere gilt als wesentlichen Faktor des Publikumsinteresses an Kriminalitätsberichterstattung. Folgenschwere bezieht sich zum einen auf die eigentliche Tat, vor allem auf die irreparablen Folgen von Tötungsdelikten. Folgenschwere bezieht sich zum anderen auf die gesellschaftliche Bedeutung - wie unterschiedlich sie zugewiesen wird, belegt die gewachsene Aufmerksamkeit für sexuelle Gewalt an Kindern. 
2. Die Reichweite von Gewaltkriminalität bestimmt aus journalistischer Sicht das Publikumsinteresse kaum im Sinne von tatsächlicher, statistisch belegbarer Gefährdung. Entscheidend ist subjektive Reichweite als Gefühl, selbst gefährdet oder betroffen zu sein. Subjektive Reichweite wird gesteigert durch die Ähnlichkeit äußerer Lebensumstände zwischen den Zuschauenden und den Personen, über die berichtet wird, vor allem den Opfern. Dagegen nimmt das Publikum nach Ansicht der Befragten umso geringer Anteil an Menschen, je kulturell fremder sie erscheinen.

3. Personen in den Vordergrund zu stellen und ihnen möglichst nahe zu kommen, gilt als weiterer Faktor für einen Publikumserfolg der Kriminalitätsberichterstattung. Das Interesse gilt vor allem den unmittelbar und mittelbar Betroffenen von Gewalt, denen die Rolle zukommt, den emotionalen Kontext einer Tat zu schildern.

4. Polarität wird als weiterer bedeutsamer Faktor betrachtet, der sich in erster Linie auf das Opfer bezieht, vor allem, wenn es als sympathisch, schwach und unschuldig betrachtet werden kann. Das ideale Opfer in diesem Sinne ist das kindliche Opfer.

5. Bewegte Bilder gelten als zentrales Mittel, um Wirkungen beim Fernsehpublikum zu erzielen. Dabei geht es nicht um drastische Details der Gewalt, sie gefährden dem Bekunden nach die Sehbeteiligung. Als entscheidend gilt vielmehr die visuelle Vermittlung der emotionalen Folgen.

\subsection{Wirkungsgerichtetes journalistisches Handeln aus Sicht der Befragten}

Im vorigen Kapitel wurde analysiert, was aus Sicht von Fernsehjournalistinnen und Fernsehjournalisten die Berichterstattung über Gewaltkriminalität bei ihrem Publikum bewirkt. Zu den zentralen Annahmen gehört, dass eine Emotionalisierung der Schlüssel ist, um ein größtmögliches Publikum zu erreichen, und dass die wirkungsstärksten Emotionen die Furcht von Zuschauenden um sich selbst und ihnen nahe stehende Personen sowie das Mitgefühl mit Verbrechensopfern sind. Als fünf aus journalistischer Sicht zentrale Nachrichtenfaktoren erweisen sich Folgenschwere, Reichweite, Personalität, Polarität und Visualität.

Im folgenden Kapitel wird untersucht, welche Handlungsmuster nach den Aussagen der interviewten Journalistinnen und Journalisten daraus folgen. Diese Muster beziehen sich sowohl auf die Selektion wie auf die Thematisierung von Ereignissen, Personen und Konstellationen. Es geht also darum, wie die Befragten auswählen und was sie leitet, wenn sie recherchieren und Beiträge erstellen. Damit richtet sich der Blick auf die dynamischen Entscheidungsprozesse im Journalismus, die auch als Intra-Transaktion (vgl. Früh 1991, Früh und Schönbach 1982, 1984, 2005) bezeichnet werden. Im Mittelpunkt steht die Frage: Wie beschreiben die Befragten selbst ihre Handlungsmuster in der Fernsehberichterstattung über Gewaltkriminalität, die sie aus ihren Annahmen vom Publikum ableiten? 


\subsubsection{Die Gewichtung der Fernsehberichterstattung über Gewaltkriminalität}

Journalistinnen und Journalisten legen die Gewichtung des Themas Gewaltkriminalität für öffentlich-rechtliche und private Fernsehsender sowie für Nachrichten und Boulevardmagazine dar. Dabei blicken sie auf deutliche Veränderungen im Zeitverlauf zurück. Die Befragten betrachten journalistisches Handeln insbesondere in der Berichterstattung über Gewaltkriminalität als einer starken Dynamik unterworfen. Einhellig messen sie den Veränderungen der Fernsehlandschaft in Deutschland mit der Einführung des Privatfernsehens eine zentrale Bedeutung zu und sehen Auswirkungen auf alle Sender.

\footnotetext{
Nachrichtenredakteur, Privatsender: „Ich glaube, dass der ganze Schub in der Tat durch privaten Hörfunk und insbesondere durch das Privatfernsehen kam. (...) Das war auch sicherlich Programmpolitik, über dieses Aufsehen erregende, nie Gesehene die Quote zu machen."
}

Magazinredakteur, öffentlich-rechtlicher Sender: „Daraufhin wurden Themenfelder überhaupt erstmal entschlossen, die im Öffentlich-Rechtlichen bis dahin als nicht nachrichtengerecht gehalten wurden. (...) Und daraus hat sich diese Konjunktur ergeben.“

Impliziert wird damit, dass stärker als zuvor Publikumsbedürfnisse befriedigt werden und sich vor allem die Entscheidungskriterien in den Sendern verändert haben.

\section{Unterschiede nach Sendern und Formaten}

Die Befragten, die für Nachrichtensendungen der öffentlich-rechtlichen Sender arbeiten, skizzieren Gewaltkriminalität als einen Bestandteil des gesellschaftlichen Alltags, der damit grundsätzlich seinen Anteil an der Berichterstattung verdient. Dies gilt, so präzisieren sie, allerdings nur für besonders außergewöhnliche Delikte.

\footnotetext{
Nachrichtenredakteur, öffentlich-rechtlicher Sender: „Entweder ist es ein herausragendes Gewaltdelikt, (...) oder es gibt eben eine gesellschaftliche Dimension, wo sich Trends herauslesen lassen, wo sich politische Verstrickungen herauslesen lassen, wo politisches Versagen eine Rolle gespielt hat. Allein die „Sex and Crime-Geschichte“ ist eigentlich kein Nachrichtenthema für uns.“
}

Damit werden zwei Kriterien genannt, die sich auf die Dimensionen des einzelnen Falls wie auf die gesellschaftlichen Folgewirkungen beziehen. Das erste Kriterium besonderer Folgenschwere des Einzelfalls (,herausragendes Gewaltdelikt") erweist sich als so hohe Schwelle, dass in der Regel selbst spektakuläre Einzelfälle nur dann als berichtenswert gelten, wenn Kinder zu Opfern tödlicher Gewalt werden. Das zweite Kriterium hoher Folgenschwere für das Gemeinwesen (,gesellschaftliche Dimension“) schränkt die Berichterstattung über Gewalttaten, die zwar von hoher Emotionalität, aber nicht von Tragweite über den Einzelfall hinaus sind, stark ein. Als Kernkategorie ihrer Entscheidungen legen die Befragten ihre eigene Deutung 
ereignisbezogener Merkmale des Geschehens und seiner Folgen zu Grunde. Das Publikumsinteresse berücksichtigen sie aus ihrem Nachrichtenverständnis und den vertraglichen Verpflichtungen öffentlich-rechtlicher Sender heraus nachrangig auch wenn damit Themen entfallen, die sie für wirkungsstark halten. Die Befragten in Nachrichtenredaktionen privater Sender dagegen skizzieren die vermutete Wirkung der Berichterstattung auf ihr Publikum als zentral, die übergeordnete Bedeutung der Ereignisse dagegen als nachrangig. Sie beschreiben Gewaltkriminalität als einen Bestandteil, der wie ein Gewürz die Komposition der Sendung abrundet.

Nachrichtenredakteurin, öffentlich-rechtlicher Sender: „Promis und Tiere ziehen noch mehr als Verbrechen, und wenn Sie nach 22 Uhr senden, auch Sex. Aber Nachrichten dürfen das nicht.“

Nachrichtenredakteur, Privatsender: „Wenn ich irgendwo eine Ballerei habe und die Leute beschießen sich auf offener Straße, dann sagt man, mein Gott, da war ja gestern richtig was los. (...) Oder dieser Typ, der in die Arztpraxis eindringt und einen Arzt und die Sprechstundenhilfe erschießt. (...) Das bleiben dann Einzelfälle, und die sind vielleicht das Chili in der Struktur des Tages.“

Der Vergleich von Kriminalitätsberichten mit Chili schließt zugleich zwei Annahmen ein: Zum einen üben Fernsehberichte über kriminelle Gewalt eine starke Wirkung aus, zum anderen aber ist der Wirkstoff nur begrenzt anzuwenden. Ein ganz anderes Bild zeigt sich bei den Boulevardmagazinen. Hier zeigen vor allem die für öffentlich-rechtliche Boulevardmagazine Tätigen eine gewachsene Neigung zu Gewaltthemen.

Freie Autorin, öffentlich-rechtlicher Sender: „Natürlich ist der Gruseleffekt auch dabei. Davon leben ja nun das Boulevardfernsehen und die Öffentlich-Rechtlichen in zunehmendem Maße. Das wäre vor acht Jahren ganz klein gefahren worden im Öffentlich-Rechtlichen. Es nähert sich an. Man hat erkannt, dass man über diese Themen nicht so hinweggehen kann.“

Magazinredakteur, öffentlich-rechtlicher Sender: „Durch diese Mischung von Mord und Totschlag, Blut, Sperma, Promigeschichten, Servicebereich stehen wir relativ gut am Markt.“

Völlig anders äußern sich ihre Konkurrenten in den kommerziellen Sendern. Sie haben aus der angenommenen „Übersättigung“ des Publikums mit medialer Gewalt Konsequenzen gezogen und halten eine weniger gewalthaltige Themenpalette für erfolgsträchtig.

Magazinredakteur, Privatsender: „In der Gewaltberichterstattung haben wir unsere Stückzahl extrem reduziert. Früher war Gewaltberichterstattung ganz klassisch Aufmacher, das werden Sie heute kaum noch erleben."

Magazinredakteur, privater Sender: „Das muss man in homöopathischen Dosen einsetzen. Wenn Sie jeden Tag mit so einem Schocker um die Ecke kommen, nimmt Sie irgendwann keiner mehr ernst.“ 
Damit zeigt sich, dass eine starke Publikumsorientierung keineswegs automatisch zu einer starken Thematisierung von Gewaltkriminalität führt, sondern zu völlig unterschiedlichen Konzepten führen kann, die mit Blick auf wahrgenommene bzw. vermutete Publikumsbedürfnisse einer starken Dynamik unterliegen.

\subsubsection{Emotionalisierung}

Quer durch alle Fernsehformate und Senderformen beschreiben die Interviewten, dass Emotionen zu einem wichtigen Baustein der journalistischen Arbeit gehören, um ein größtmögliches Publikum zu erreichen. Daher fokussieren die Befragten ihre Berichterstattung über Gewaltkriminalität vor allem auf die emotionalen Folgen der Gewalt für die Kriminalitätsopfer.

Magazinredakteur, Privatsender: „Natürlich gibt es dieses emotionale Interesse des Zuschauers und deshalb auch von uns, diese leidende, menschliche Seite an diesem ganzen Drama zu zeigen."

Wie Journalistinnen und Journalisten die Bedeutung von Emotionen für die Berichterstattung bewerten, ist Teil eines dynamischen Prozesses. Dies zeigt sich bei Befragten mit längerer Berufspraxis. Sie charakterisieren diesen Wandel als veränderte Wahrnehmung von Publikumsbedürfnissen bei allen untersuchten Fernsehformaten. Als Urknall der verstärkten Gefühlsausladung gilt einhellig die Einführung privater Fernsehprogramme in Deutschland.

Unterschiede nach Sendern und Formaten

Die in Nachrichtenredaktionen öffentlich-rechtlicher Sender Befragten skizzieren Emotionalität als Mittel der Informationsvermittlung, das im deutschen Fernsehen an Bedeutung gewonnen hat.

Nachrichtenredakteur, öffentlich-rechtlicher Sender: „Ich kann nicht verhehlen, dass emotionale O-Töne natürlich den Beitrag interessanter gestalten. Klingt zynisch, aber es ist so.“

Zugleich aber gilt Emotionalität nur in engen Grenzen als Mittel, um eine Wirkung beim Publikum zu erzielen. Daraus leiten die Beschäftigten öffentlich-rechtlicher Nachrichten einen eher zurückhaltenden Einsatz von Emotionen ab und vermuten, dass eine Annäherung an die Nachrichtenkonzepte privater Sender nicht stattfinden wird, was eine stärkere Betonung von Emotionalität bei der Themenauswahl und Beitragsgestaltung angeht. Die in Nachrichtenredaktionen privater Sender Beschäftigten dagegen bekennen sich zum Einsatz von Emotionen, um Aufmerksamkeit für ihre Informationsangebote zu wecken. Die gezeigten Personen, vor allem unmittelbar Betroffene, in zweiter Linie Augenzeuginnen und Augenzeugen oder professio- 
nell Beteiligte, sollen Emotionen zeigen und sich emotional äußern. In dieser Ausprägung sehen die Interviewten einen klaren Unterschied zu den Nachrichten der öffentlich-rechtlichen Konkurrenz.

Nachrichtenredakteurin, Privatsender: „Natürlich sprechen die Medien die Emotionen an, (...) und als Privatsender geht man anders an die Zuschauer heran.“

Analog zur Annahme, dass Zuschauende Nachrichten und Boulevardmagazine mit unterschiedlichen Erwartungshaltungen betrachten, definieren die Befragten für diese Fernsehformate jeweils unterschiedliche Wirkungsabsichten. Während die Emotionalisierung für Nachrichten als weniger zentral gesehen wird, steht sie für Boulevardmagazine im Vordergrund.

Redakteurin für Nachrichten und Magazine, öffentlich-rechtlicher Sender: „Das Boulevardmagazin macht man emotionaler. Da kann man auch mal den Ausdruck eines Gefühls einflieBen lassen, der sicherlich in den Nachrichten so nicht stattfinden dürfte.“

Die Befragten beobachten für die Magazine eine gegenläufige Entwicklung, analog zum veränderten Umgang mit Gewalt: So gelten das regelmäßige Zeigen von Gefühlsausbrüchen in der Frühzeit des Privatfernsehens bereits als ein Stück Fernsehgeschichte und reines „Emotionsfernsehen“ als überholt. Die in öffentlichrechtlichen Sendern Beschäftigten dagegen sehen tendenziell weiteren Nachholbedarf, in großer Bandbreite Gefühle zu wecken.

Magazinredakteurin, öffentlich-rechtlicher Sender: „Es wird zunehmend verlangt, das meine ich aber gar nicht negativ, nicht streng nachrichtlich zu berichten, sondern den Zuschauer damit eher zu kriegen, dass es ihn berührt.“

Magazinredakteurin, Privatsender: „Wir zeigen schon lange keinen weinenden Menschen mehr. Das ist einfach schwierig, um es mal derbe auszudrücken. Das ist auch etwas, das der Zuschauer nicht mehr sehen will.“

So einhellig die Befragten also Emotionalisierung als Schlüssel begreifen, um ihr Publikum an ihr Programm zu binden, so stark vertreten sie auch die Annahme, dass es einer jeweils angemessenen Dosierung medial vermittelter Gefühle bedarf. Eine erfolgreiche Emotionalisierung bedient sich ihrer Mittel nicht maßlos, sondern sparsam.

\subsubsection{Erregung von Furcht}

Im Mittelpunkt steht hier die Frage, in wie Programmverantwortliche es darauf anlegen, Furcht zu erregen, welche Bedingungen dafür maßgeblich sind, und welche 
Rolle es schließlich spielt, Furcht wieder aufzulösen. Die Befragten nennen als ein wichtiges handlungsleitendes Motiv in der Berichterstattung über Gewaltkriminalität, Furcht zu erregen.

Magazinredakteur, Privatsender: „Ein bisschen Horror-Kino, ein bisschen Psychothriller, so sehe ich die Stücke, die wir machen müssen.“

Die Tat beschreiben die Befragten als desto furchterregender für das Publikum, je zerstörerischer sie ist. Die größte Wucht wird schwerer physischer und sexueller Gewalt zugeordnet. Sie zeigt sich journalistischer Einschätzung zufolge vor allem an den nachhaltigsten emotionalen Folgen für die Opfer selbst bzw. ihr Umfeld. Zentral ist die Tatkonstellation, die ein Redakteur als „Psychogramm der Tat“ bezeichnet. Je abgründiger ein Motiv erscheint, umso stärker erregt es Furcht, vermuten die Befragten. Dies führt in der Konsequenz dazu, Gewaltdelikte vor allem dann aufzugreifen, wenn sie nicht durch unglückliche Verkettungen, sondern durch planvolles, schuldhaftes Verhalten entstanden zu sein scheinen.

Nachrichtenredakteurin, öffentlich-rechtlicher Sender: „Affektmorde emotionalisieren die Leute nicht so sehr, als wenn sie in den Taten die Verwerflichkeit wie Gier, sexuelle Lust, Niedertracht, Heimtücke erkennen. Je mehr dieser Faktoren es gibt, umso emotionaler sind die Themen auch.“

Die Wirkungsabsicht, Furcht zu erregen, wird so mit Auswahl- und Thematisierungsstrategien erreicht, die sich beispielsweise als eine Dramatisierung der Gewalt zeigen. Als besonders erschreckend wird die Gewalt beschrieben, die Kinder und damit selbst die Schwächsten trifft. Der Annahme, dass diese Gewalt die höchste Aufmerksamkeit erregt, entspricht eine Akzentuierung kindlicher Opfer in der Berichterstattung. Gleichsam spielt eine wichtige Rolle, das Tatgeschehen und die Lebenswirklichkeit der Zuschauenden miteinander zu verknüpfen, um kriminelle Gewalt nicht als fernes Geschehen, sondern als reale Bedrohung für das Publikum selbst zu vermitteln. Die Darstellung von Gewalt als letztlich unbegreiflich und unberechenbar gehört zur Grundstruktur der Beiträge über Gewaltkriminalität: Kein Ort ist sicher, weder vor der Kamera noch vor dem Bildschirm.

Um diese Strategie einer subjektiven Entgrenzung der Gewalt umzusetzen, bedarf es einer dichten Darstellung der beteiligten Personen möglichst im Originalton und in bewegten Bildern. Um größtmögliche Furcht zu erregen, darf man den Befragten zufolge allerdings keine Art Raubbau betreiben. Um einer Abstumpfung des Publikums gegen Angstreize entgegenzuwirken, nennen sie als ein wesentliches Anliegen, ihrem Publikum abschließend Erleichterung zu verschaffen. Einige der Befragten plädieren für eine Erlösung als dramaturgisches Element der Dramaturgie jedes einzelnen Beitrags. Sie beziehen sich dabei auf das Konzept der Heldenreise, das der Drehbuchanalytiker Christopher Vogler aus seiner Arbeit für große Hollywood-Studios und in Anlehnung an Joseph Campbell entwickelt hat (vgl. Vogler 2004, Campbell 1999). 
Magazinredakteur, Privatsender: „Es ist immer eine Heldenreise, die nach Möglichkeit einen positiven Ausgang nehmen sollte, dass nach einem Gerichtsprozess die Angehörigen zumindest eine Erlösung dahingehend finden, dass sie jetzt wissen, was mit dem Täter passiert. (...) Dass es eine Erlösung gibt im wahrsten Sinne des Wortes. Das sind Prinzipien, die wir mit unseren Mitarbeitern über Jahre hinweg schulen, trainieren, Workshops machen. Da geht man nach ganz klassischen Filmkriterien vor.“

Während nur einige der Befragten für die Erlösung bereits am Ende eines Beitrages plädieren, vertreten die Befragten einhellig die Position, dass die Auflösung der Furcht zum Ende der Sendung - in der Regel also per Themenwechsel - ein zentrales dramaturgisches Element ist.

Magazinredakteur, öffentlich-rechtlicher Sender: „Wir müssen den Zuschauer am Ende versöhnlich hinauslassen. Wir müssen nette Geschichten, schöne Geschichten am Ende erzählen, damit er nicht die Lust am Leben verliert. Der muss morgen wieder einschalten.“

Nachrichtenredakteurin, öffentlich-rechtlicher Sender: „Ich mache zumindest den Versuch, hinten ein bis zwei Stücke zu platzieren, die etwas leichter sind, die eine positive Nachricht transportieren, die den Hammer dessen, was Nachrichten im Allgemeinen verursachen, abschwächen oder abfedern.“

Darin zeigt sich das Paradoxon, dass zur Bindung des Publikums nicht nur dessen Verbrechensfurcht stimuliert wird, sondern auch die Linderung dieser Furcht gerade wieder dazu dient, das Interesse für Gewaltkriminalität und die Empfänglichkeit für Ängste zu erhalten.

\subsubsection{Wecken von Mitgefühl}

Journalisten und Journalistinnen offenbaren, wie sie eine Anteilnahme mit Betroffenen von Gewalt herbeiführen und welche Bedingungen sie dafür für wesentlich halten. Um das Publikum für die Berichterstattung über Gewaltkriminalität zu gewinnen, erweist sich den Programmverantwortlichen zufolge als wirkungsvoll, das Mitgefühl mit leidenden Menschen zu wecken und zu verstärken. Damit ist implizit als zentraler Faktor benannt, dass Menschen Gestalt gewinnen, um als Kristallisationspunkte für Mitgefühl zu wirken, und dies sind vor allem die unmittelbar und mittelbar Betroffenen von Gewalt. Von ihnen wird erwartet, dass sie ihre Rolle entsprechend ausfüllen, also ihr Leid fernsehgerecht zeigen.

Freier Autor, öffentlich-rechtliche und private Sender: „Der Zuschauer soll Mitleid empfinden oder mitfühlen. Er soll gebannt vor dem Fernseher sitzen und sagen: ,Oh je, was die erlebt haben.' Also die Emotionen sollen schon rüber kommen.“

Eng verknüpft mit der Weckung von Mitgefühl ist, dass eine emotionale Verknüpfung erleichtert und Ambivalenzen vermieden werden. Daher sollen die Protagonisten der Berichterstattung besonders günstige Eigenschaften erfüllen bzw. in besonders vorteilhafter Weise dargestellt werden. Denn das Mitgefühl des Publikums gilt 
aus journalistischer Sicht den Verbrechensopfern nicht gleichermaßen und zwangsläufig, sondern am ehesten den idealtypischen Opfern. Daraus folgern die Befragten, Fälle so auszuwählen und aufzuarbeiten, dass die Opfer als schwach, sympathisch und unschuldig idealisiert werden können.

Agenturreporter: „Bei Kindern ist die Betroffenheit des Zuschauers am größten, das Mitleid für die Eltern, für die Angehörigen. (...) [Angelpunkte sind] das unbescholtene Kind, der unbescholtene Bürger, der brave Arbeiter, der sich nie hat nie was zu Schulden kommen lassen.“

Als weitere Bedingung für eine Empathie des Publikums ist aus journalistischer Sicht die gefühlte Nähe zu den Menschen, über die berichtet wird und die sich in einer Ähnlichkeit der Lebensumstände spiegelt. Dies führt dazu, dass bereits mit Beginn der Recherchen die Entscheidung fallen kann, über eine Gewalttat nicht zu berichten, weil das Opfer in sozialer und kultureller Hinsicht zu stark vom gesuchten Idealtypus abweicht, oder eben das Opfer auszuwählen, das in wohlsituierten Verhältnissen lebt.

Magazinredakteur, öffentlich-rechtlicher Sender: „Wenn ich schon sehe, wo der Fall passiert ist: Ist es in einem Einfamilienhaus in München-Grünwald, oder ist es in einem Mehrfamilienhaus in München-Hasenbergl. Ist ja schon mal ein erstes Indiz, ob der jetzt sympathisch sein könnte oder nicht. Dann: Wie spricht der Mensch? Formuliert er klare Sätze oder formuliert er keine klaren Sätze? Hat er einen Job? Hat er keinen Job?“

Das Ziel, Sympathie für Gewaltbetroffene zu erwecken, wirkt sich über Auswahlentscheidungen hinaus auch auf dramaturgische Entscheidungen aus, nachdem die Entscheidung, über ein Ereignis und bestimmte Protagonisten zu berichten, grundsätzlich gefallen ist. Dies schließt Strategien der Inszenierung und der Visualisierung ein, um den Gewaltbetroffenen Gestalt zu geben, ihr Leiden zu vermitteln und so das Mitgefühl mit ihnen zu verstärken. Als weiteren Faktor nennen die Interviewten, vor allem drastische Gewalt aufzugreifen und die Wucht der emotionalen Folgen besonders hervorzuheben. Als weitere Tatumstände nennen sie besonders abgründige Tatmotive und Heimtücke.

\subsubsection{Journalistische Handlungsmuster}

Wie zuvor gezeigt wurde, lassen sich aus den Interviews fünf Nachrichtenfaktoren herausfiltern, die den Befragten zufolge wesentlich dazu beitragen, dass Menschen Furcht oder Mitleid empfinden und sich vor allem aus diesen Emotionen heraus der Fernsehberichterstattung über Gewaltkriminalität zuwenden. Diese Faktoren werden als Folgenschwere, Reichweite, Polarität, Personalität und Visualität bezeichnet. Im Folgenden wird das daraus abgeleitete journalistische Handeln genauer betrachtet. Den fünf wirkungsrelevanten Nachrichtenfaktoren entsprechen Handlungsmuster, die als Dramatisierung der Gewalt, Entgrenzung des Schreckens, Personalisierung des Leids, Idealisierung des Opfers und Schaffung innerer Bilder umrissen werden. 
Abb. 11: Wirkungsgerichtete journalistische Strategien der Fernsehberichterstattung über Gewaltkriminalität aus journalistischer Sicht

Beabsichtigte Folgen

Frhöhung der Sehbeteiligung bzw. des Markterfolgs

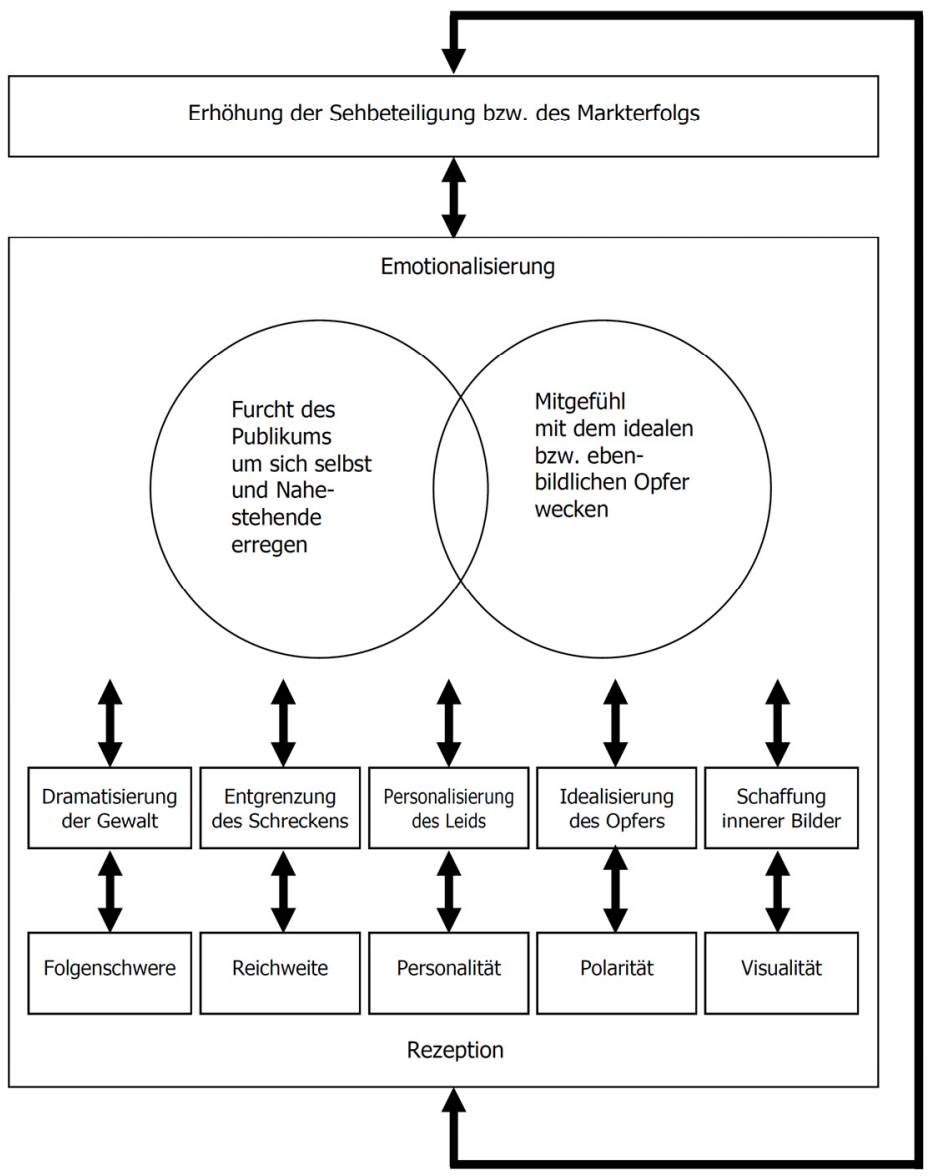

Beabsichtigte Wirkung

Journalistische Deutungsund Handlungsmuster

Wirkungsrelevante Nachrichtenfaktoren

Deutungs- und Handlungsmuster von Journalistinnen und Journalisten im Kontext ihrer Wirkungsannahmen und Wirkungsabsichten. Quelle: eigene Grafik.

\subsubsection{Dramatisierung der Gewalt}

Journalistische Auswahlentscheidungen und Thematisierungsstrategien werden daran gemessen, wie gravierend die unmittelbaren und mittelbaren Auswirkungen von Straftaten gesehen werden. Aus der Annahme heraus, dass Tötungsdelikte und sexuelle Gewalttaten das Publikum in besonderer Weise berühren, werden diese Delikte bevorzugt thematisiert. 
Freier Autor, öffentlich-rechtlicher Sender: „Wenn man überlegt, welchen Stoff kriege ich am besten los, da kommt man schon in einen Gedankenbereich, den ich nicht mag und den ich selber ein bisschen pervers finde, aber mit Mord und Totschlag kriege ich die Tür eher auf.“

Agenturjournalist: „Sexualität ist emotional, sexueller Missbrauch von Kindern ist erst recht emotional hoch besetzt. Die privaten Fernsehsender sind darauf massiv eingestiegen. Dadurch ist ein gewisser Marktdruck entstanden, auch auf die öffentlich-rechtlichen Sender und in die Printmedien hinein.“

Den höchsten medialen Wirkungsgrad erfüllen damit Delikte, die sowohl tödlich verlaufen wie sexuell motiviert sind und bei denen den Opfern idealtypische Eigenschaften zugeschrieben werden können. Als Beispiel dafür nennen die Befragten die außerordentliche Beachtung von Sexualmorden an Kindern. Diese sind zwar so selten, dass sie im journalistischen Alltag in absoluten Umfängen eine geringe Rolle spielen, aber anteilig zur Fallzahl enorm stark thematisiert werden.

Gravierende Gewaltdelikte gelten den Befragten als berichtenswert, auch wenn sie auf keinen gesellschaftlichen Kontext verweisen oder gesellschaftliche Debatten auslösen. Bei der Thematisierung von Einzelfällen stehen nicht die physischen Verletzungen im Vordergrund, sondern der emotionale Nachhall - sei es die vielfach lebenslange Traumatisierung von Gewaltopfern selbst, sei es die Trauer der Angehörigen. Die Nachhaltigkeit dieser emotionalen Zerstörung gilt es den Befragten zufolge zu zeigen, um die eigentliche Folgenschwere der Tat zu belegen und damit das Publikum an das Programm zu binden.

Redakteurin für Magazine und Nachrichten, öffentlich-rechtlicher Sender: „Der trauernde nächste Angehörige ist zweifelsohne das stärkste Gefühl, das man jemandem anbieten kann. (...) Ich glaube, dass Trauer die Menschen am stärksten berührt. Dass das eben ein Gefühl ist, was sehr, sehr langsam nur vergeht.“

Für eine solcherart fokussierte Berichterstattung bedarf es also der Mitwirkung des nahen Umfeldes, um an die Emotionen der Verletzten herandringen und sie vermitteln zu können. Die Befragten nennen als Ausgangspunkt von Recherchen und Berichterstattung in aller Regel den Einzelfall. Am Anfang steht das spektakuläre Ereignis, und dann wird es, wenn möglich, mit weiterer Bedeutung aufgeladen. So beginnt die journalistische Betrachtung von Ereignissen mit einer Nahaufnahme, die sich - ein vertieftes Interesse vorausgesetzt - zur Totale erweitert. Dieses induktive Verfahren wird angestoßen durch das unerhörte einzelne Ereignis und stellt dann Zusammenhänge her. Ein Redakteur spricht vom Blick auf die „Peripherie des Einschusslochs“. Somit ist Folgenschwere im Sinne gesellschaftlicher Tragweite ein weiteres gewichtiges Kriterium journalistischer Entscheidungen.

Magazinredakteur, Privatsender: „Große Themen sind die, die zunächst Blaulicht oder ein Kriminalfall sind, aber dann eingebettet sind in eine große Diskussion. (...) Jeder Kriminette hinterher zu laufen, finde ich nicht interessant."

Nachrichtenredakteur, öffentlich-rechtlicher Sender: „Bei den Kriminalfällen, die wir reportieren und melden, achten wir darauf, dass es eine übergeordnete Themenstellung gibt.“ 
Dem Einzelfall („Kriminette“), der als spektakulär, aber nicht als weithin bedeutsam betrachtet wird, stellen die Befragten das Ereignis gegenüber, das auf eine Bedeutung über den Einzelfall hinaus verweist. Streng genommen, geht es dabei nicht nur um Folgenschwere, sondern zunächst um Ursachenschwere: Indem nicht nur gewichtige Folgen, sondern auch gewichtige Ursachen konstruiert werden, wird das Ereignis in doppelter Hinsicht mit Bedeutung aufgeladen. Dies wird beispielsweise dadurch erreicht, dass Gewalttaten auf ein Versagen staatlicher Einrichtungen oder ungenügende Gesetze zurückgeführt werden. Die Folgenschwere einer Gewalttat wird aus journalistischer Sicht besonders dadurch validiert, dass sich politisch Verantwortliche selbst äußern.

Nachrichtenredakteur, Privatsender: „Wenn wir über Themen wie Vernachlässigung von Kindern oder Kindesmissbrauch berichten, wo politische Konsequenzen gezogen werden könnten, und die Politik beschäftigt sich anschließend damit, ist das eine andere Dimension.“

Gelingt es also, Verantwortungsträger dazu zu bewegen, den Einzelfall als Ausdruck eines gesellschaftlichen Prozesses zu deuten, lässt sich die Folgenschwere der Gewaltkriminalität intensiv vermitteln und der Wirkungsgrad der Berichterstattung erhöhen.

\subsubsection{Entgrenzung des Schreckens}

Journalistische Entscheidungen in der Fernsehberichterstattung über Gewaltkriminalität werden daraufhin überprüft, inwieweit sie von Annahmen über das tatsächliche oder gefühlte Risiko, Opfer einer Gewalttat zu werden, geleitet sind. Zu unterscheiden sind statistische und gefühlte Reichweite. Statistische Reichweite stützt sich auf überprüfbare Werte wie den so genannten Kriminalitätsquotienten der Polizeistatistik oder auf gesicherte Forschungserkenntnisse über das Dunkelfeld. Keiner der Befragten nennt die statistische Reichweite als Entscheidungskriterium, wonach also besonders häufige Gewaltdelikte besonders häufig berichtet werden würden. Gefühlte Reichweite stützt sich primär darauf, wie stark das Publikum von Kriminalitätsberichterstattung eine Verknüpfung von Gewaltkriminalität mit dem eigenen Alltag sieht. Ob die Befragten es darauf anlegen, die gefühlte Reichweite zu erhöhen und damit den Schrecken aus seinem engen statistischen Maß zu entgrenzen, ist abhängig davon, für welche Sendungen sie arbeiten.

\section{Unterschiede nach Sendern und Formaten}

In der Abwägung zwischen messbarer und gefühlter Reichweite von Gewaltkriminalität nehmen die für öffentlich-rechtliche Nachrichten Tätigen eine Sonderrolle ein. Analog zu ihrem Bekenntnis, dass ihre Orientierung an Publikumsbedürfnissen begrenzt ist, nennen sie die subjektive Reichweite nur bedingt handlungsrelevant. 
Nachrichtenredakteurin, öffentlich-rechtlicher Sender: „Das einzuschätzen durch Kriminologen, Polizisten, auch Statistiken, oder zu sagen, das ist eine Reihe, aber es sind sieben und nicht 700: Diesen Versuch machen wir immer wieder. Aber es ist dann etwas in der öffentlichen Diskussion. Wir sind auch gefordert, Themen abzubilden, die eine gewisse Virulenz besitzen.“

Dies bedeutet, dass sich auch die Redakteurinnen und Redakteure öffentlichrechtlicher Nachrichten unter Druck sehen, Kriminalitätsthemen in einer Weise zu gewichten, die ihnen aus eigener Sicht faktisch nicht zukommt, aber vom Publikum so gewollt ist. Gleichwohl überwiegt das Bemühen, intersubjektiv überprüfbare Kriterien einzubringen, auch wenn damit eine Emotionalisierung, vor allem ein Schüren von Verbrechensfurcht, erschwert wird.

Die Befragten aller anderen Formate gewichten anders. Für sie spielt die subjektive Reichweite eine gewichtigere Rolle. Es gilt also nicht vorrangig, rational begründeten Konstrukten der Wirklichkeit gerecht zu werden, sondern den Wirklichkeitsannahmen des Publikums. Die gefühlte Kriminalität bestimmt, wie berichtet wird. Der Hinweis etwa darauf, dass jährlich weniger als zehn Kinder Sexualmorden zum Opfer fallen und diese Zahl seit den 70er Jahren sinkt, spielt dabei kaum eine Rolle. Nicht die Zahlen der Polizei oder der Kriminologie sind entscheidend, sondern die Zahlen der Sehbeteiligung.

Magazinredakteur, Privatsender: „Soweit ich informiert bin, werden die Fälle grundsätzlich gar nicht mehr. Es entsteht nur der Eindruck, dass es mehr wird. Das will aber gar keiner so richtig hören."

Agenturjournalist: „Ich bediene nur einen Markt. Wenn ich dem Kunden sage, das mache ich nicht, weil ich nicht dem Fernsehzuschauer suggerieren möchte, dass es immer schlimmer wird in Deutschland, dann lacht der mich aus."

Für die Befragten außerhalb der öffentlich-rechtlichen Nachrichten ist nicht die wissenschaftlich belegte Kriminalitätsbelastung die maßgebliche Kategorie, sondern die Aufgeregtheit des Publikums. Damit geht es um ein Paradoxon: Im Mittelpunkt der Berichterstattung über Gewaltkriminalität steht das außergewöhnliche, gleichsam jenseitige Ereignis, das erst dadurch bedrohlich wirkt, dass es in gewöhnlichen, diesseitigen Umständen geschieht bzw. geschehen kann. Diese gegensätzlichen Aspekte zu vereinen, bedeutet eine dramaturgische Herausforderung.

Magazinredakteur, Privatsender: „Im Grunde geht es darum, das Besondere in der Normalität zu suchen. Das ist im Grunde der Clou dabei.“

Nachrichtenredakteur, Privatsender: „Ich muss es so nahe wie möglich an meine Lebenswirklichkeit heranziehen. Bei Crime gelingt das nicht immer."

Damit wird eine aktive Inszenierung beschrieben, das außergewöhnliche Ereignis mitten im gewöhnlichen Leben des Publikums zu verorten. Dafür beschreiben die Befragten eine Reihe von Auswahlstrategien. Um größtmögliche subjektive Reichweite zu vermitteln, sind Irritationen, die zu einer Distanzierung bei den Zuschauen- 
den führen könnten, möglichst auszuschließen. Signale sozialer Randständigkeit sind zu vermeiden, Personen, die in problematischen Stadtteilen leben und arm sind, zu übergehen. Keine störenden Unterschiede sollen verhindern, dass das Publikum das anderen Menschen zugefügte Leid auch auf sich selbst überträgt und daher Furcht oder Mitleid empfindet.

Magazinredakteur, öffentlich-rechtlicher Sender: „Oftmals nehmen wir keine Geschichten, weil die Opfer nicht sympathisch sind, (...) wenn die Opfer aus einer gewissen Schicht kommen.“

Die Konstruktion sozialer Übereinstimmung wird besonders bei der Auswahl nach dem Alter deutlich. Die Auswahl des Verbrechensopfers als zentraler Figur der Kriminalitätsberichterstattung folgt diesem Muster. Ein Reporter spricht von „zielgruppiger“ Recherche. Dabei werden Menschen im Alter der so genannten werberelevanten Zielgruppe, also möglichst unter 49 Jahren ausgewählt. Den Befragten zufolge, die sowohl für öffentlich-rechtliche wie für private Sender arbeiten, gilt dieser Grundsatz quer durch alle Sender, aber in besonderem Maße für die werbefinanzierten Privatsender.

Agenturjournalist: „Wir werden angehalten, wenn wir uns Protagonisten suchen, (...) dass man an die so genannte Zielgruppe denkt. Dazu gehören nicht Rentner. Also, wenn ich einen Augenzeugen oder einen Betroffenen suche, dann sollte das nach Möglichkeit in der Zielgruppe sein, (...) junge Leute, die das Geld haben, die das Geld gerne ausgeben, die Kaufkraft haben.“

Die Befragten schildern, dass sie im Regelfall über deutsche Tatverdächtige und deutsche Verbrechensopfer berichten. Dies begründen sie einerseits aus ihrer Annahme, dass ihr - implizit deutsches - Publikum sich vor allem für Menschen gleicher, also deutscher Nationalität interessiert. Das Geschehen in fernen Welten gilt als schwer vermittelbar, auch wenn sie mitten in Deutschland liegen, die Ferne sich also nicht räumlich, sondern allein sozio-kulturell abbildet. Danach werden vor allem Verbrechensopfer als zentrale Figuren der Emotionalisierung nach ihrer Nationalität ausgewählt und gilt es erst recht zu vermeiden, dass alle Tatbeteiligten Nichtdeutsche sind.

Magazinredakteur, Privatsender: „Es muss irgendein deutscher Bezug da sein. Wir machen nie Geschichten, wo nur Ausländer dabei sind. Ist dann eher nicht so spannend.“

Diese Strategien beziehen sich auf Alltagskriminalität - bei ausländerfeindlicher, womöglich organisierter Gewalt führt dagegen der Nachrichtenfaktor Folgenschwere wiederum zu stärkerer Beachtung. Der Entgrenzung des Schreckens dienen auch Originaltöne, die explizit zur Auflösung der Grenzen zwischen dem Grauen hinter der Mattscheibe und der Normalität der Zuschauenden beitragen. 
Agenturjournalist: „Dass man sagt, (...), ich kenne so etwas nur aus dem Fernsehen, und jetzt [geschieht es] bei uns im Dorf', so etwas wird immer gerne genommen. Um den Leuten zu zeigen, die Welt ist eine schlechte und nicht nur in der Welt, sondern auch bei euch zu Hause.“

Der Akteur, der heute zumindest am Rande beteiligt ist und sein Erstaunen darüber schildert, hat gestern noch selbst nur aus der Ferne zugesehen. So können sich diejenigen, die zuschauen, in den im Fernsehen auftretenden Menschen spiegeln, die wie sie womöglich selbst - die Berichterstattung über Gewaltkriminalität bislang wie einen Spielfilm und das Grauen als etwas betrachtet haben, das anderen und anderenorts passiert. Das Fernsehen belehrt sie eines Besseren: Niemand ist sicher.

Nachrichtenredakteur, Privatsender: „Es geht immer nur um das Potenzial: potenziell könnte ich auch Opfer sein. Potenziell könnte es auch mein Kind erwischen.“

Dieses strategische Handeln zur Entgrenzung des Schreckens zielt auf zweierlei: zum einen Auswirkungen auf den Alltag des Publikums zu vermitteln, so dass es mit Verbrechensopfern mitfühlt, und zum anderen darauf, Zuschauerinnen und Zuschauer die Furcht vor Gewaltkriminalität nahezubringen, auch wenn sich dies nicht durch ein statistisch hohes Risiko begründen lässt. Diese subjektive Reichweite schildern die Befragten außerhalb der öffentlich-rechtlichen Nachrichten als ein wesentliches Auswahlkriterium. So wird der Konjunktiv Irrealis zum Konjunktiv Potentialis umgedeutet: Es könnte jeden und jede treffen. Die subjektive Reichweite ist grenzenlos.

\subsubsection{Personalisierung des Leids}

Die Befragten sehen das Publikumsinteresse vor allem auf einzelne Verbrechen und auf die emotionalen Folgen für die Opfer und ihr Umfeld gerichtet. Daraus leiten sie eine personalisierte Berichterstattung ab. Diesen Anspruch sehen sie vor allem dadurch verwirklicht, zu den Personen im Kern des Geschehens vordringen. Daher bevorzugen sie Bild- und Tonaufnahmen der von Gewalt unmittelbar Betroffenen gegenüber den mittelbar Beteiligten oder den professionellen Akteuren.

Agenturreporter: „Wenn ich Betroffenen-O-Töne habe, ist das mehr ein Thema, als wenn ich nur den sachlichen Polizei-O-Ton habe. Umso mehr kann ich einen Beitrag emotional aufbauen.“

Entscheidend ist allerdings nicht allein, dass Protagonisten emotional betroffen sind, sondern dass sie diese Betroffenheit vermitteln, in dem, was sie sagen, und vor allem, wie sie es sagen. Damit werden nicht nur Rollen beschrieben, sondern auch bestimmte Rollenerwartungen.

Agenturreporter: „Er muss gut reden, er muss emotional reden, dass ich ihm das glaube. (...) Er muss authentisch wirken, er muss gut erzählen können. Es ist schon auch wichtig, was er erzählt, aber er muss es einfach gut erzählen.“ 
Um diese Rollenerwartung zu erfüllen, sollen die dargestellten Personen Gefühle zeigen, was einschließt, dass sie möglichst in bewegten Bildern zu sehen sind. Dies entspricht der Betrachtung einer Gewalttat als eines Ereignisses, das seine Bedeutung nicht vorrangig aus den äußeren Umständen gewinnt, sondern daraus, was es für Menschen emotional bedeutet: Das Sichtbare tritt hinter das Fühlbare zurück. Indem also die Gewalttat als Ausdruck äußerster seelischer Spannungszustände und die Folgen einer Gewalttat im Kern als verstörend und zerstörerisch gesehen werden, liegt es nahe, dass Menschen diese Folgen in der größtmöglichen Unmittelbarkeit schildern. Soweit vor allem bei tödlichen Gewaltverbrechen, gravierenden Sexualdelikten und Verbrechen an Minderjährigen die Opfer selbst unerreichbar sind, fällt es bevorzugt den nächsten Angehörigen zu, die für Außenstehende unvorstellbaren Tatfolgen vorstellbar zu machen.

Die Funktion solcher Interviews mit Betroffenen liegt darin, anteilnehmende Beobachtung zu ermöglichen, also Empathie zu wecken. Aus dem Kontext ergibt sich auch ihre mögliche Funktion, Furcht zu erregen - denn erst durch die Personalisierung erschließt sich, die Dimension einer Gewalttat zu erfassen, deren Folgen weit über die unmittelbar Betroffenen reicht und die auch ihr Umfeld erschüttert, zuweilen ein Leben lang. Die Befragten betonen, dass diese Vermittlung dieser Gefühle nur in sorgfältig bemessener Dosierung gelingt.

Magazinredakteur, Privatsender: „Bei uns intern heißt das ,noble Erzählhaltung': Da sind alle journalistischen Kriterien natürlich zu erfüllen, aber es geht vor allem darum, mit den Menschen so zu arbeiten, dass sie danach mit einem telefonieren, dass man jederzeit wieder mit ihnen sprechen kann. (...) Das klassische Boulevard-Witwenschütteln ist bei uns als Redaktionsarbeit nicht erlaubt. Das heißt, keine Türen stürmen, nirgends reinrennen, die Leute überfallen, verbrannte Erde hinterlassen.“

Insofern beschreiben die Interviewten einen Wandel in der Emotionalisierung, wie er zuvor bereits beschrieben wurde. Sie verwerfen eine Steigerungslogik, wonach sich Menschen vor der Kamera emotional immer stärker entblößen, mit Blick auf die Wirkung auf das Publikum als kontraproduktiv. Stattdessen sehen die Befragten den Trend zu einem behutsameren Umgang mit Protagonistinnen und Protagonisten. Mit einer personalisierten Betrachtung von Gewaltkriminalität ist untrennbar verbunden, dass es nicht nur Leidende gibt, sondern auch Menschen, die anderen Leid zugefügt haben. Sie allerdings bleiben in der Regel blasse Nebenfiguren - ihre Kontur gewinnen sie in der Regel aus dem Kontrast zu den Hauptfiguren heraus.

Magazinredakteur, Privatsender: „Die Geschichte muss rund sein. Wir brauchen einen Hauptdarsteller, wir brauchen einen Nebendarsteller: Wir brauchen einen Helden, wir brauchen einen Täter. Und wir brauchen O-Töne, die uns in dieser Geschichte über Herausforderungen, Hürden, Cliffhanger bis hin zur Wiedererweckung führen können.“

Damit ist das Handeln der Programmmacher vorrangig auf die Opfer und ihr Umfeld gerichtet und zielt auf die Personalisierung deren Leids bzw. dessen Überwindung. Denn einen Menschen zu sehen, der seine Gefühle offenbart, bringt ihn dem 
Publikum näher, zeigen sich die befragten Journalistinnen und Journalisten überzeugt - was für die Verbrechensopfer und die ihnen nahe stehenden Menschen als erwünscht gilt, entfaltet allerdings auch Wirkung, wenn Tatverdächtige Gestalt gewinnen. Eine Identifikation mit dem Täter soll aber nicht angeboten werden. Eine Berichterstattung, die auf Empathie beispielsweise mit einem Täter setzt, der zuvor selber Gewaltopfer war, könnte das Publikum irritieren.

Magazinredakteur, Privatsender: „Das würden wir nicht machen: ,Er wurde von seinen Eltern missbraucht.' Niemals! Das kracht ja nicht mehr. Wir würden ja dann Mitleid für den Täter erwägen."

Ambivalenzen beeinträchtigen den Befragten zufolge die Wirkung der Berichterstattung und werden zugunsten einer primären Personalisierung der Opferseite gemieden.

Unterschiede nach Sendern und Formaten

Alle Befragten betonen, dass sie Personalisierung für einen wesentlichen Faktor halten, allerdings gewichten sie diesen Faktor je nach Sendungsformat unterschiedlich. Für die Boulevardmagazine beschreiben sie eine stärkere Bedeutung von Personalisierung: Dies machen insbesondere die Gespräche mit den Befragten deutlich, die sowohl für Nachrichten wie für Boulevardmagazine arbeiten.

Redakteurin, öffentlich-rechtlicher Sender: „Beim Boulevardmagazin (...) versucht man, ein bisschen mehr zu personalisieren."

Unstrittig ist die Personalisierung des Leids als Mittel, unterschiedlich wird ihr Stellenwert betrachtet.

\subsubsection{Idealisierung des Opfers}

Fernsehjournalistinnen und Fernsehjournalisten polarisieren in der Berichterstattung über Gewaltkriminalität, insbesondere indem sie Opfer idealisieren. Sie wählen ihrem Bekunden nach Personen, Ereignisse bzw. Tatkonstellationen nach höchster Polarität aus und arbeiten diese Polarität in der Berichterstattung so weit wie möglich heraus. Damit sind Muster der Auswahl wie auch der Thematisierung beschrieben.

Magazinredakteurin, öffentlich-rechtlicher Sender: „Polarität macht es einfach. Nuancen sind immer schwieriger abzubilden. Pepita ist auch immer schwieriger als Schwarz und Weiß. Da kann man klar die Dinge verfolgen, Gut und Böse.“ 
Trotz dieser beschriebenen Bipolarität zwischen Gut und Böse setzt die Strategie der Polarisierung nicht gleichermaßen an beiden Polen an - ihr Angelpunkt ist vor allem das Verbrechensopfer. So bekennen sich die Befragten zu formaler Symmetrie wie zu inhaltlicher Asymmetrie, nachrichtlich vs. emotional: Opfer und Tatverdächtige sollen beide Gestalt gewinnen, indem sie gezeigt werden und möglichst zu Wort kommen, aber auf ganz verschiedene Weise. Tatverdächtige sollen eher nüchtern in ihrem mutmaßlichen Handeln beschrieben werden, Opfer sehr viel emotionaler in ihrem Erleben von Tat und Tatfolgen. Die formal zurückhaltende Berichterstattung über Tat und Täter/in wird emotional aufgeladen durch die Empfindungen der Opferseite.

Magazinredakteur, Privatsender: „Es geht immer darum, eine Balance zu halten zwischen nachrichtlicher Berichterstattung, die in der Regel die Täterseite abdeckt, und dem emotionalen Teil, der für ein Boulevard-Magazin sehr wichtig ist, und das muss zwingend für uns die Opferseite sein.“

Nachrichtenredakteurin, öffentlich-rechtlicher Sender: ,Wir halten ein Stück immer dann für gelungen, wenn wir das Gefühl haben, die Opferperspektive ist angemessen wiedergegeben worden. Und die Tätersituation ist objektiv beschrieben, ohne Geifer.“

Die Befragten sind von der Annahme geleitet, dass ihr Publikum tendenziell mit den Opfern sympathisiert, dass aber das Mitgefühl den Betroffenen von Gewalt nicht bedingungslos gilt. Daraus folgt die Auswahlstrategie, bereits bei den Recherchen im Vorfeld der Berichterstattung, also beispielsweise bei ersten Telefongesprächen mit Betroffenen, jene herauszufiltern, die auf sie sympathisch wirken und über Fälle eher nicht zu berichten, wenn die Opfer nicht als ideal beurteilt werden. Daneben erläutern die Interviewten auch Strategien der Inszenierung, die sich vor allem auf Gesprächsführung und Visualisierung beziehen. Dabei geht es darum, Gewaltopfer so zu beeinflussen, dass sie vorteilhaft wirken, und die Bildführung so zu gestalten, dass sie in besserem Licht dastehen. Als zentrale Bedingung für die Empathie des Publikums wird die Unschuld des Verbrechensopfers gesehen. Dies führt im Vorfeld der Recherche bereits dazu, dass Fälle gemieden werden, in denen die Täter/inOpfer-Konstellation nicht eindeutig genug erscheint. So werden Gewalttaten im Rotlichtmilieu in aller Regel nicht aufgegriffen, da bestenfalls eine ambivalente Haltung des Publikums zu den Gewaltopfern angenommen und eine Empathiebildung ausgeschlossen wird.

Magazinredakteur, Privatsender: „Was wir gar nicht machen, sind Milieu-Geschichten. (...) Was dann oft gesagt wird, wer hat schon Mitleid mit einer, die jeden Tag mit zwanzig Männern schläft.“

Über die Meidung bestimmter Szenerien und Delikte hinaus führt diese Strategie auch dazu, dass Recherchen abgebrochen werden, wenn sich eine Idealisierung des Opfers und damit die Konstruktion von Eindeutigkeit nicht erreichen lassen. Dafür sind wiederum der Augenschein und letztlich die Wirkung zentral - es reicht nicht, dass potenzielle Protagonisten gesicherten Quellen zufolge unschuldig am Gewaltgeschehen sind, sie müssen auch unschuldig wirken. 
Agenturjournalist: „Da kann der Fall noch so schlimm sein, selbst von der Polizei bestätigt, aber wenn sie rüber kommt, wo ich einfach so ein Geschmäckle habe, wo man fragt, ,na, hat sie die Tochter dem Vater nicht noch zugeführt?' Dann kann es schon eher sein, dass man es nicht macht."

Einer größtmöglichen Emotionalisierung zuliebe gilt es, das gleichsam ideale Opfer zu finden. Dessen wichtigste Eigenschaften, sympathisch und eindeutig unschuldig zu sein, erfüllen den Befragten zufolge vor allem Kinder. Die daraus abgeleitete Strategie, gehäuft über die Gewalt an Kindern zu berichten, wird vielfach nicht bewusst, gleichwohl sehr konsequent verfolgt. Das Kriterium der Kindlichkeit ist weiter zu differenzieren: Das ideale Opfer ist ein kleines Kind, und implizit wird es als Mädchen beschrieben. Aus diesem Ziel größtmöglicher Polarität ergeben sich geradezu mechanische Auswahlverfahren.

Nachrichtenredakteurin, öffentlich-rechtlicher Sender: „Welches Kind ist es wert, in die Hauptnachrichten zu kommen und welches nicht? Da versuchen wir, uns immer wieder Kriterien zu zimmern und die allgemein gültig zu machen. Aber die sind schwierig. Eine 16-Jährige kommt nicht hinein, bei einer 12-Jährigen diskutieren wir, und eine 9-Jährige ist ganz sicher drin.“

Eine Idealisierung des Opfers erreichen die Programmverantwortlichen ihrem Bekunden nach vor allem durch eine gezielte Auswahl von Delikten und Akteuren. Eine Strategie der polarisierten Darstellung durch Unterschlagung oder gar Verdrehung von Fakten halten die Befragten für unprofessionell - dennoch schließen sie sie nicht gänzlich aus.

Nachrichtenredakteur, Privatsender: „Kein Journalist wird auf Details verzichten, nur um die Geschichte in eine Richtung sozusagen stärker zu machen. (...) Bewusst macht er das nicht, unbewusst macht er es schon.“

Für ein planvolles Ausblenden von Tatsachen findet sich kein Anhaltspunkt in den Aussagen der Interviewten über ihre eigene Arbeit. In einem einzigen Interview zeigt sich, dass konkrete Anhaltspunkte vernachlässigt werden, um die gewünschte Eindeutigkeit der Tatkonstellation zu konstruieren. Ein Redakteur berichtet von seinem Beitrag über einen jungen Mann, der einem anderen zur Hilfe kommt und dabei selber von angeblich Fremden niedergeschlagen wird. Recherchen allerdings erbringen den Hinweis, dass das Opfer die Tatverdächtigen möglicherweise bereits kannte und sich die Vorgeschichte damit anders darstellt. Dies wird nicht berücksichtigt: Der Beitrag präsentiert das Opfer widerspruchsfrei in der Rolle des barmherzigen Samariters.

Magazinredakteur, öffentlich-rechtlicher Sender: „Das wollte ich überhaupt nicht so machen, sondern das wurde mir dann reingedrückt von der Schlussredakteurin. Aber da muss man sich halt auf einen Aussagewunsch einigen." 
Der Begriff des „Aussagewunsches“ illustriert, wie eine Polarisierung angestrebt und damit die Darstellung dieses Fall in Bild und Text angepasst wird. Die Strategie der Polarisierung bezieht sich auf das Opfer. Damit sind Eigenschaften des Opfers das wesentliche Auswahlmerkmal, kaum spezifische Eigenschaften des Täters oder der Täterin. In der aktuellen Berichterstattung, in der das Handeln der Beschuldigten nicht nachgewiesen ist und damit die Unschuldsvermutung gilt bzw. gelten soll, kann sich eine Polarisierung nur begrenzt auf die Beschuldigten beziehen: Berichten lässt sich nur ein Verdacht. Gleichwohl beschreiben Befragte Strategien, implizit Schuld zuzuweisen.

Magazinredakteur, Privatsender: „Dann ist es so ein Feigenblättchen, wir haben es immerhin gesagt, angeblich soll er das und mutmaßlich dies. Da kann man natürlich auch immer mit der Betonung ein bisschen spielen. Das heißt, es steht da zwar und man liest es vor, aber es wird halt nicht so präsent betont, und der ganze anklagende Teil ist in einem anderen Duktus vertont, so dass klar wird, da Böse, da Gut.“

Tatverdächtige in den Mittelpunkt zu rücken, gilt als riskant, da dies eine Idealisierung des Opfers gefährdet. Die Befragten äußern die Befürchtung, sie könnten die Schuld des Täters schmälern, indem sie seine Beweggründe und sein Vorleben beleuchten: Erklärung wird mit Entschuldigung gleichgesetzt. Damit scheitert das Angebot von Erklärungen nicht in erster Linie daran, dass sie nicht verfügbar sind, sondern dass sie gar nicht erst gesucht werden.

Dokumentarfilmerin, öffentlich-rechtlicher Sender: „Das ist eine große Problematik insgesamt von Berichterstattung über Kriminalfälle, dass wir sehr dazu neigen, uns mit dem Täter zu beschäftigen, mit der Suche nach den Motiven, und damit zwangsläufig mit der Lebensgeschichte des Täters auch eine Reihe möglicher Entschuldigungsgründe finden. Ich sage mal zugespitzt, schlimme Kindheit, gleich nicht verantwortlich: Der Arme konnte ja nicht anders.“

So distanziert sich ein Magazinredakteur von einem Beitrag, in dem ein Psychologe eingangs den Ausbruch eines Untersuchungshäftlings mit dessen Stressempfinden erklärt. Ein solcher Versuch, das Handeln des Beschuldigten zu deuten, gilt als „Täterberichterstattung“.

Magazinredakteur, Privatsender: ,Allein durch den ersten O-Ton, der sich mit dem Täter beschäftigt, und zwar mit einem verständnisvollen O-Ton, stellen wir Empathie mit dem Täter her. Und das wollen wir in dem Fall grundsätzlich nicht machen.“

Gleichfalls erteilen die Befragten eine klare Absage an stark wertende Begriffe, wie sie gelegentlich in Boulevardzeitungen verwendet werden, und wie sie einige Journalisten selber verwenden, wenn sie über Beschuldigte sprechen.

Magazinredakteur, Privatsender: „Das Fernsehen bemüht sich im Augenblick sehr, erwachsen zu werden, auch das Privatfernsehen. Und da gibt es schon das Bemühen um große politische Korrektheit. (...) Wir erstatten Bericht, aber wir sagen nicht, die Bestie', ,die Sex-Bestie' und so weiter, ,das Monster', ,der Drecksack'.“ 
Um die Grenzen der Polarisierung auszuloten, wurde in den Interviews die Äußerung eines Mannes aus einem Fernsehbeitrag (hallo deutschland, ZDF 21.7.06) zur Diskussion gestellt. Der Vater eines getöteten Mädchens sagt: „Das tut natürlich sehr weh, dass so ein Mensch wie sie einfach ausgelöscht wird, und im Endeffekt dieser Mörder, dieser Schlächter in Person weiterleben [darf].“ Einig sind sich die Befragten darin, dass ein polarisierender Begriff wie „Schlächter“ die Grenze des Erlaubten markiert.

Reporterin für Nachrichten und Magazine, öffentlich-rechtlicher Sender: „Das sind diese O-Töne, die man gerne für seine Stücke hat, aber bei denen man wissen muss, welchen Wirbelwind sie entfachen. (...) Das ist wirklich der Punkt, wo man dann versucht zu sagen, denkt dran, der Mann steht unter extremer Anspannung, macht euch das nicht zu eigen.“

Eine solche Emotionalität und Schärfe an Formulierungen wird allenfalls den Opferangehörigen zugebilligt. Den Interviewten zufolge darf aber kein Bericht über Gewaltverbrechen, der den Zorn der Angehörigen thematisiert, als Aufruf zur Selbstjustiz verstanden werden.

\section{Unterschiede nach Sendern und Formaten}

Keiner der Befragten hält die zitierte Brandmarkung eines mutmaßlichen Täters als „Schlächter" für einen Nachrichtenbeitrag für tauglich. Für boulevardeske Magazine halten die Interviewten dagegen eine stärkere Polarisierung für angemessen. Ihr Publikum, so vermuten sie, hat ein eher flüchtiges Interesse an den jeweiligen Beitragsthemen. Daraus folgern die Befragten, dass bei Boulevardmagazinen eine deutlichere Zuspitzung erforderlich ist, damit das Publikum mitfühlt oder sich ängstigt.

Magazinredakteur, öffentlich-rechtlicher Sender: „Der Zuschauer ist nicht so aufmerksam wie abends, wo er sehr bewusst Sehentscheidungen trifft, bestimmte Magazine guckt. (...) Oft ist Fernsehen eine Nebentätigkeit. Das heißt, im Boulevardmagazin ist es sehr wichtig, sehr klar Dinge darstellen zu können. (...) Heiß und kalt, gut und böse.“

Vermutet wird, dass mit einem insgesamt unaufmerksamer werdenden Sehverhalten dieses Bedürfnis nach einer emotionalen Lenkung durch Polarisierung wächst. Unschärfen in der Rollenzuweisung sind damit kaum noch vermittelbar.

\subsubsection{Schaffung innerer Bilder}

Im folgenden Kapitel wird der Frage nachgegangen, wie die Verfügbarkeit von Bildmaterial journalistische Auswahlentscheidungen beeinflusst und welche Strategien der Visualisierung die Befragten verfolgen. Die Befragten nennen als ein wichtiges Auswahlkriterium, dass sich ein Thema visualisieren lässt. Danach werden auch Ereignisse, die als weniger publikumsattraktiv gelten, aufgrund wirkungs- 
starker und möglichst bewegter Bilder ausgewählt. Ebenso wird der Effekt beschrieben, dass Ereignisse, die grundsätzlich als berichtenswert gelten, aufgrund von Bilderarmut nicht aufgegriffen werden.

Magazinredakteur, Privatsender: „Wobei wir voyeuristisch sind, weil wir vom Fernsehen sind. Wir müssen ja den Voyeurismus der Zuschauer bedienen.“

Als stärkstes Mittel, Gefühle beim Publikum zu wecken, nennen die Befragten die Visualisierung des Schreckens der Opfer selbst und der Erschütterung derer, die zurückbleiben. Sie dient dazu, die Dimension der Gewalt an den Emotionen der Opferseite zu verdeutlichen.

Redakteur Nachrichten und Magazine, öffentlich-rechtlicher Sender: „Wenn einer mit den Tränen ringt, dann kann man an so einem O-Ton fast nicht dran vorbei. Muss man ja auch nicht. Wenn das die Stimmung trifft und wenn es das echter oder authentischer macht, dann nimmt man den natürlich.“

Um die Emotionen auf die Opfer zu lenken, sollen sie zu sehen sein. Dies bedeutet bei tödlichen Delikten, dass der Einbruch von Gewalt in den Alltag vor allem durch das noch intakte Leben vor der Tat gezeigt wird. So sprechen Reporter davon, wie wichtig die „Lebendfotobeschaffung“ ist. Zur Visualisierung des Opfers gehört die umfassende Darstellung als Person durch möglichst starke Symbole - indem etwa das Spielzeug des ermordeten Kindes ins Bild rückt, um die Kindlichkeit und Unschuld des Opfers gegenüber der Gewalttätigkeit und Gnadenlosigkeit des Gewaltverbrechens zu konturieren. Die Befragten offenbaren überdies Strategien, Opfer und ihre Angehörigen mit visuellen Mitteln zu idealisieren.

Magazinredakteurin, Privatsender: „Ich versuche dem Protagonisten, sollte er ganz dumme Antworten geben und gar nicht gut wirken, zu erklären, wie man redet, dass er ein bisschen gestikulieren soll, mit den Händen ein bisschen spielen soll, dass er langsam redet, dass er meine Fragen einfach noch mal aufgreift. Und wenn der Ton zu laut ist, dann sage ich einfach, , das Mikro ist nicht gut, reden Sie ein bisschen leiser'. Also, es gibt da schon Möglichkeiten, dass man, ohne dass er es merkt, ihn so ein bisschen in seiner Art zügelt.“

Diese Inszenierungsstrategien schließen ein, das gesamte Umfeld der Dreharbeiten zu arrangieren, damit sich im buchstäblichen Sinne das gewünschte Bild ergibt, sei es durch eine Inszenierung wie das Blättern in Fotoalben, durch eine emotionale Aufladung eines Gesprächs, indem man es am Tatort führt, durch Arrangements am Drehort wie das Aufstellen von Bildern und das Entfernen von störenden Gegenständen, oder durch eine emotionsgerechte Kleiderordnung.

Magazinredakteurin, Privatsender: „Wenn jemand allein durch sein Auftreten und seine Antworten pampig oder nicht gut rüberkommt, dann gibt es die Möglichkeit, ihn gesichtstechnisch aufzumotzen. Also, ein Hartz-IV-Empfänger, der sich in seinem T-Shirt, das er seit drei Tagen an hat, mit Flecken bekleckert, hin setzt und sagt, er fühlt sich so gut, da versuche ich ihm klar zu machen, dass wir uns jetzt ein neues T-Shirt anziehen und dass wir uns ein bisschen die Haare hinterkämmen.“ 
Tatverdächtige als Gegenpol und damit als Inbegriff des Bösen zu visualisieren, scheint nicht in gleicher Weise möglich wie die visuelle Idealisierung des Opfers. Die Interviewten offenbaren allerdings Techniken, durch Eingriffe in die Optik beide Seiten unterschiedlich aussehen zu lassen.

Freier Reporter, öffentlich-rechtliche und private Sender: „Wenn ich einen richtig bösen Menschen habe, wenn ich einen Vergewaltiger habe, dann setze ich den nicht noch schön in warmes Licht, dass er toll und sympathisch herüberkommt, sondern dann versuche ich eine Atmosphäre zu schaffen, dass ich ganz klar durch das Bild abgrenzen kann: das ist der Gute, das ist der Schlechte. Also das Opfer zum Beispiel setze ich in eine positive Umgebung, vielleicht noch irgendwo eine Kerze, wenn es passt, oder mit ein bisschen Tiefenschärfe, hinten angestrahlt.“

Den Befragten zufolge ist es kaum möglich, durch eine Visualisierung von Tatverdächtigen Abscheu zu erzielen, im Gegenteil: Ihnen zufolge kann das Unmenschliche einer Gewalttat mit der Abbildung eines menschlichen Gesichts geradezu konterkariert werden. Zudem stößt eine polarisierende Bildsprache an Grenzen, weil aus Gründen des Persönlichkeitsschutzes vielfach Opfer wie Tatverdächtige gleichermaßen verfremdet werden müssen.

Magazinredakteur, öffentlich-rechtlicher Sender: „Deswegen haben wir die größeren Schwierigkeiten, dass unsere Opfer manchmal formal so wie die Täter aussehen. Das macht uns mehr Bauchschmerzen. Und das ist nicht unser Ziel.“

Einhellig beschreiben die Befragten als wesentliche Funktion der bewegten Bilder, das Ereignis dicht zu rahmen und damit größtmögliche Nähe zu vermitteln. In der Regel konzentriert sich diese Visualisierung auf das Geschehen unmittelbar nach der Tat, beispielsweise die Ermittlungen der Polizei, den Abtransport der Opfer und die Reaktionen des Umfelds. In der Regel zeigen sie nicht Gewalt, sondern symbolisieren Gewalt.

Agenturjournalist: „Wenn ich so eine Story habe, brauche ich Klassiker, und diese schnell. Angenommen, es handelt sich um ein Gewaltverbrechen, brauche ich sehr schnell ein Bild vom Tatort. Wenn es eine Geschichte ist, die emotional aufrührt, brauche ich Menschen, die Blumenkränze, Kerzen, was auch immer, an einem Wohnort, Tatort, wo auch immer, niederlegen. (...) Es ist immer wieder die gleich bleibende Routine, da müssen wir das Rad nicht neu erfinden."

Als besonders wirkungsstark gelten Bilder, in denen - in der Regel mit Aufnahmen von Überwachungskameras - die Anbahnung der Tat unmittelbar gezeigt wird und die Gewalt im Hintergrund bleibt. So wird beispielsweise die Aufnahme, die einen Mann und einen neunjährigen Jungen in einer Straßenbahn offenbar in ein freundliches Gespräch vertieft zeigt, emotional aufgeladen durch das Wissen, dass der Mann diesen Jungen nur Stunden später missbrauchen und töten wird. 
Nachrichtenredakteur, Privatsender: „Dieses Kind, das dort neben dem Mörder in der Straßenbahn sitzt, ist exakt das Bild, exakt die Situation, vor der man als Eltern seine Kinder immer wieder warnt. Es ist also nicht der viel zitierte Alptraum aller Eltern, sondern es ist wirklich ein ganz konkretes Szenario.“

Täter und Opfer, die fröhlich nebeneinander sitzen, werden zu Ikonen der Angst. Ein kleiner Junge, der gleichsam vor den Augen des Publikums in sein Verderben geht, zieht alle Anteilnahme auf sich: So sollen die Bilder starke Gefühle wecken, während sie den Gewaltakt auslassen. Dahinter steht das Konzept vom Kino im Kopf. Es bezieht seine besondere Wirkungskraft daraus, dass Gefühle nur angedeutet werden und der Ausformung durch das Publikum selbst bedürfen. Das Unvollständige, so die Annahme, verstärkt die aktive Rolle der Zuschauenden, bindet ihre Aufmerksamkeit und Emotionen. Eine emotionale Aktivierung der Zuschauenden ist der Schlüssel zu ihrer Bindung an das Programm. Letztlich geht es nicht um die äußeren Bilder, die ein Beitrag enthält, sondern um die inneren Bilder, die er beim Publikum hervorruft.

Magazinredakteur, öffentlich-rechtlicher Sender: „Es gibt keine Toten in Großaufnahme bei uns. Klar, es gibt eine Bahre, die durch das Bild getragen wird, worauf ein Toter liegt, mit einer Decke darüber. Und da hängt meinetwegen noch der Arm heraus. Bueno! Da weiß man, da liegt ein Toter. Das Kopfkino spielt da alle Bilder ein, die man braucht.“

Magazinredakteurin, Privatsender: „Wenn man Dinge nicht zeigt und nur andeutet, erhöht sich die Spannung.“

Insofern sind die gezeigten Bilder das Mittel von Visualisierung auf einer ersten Ebene, als entscheidende Ebene gilt die Formung von Bildern in der Vorstellungskraft des Publikums.

\subsubsection{Zusammenfassung}

Die Fernsehberichterstattung über Gewaltkriminalität ist einem starken Wandel unterworfen. Als wichtige Zäsur nennen die Befragten die Einführung des Privatfernsehens in Deutschland. Je nach Sender und Format zeigen sich deutliche Unterschiede. Die in öffentlich-rechtlichen Nachrichtenredaktionen Interviewten halten Gewaltkriminalität nur bei besonderer Folgenschwere für berichtenswert, während die in den Nachrichtenredaktionen der Privatsender Interviewten auch Einzelfälle als wichtigen Bestandteil beschreiben, als so etwas wie Chili in der Mischung des Tages. Die Befragten, die für Boulevardmagazine arbeiten, setzen in den öffentlichrechtlichen Sendern auf gewachsene Gewaltanteile, während die Beschäftigten in den Privatsendern eine deutlich gesenkte Dosierung für publikumsaffin halten. 
Die Befragten heben die hohe Bedeutung von Emotionen quer durch alle Fernsehformate hervor. Emotionalisierung in der Fernsehberichterstattung ist mit dem Auftreten privater Sender bedeutsamer geworden. Für die Nachrichten des Privatfernsehens sehen die Interviewten einen höheren Stellenwert von Emotionen als für öffentlich-rechtliche Nachrichten. Die Verbrechensfurcht des Publikums zu erregen, nennen die Befragten als bedeutsam für die Emotionalisierung des Publikums durch die Kriminalitätsberichterstattung. Als Mittel dienen vor allem die Fokussierung auf gravierende Gewalt und die Vermittlung scheinbar grenzenloser Reichweite. Dazu werden die emotionalen Gewaltfolgen für die Opfer und ihre Angehörigen visualisiert.

Als Leitmotiv der Erregung von Furcht gilt deren anschließende Auflösung, um die Aufnahme von Angstimpulsen weiter zu sichern. Um das Mitgefühl des Publikums zu stimulieren und zu steigern, gilt es aus journalistischer Sicht, den Leidenden ein Gesicht zu geben und idealtypische Opfer auszuwählen bzw. die Leitfiguren zu idealisieren. Um diese Wirkung zu verstärken, werden Delikte von großer Folgenschwere aufgegriffen. Damit zeigen sich analog zu den Annahmen von Wirkungen der Berichterstattung auf das Publikum fünf Muster journalistischer Auswahl und Thematisierung:

1. Um die Folgenschwere der Gewalt zu vermitteln, werden meist tödliche und sexuell motivierte Delikte fokussiert. Die Interviewten legen es darauf an, eine gesellschaftliche Folgenschwere von Gewalttaten möglichst über den Einzelfall hinaus darzustellen.

2. Die statistische Reichweite, also die Wahrscheinlichkeit, dass Menschen von einem Ereignis unmittelbar betroffen sind, ist für die Befragten - außer für die für öffentlich-rechtliche Nachrichten Tätigen - kein Maß für Häufigkeit und Umfang der Kriminalitätsberichterstattung. Für die übrigen Befragten ist die subjektive Reichweite von zentraler Bedeutung. Die Befragten wählen Delikte und Akteure „zielgruppig“ danach aus, dass sich aufgrund ähnlicher Lebensumstände, der Entsprechung des Alters und der Nationalität eine emotionale Verknüpfung mit dem Alltag der Zuschauenden und damit eine Entgrenzung des Schreckens erreichen lässt.

3. Journalisten und Journalistinnen beschreiben ihren Anspruch, die unmittelbar Betroffenen von Gewalt zu Wort kommen zu lassen, um den Schrecken der Gewalt emotional vermitteln. Tatverdächtige werden als Randfiguren charakterisiert - sie sollen nur insofern Gestalt gewinnen, als sie damit nicht zu Identifikationsfiguren werden. Personalisierung gilt für Boulevardmagazine als wichtiger als für Nachrichten.

4. Die Konstruktion von Eindeutigkeit ist aus Sicht der Befragten zentral - sie wird durch Polarisierung und vor allem durch eine Idealisierung des Opfers als sympathisch und unschuldig erreicht. Dafür werden entsprechende Delikte und als Opfer 
vorrangig Kinder jüngeren Alters und bevorzugt Mädchen ausgewählt. Eindeutigkeit wird inszeniert vor allem durch bestimmte Techniken der Gesprächsführung und der Visualisierung. Die Polarisierung der Tatverdächtigen spielt eine geringere Rolle. Um sie zu erreichen, werden Erklärungen für die Gewalttat gemieden, die als Entschuldigung verstanden werden könnten. Als tabu gelten stark wertende Begriffe.

5. Die Befragten nennen als ein wichtiges Auswahlkriterium, dass sich ein Thema in bewegten Bildern realisieren lässt. Im Mittelpunkt stehen die Opfer und ihre Angehörigen. Sie werden idealisiert, indem auf ihr Gesprächsverhalten eingewirkt und die Szenerie zielgerecht arrangiert wird. Die Visualisierung der Tatverdächtigen soll sich von jener der Opfer abzusetzen, allerdings sehen die Bilder beider Seiten oft ähnlich aus, da sie zur Anonymisierung gleichermaßen verfremdet werden. Die Tat soll visuell eng gerahmt werden, um subjektiv eine Nähe zum Geschehen zu erzeugen. Dabei bleiben Details der Gewalt ausgeblendet, um die Spannung gerade zu erhöhen. So wird das Kino im Kopf realisiert. 
Nachdem es im vorigen Kapitel darum ging, aus der Befragung von 33 Fernsehjournalistinnen und Fernsehjournalisten deren Beschreibungen wirkungsgerichteter Berichterstattung über Gewaltkriminalität zu untersuchen, folgt daraus nun die Frage: Inwieweit bilden sich diese Muster in den untersuchten Formaten tatsächlich ab? Dazu werden in diesem Kapitel die Transkripte von 264 Fernsehbeiträgen aus Nachrichten und Boulevardmagazinen über Gewaltkriminalität im Inland ausgewertet und mit den Interviewäußerungen abgeglichen. Um journalistische Auswahlmuster zu beleuchten, werden ausgewählte Merkmale der Berichterstattung mit Kriminalstatistiken verglichen. Die polizeilichen Erkenntnisse repräsentieren zwar keine objektive Wirklichkeit, die der Medienwirklichkeit gegenübergestellt werden könnte, aber sie stehen für den Fundus an theoretisch verfügbaren Ereignissen: Das Fernsehen berichtet kaum über Gewalttaten, die nicht polizeilich bekannt wären, und die Polizei ist wichtige Informationsquelle und liefert mit einem Anteil von 36,7 Prozent aller Beiträge am häufigsten Originaltöne (zur Konstruktion von Kriminalität in der Berichterstattung und in Statistiken siehe auch Kap. 1.2).

\subsubsection{Die Gewichtung der Berichterstattung über Gewaltkriminalität}

Beschrieben werden zunächst die Längenanteile der Berichterstattung über Gewaltkriminalität an den Hauptnachrichten von acht Sendern sowie an sechs ausgewählten Boulevardmagazinen öffentlich-rechtlicher und privater Sender: Dies sind die Nachrichtensendungen Tagesschau (ARD), heute (ZDF), RTL aktuell, Sat.1 News, Newstime (ProSieben), Vox Nachrichten, RTL2 News und K1 Nachrichten (kabel eins) sowie die Boulevardmagazine Brisant (ARD), hallo deutschland (ZDF), Sat.1 am Abend, Explosiv (RTL), taff (ProSieben) und SAM (ProSieben).

\subsubsection{Nachrichten}

In der Bewertung von Gewaltkriminalität nehmen die Befragten aus öffentlichrechtlichen Nachrichtenredaktionen eine Sonderrolle ein - sie gewichten die Emotionalisierung des Publikums durch gravierende Gewalt geringer als die übrigen Interviewten und stellen der emotionalen Wucht des Einzelfalls stärker als alle anderen Befragten rationale Bewertungsmuster gegenüber. Daraus folgern sie, die Schwelle der Berichterstattung besonders hoch zu setzen und nur über herausragende Einzelfälle oder bei besonderer gesellschaftlicher Tragweite zu berichten (s.o.).

Diese unterschiedlichen Handlungsmuster lassen sich mit der Programmanalyse beim Vergleich der Zeitanteile bestätigen: Die Nachrichten der Privatsender widmen sich der Gewaltkriminalität rund fünfmal so umfangreich wie die öffentlich- 
rechtlichen Nachrichten. Dies gilt sowohl für die Betrachtung der Inlandsberichterstattung, die im Fokus der Untersuchung steht, wie auch für die gesamte Berichterstattung. Dabei sind auch innerhalb der Sendergruppen deutliche Unterschiede festzustellen - einen starken Akzent in der Kriminalitätsberichterstattung setzen im Untersuchungszeitraum die Vox News, während die RTL2-News sehr viel umfangreicher auf Nachrichten aus der Unterhaltungsbranche als auf Gewaltkriminalität fokussieren.

Tabelle 14: Zeitanteil der Berichterstattung über Gewaltkriminalität an Nachrichten

\begin{tabular}{|l|r|r|}
\hline Sendung & gesamt in \% & Inland in \% \\
\hline Tagesschau, ARD & 1,7 & 0,9 \\
\hline heute, ZDF & 2,5 & 1,6 \\
\hline Nachrichten öffentlich-rechtliche Sender & 2,1 & 1,3 \\
\hline RTL aktuell & 9,1 & 5,1 \\
\hline Sat.1 News & 9,7 & 5,3 \\
\hline Newstime, ProSieben & 8,1 & 4,4 \\
\hline Vox Nachrichten & 20,9 & 14,8 \\
\hline RTL2 News & 7,3 & 2,7 \\
\hline K1 Nachrichten, kabel eins & 13,0 & 5,8 \\
\hline Nachrichten private Sender & 11,4 & 6,4 \\
\hline
\end{tabular}

$\mathrm{N}=310$ Ausstrahlungen der Hauptabendnachrichten aus vier Kalenderwochen im März, April, Mai und Juni 2007, bei der Tagesschau über die kompletten Monate in einer Gesamtlänge von 70 Stunden, 32 Minuten und 46 Sekunden (ohne Wetter). Anteilig berechnet wurden die Beitragslängen einschließlich Moderation.

\subsubsection{Boulevardmagazine}

Die befragten Journalistinnen und Journalisten beschreiben als wesentliches Auswahlkriterium für Gewaltkriminalität als Thema von Boulevardmagazinen, dass sich eine starke emotionale Wirkung erzielen lässt. Die bekundeten Wirkungsannahmen von Journalistinnen und Journalisten zur Dosierung von Gewalt in boulevardesken Fernsehmagazinen bilden sich in der Programmanalyse mit einer insgesamt umfangreicheren Berichterstattung als in den Nachrichten ab. Während sich allerdings die Befragten in Privatsendern dagegen wenden, ,jeden Tag mit so einem Schocker um die Ecke zu kommen“, sprechen die Interviewten für öffentlich-rechtliche Magazine von einer hohen Attraktivität des „Gruseleffekts“ (vgl. Kap. 5.4.1). Tatsächlich berichten die untersuchten öffentlich-rechtlichen Boulevardmagazine über Gewaltkriminalität mehr als doppelt so viel wie ihre kommerzielle Konkurrenz. 
Analog zur Programmanalyse der Fernsehnachrichten zeigen sich jeweils auch für die einzelnen Boulevardmagazine jeweils sehr unterschiedliche Werte - so thematisiert Sat.1 am Abend im Untersuchungszeitraum Gewaltkriminalität im Inland sechsmal so stark wie taff (ProSieben).

Tabelle 15: Zeitanteil der Berichterstattung über Gewaltkriminalität an Boulevardmagazinen

\begin{tabular}{|l|r|r|}
\hline Sendung & gesamt in \% & Inland in \% \\
\hline Brisant, ARD & 19,7 & 14,9 \\
\hline hallo deutschland, ZDF & 18,8 & 15,9 \\
\hline Boulevardmagazine öffentlich-rechtl. Sender & 19,2 & 15,4 \\
\hline taff, ProSieben & 4,1 & 1,9 \\
\hline SAM, ProSieben & 10,6 & 8,2 \\
\hline Explosiv, RTL & 6,0 & 6,0 \\
\hline Sat.1 am Abend & 12,9 & 11,4 \\
\hline Boulevardmagazine private Sender & 8,4 & 6,9 \\
\hline
\end{tabular}

$\mathrm{N}=128$ Ausstrahlungen von Boulevardmagazinen aus vier Kalenderwochen im März, April, Mai und Juni 2007 in einer Gesamtlänge von 68 Stunden, 6 Minuten und 40 Sekunden (ohne Werbung). Anteilig berechnet wurden die Beitragslängen einschließlich Moderation. Die Sendung Sat.1 am Abend wurde im Juli 2007 eingestellt.

Die geäußerte Einschätzung, dass private Magazine - anders als öffentlichrechtliche Sendungen - gesunkene Gewaltanteile enthalten, lässt sich für drei untersuchte Boulevardmagazine durch den Vergleich mit einer zehn Jahre zurückliegenden Analyse (Mikos 1998: 64ff.) stützen. Ein weiteres Boulevardmagazin, Blitz (Sat.1), das Mikos mit einem hohen Anteil von 19,0 Prozent erfasste (ebd.), verabschiedete sich später völlig aus der Gewaltberichterstattung und wurde darum in die aktuelle Erhebung nicht aufgenommen. Mikos berücksichtigt auch Delikte über Gewalttaten hinaus. Diese spielen allerdings in der Berichterstattung in der Regel eine geringe Rolle. 
Tabelle 16: Boulevardmagazine 1997 und 2007: Längenanteile im Vergleich

\begin{tabular}{|l|r|r|}
\hline Sendung & $\begin{array}{l}\text { Kriminalität } \\
1997 \text { in \% }\end{array}$ & $\begin{array}{l}\text { Gewaltkriminalität } \\
\text { 2007 in \% }\end{array}$ \\
\hline Brisant, ARD & 20,3 & 19,7 \\
\hline taff, ProSieben & 29,3 & 4,1 \\
\hline Explosiv, RTL & 21,1 & 6,0 \\
\hline
\end{tabular}

N1: 205 Sendungen von insgesamt fünf Boulevard-Magazinen vom 1. bis 31. Juli und vom 1. bis 14. Dezember 1997. Erfasst wurden die Anteile der Kategorien a) Kriminalität, b) Mord und Totschlag, c) Missbrauch und Vergewaltigung (Mikos 1998).

N2: 128 Sendungen aus vier Kalenderwochen im März, April, Mai und Juni 2007. Errechnet wurden die Anteile von Berichten zur Gewaltkriminalität im In- und Ausland an der Sendungslänge ohne Werbung.

\subsubsection{Handlungsrelevanz journalistischer Wirkungsabsichten}

Zuvor haben Journalisten und Journalistinnen dargelegt, welche Wirkungen der Fernsehberichterstattung über Gewaltkriminalität sie bei ihrem Publikum vermuten. Dabei kristallisieren sich fünf Wirkungsfaktoren heraus, die als Folgenschwere, Reichweite, Polarität, Personalität und Visualität umrissen werden (s. Kap. 5.3.3). Im Anschluss daran wurden die entsprechenden wirkungsgerichteten Handlungsmuster der Auswahl und Thematisierung krimineller Gewalt dargestellt: die Dramatisierung der Gewalt, die Entgrenzung des Schreckens, die Personalisierung des Leids, die Idealisierung des Opfers und die Schaffung innerer Bilder (s. Kap. 5.4.3). Im Folgenden werden die ersten vier dieser Strategien auf ihre Handlungsrelevanz hin untersucht. Dazu werden die in den Transkripten der untersuchten 264 Fernsehbeiträge aus Nachrichten und Boulevardmagazinen codierten Angaben genutzt, die so etwas wie die Demographie der berichteten Gewaltkriminalität ergeben. Ergänzend wurden alle Texte durchsucht, beispielsweise nach bestimmten Begriffen oder inhaltlichen Merkmalen. Eine Analyse, wie deren Visualisierung als von den Interviewten beschriebene Schaffung innerer Bilder gelingt, war im Rahmen dieser Auswertungsstrategie nicht möglich und hätte den Rahmen des Forschungsvorhabens gesprengt. In welcher Bildsprache Gewalt vermittelt wird, ist zweifellos von hoher Aussagekraft. Hier besteht weiterer Forschungsbedarf. 


\subsubsection{Dramatisierung der Gewalt}

Untersucht wird, inwieweit die Berichterstattung vor allem gravierende Gewalttaten aufgreift. Besonders hohe journalistische Aufmerksamkeit gilt tödlicher Gewalt, da sie mit extremen Gefühlen und herausragender Folgenschwere verknüpft wird. Die gravierenden Tatfolgen werden von den Befragten einhellig als Auswahlkriterium genannt. Tatsächlich handeln 187 aller 259 Beiträge, die konkret Gewaltdelikte im Inland aufgreifen, von tödlicher Gewalt (72,2 Prozent).

Dagegen gilt die geringe statistische Reichweite allein in den öffentlichrechtlichen Nachrichtenredaktionen als ein Kriterium, besonders verstörende, aber seltene Gewaltdelikte etwas weniger zu beachten, auch wenn damit auf eine Emotionalisierung des Publikums verzichtet wird (s.o.). Dieser Haltung entspricht, dass die öffentlich-rechtlichen Nachrichten mit 62,5 Prozent tödlicher Delikte an allen berichteten Gewalttaten einen etwas geringeren Anteil als die übrigen untersuchten Formate aufweisen - allerdings bei immer noch starker Betonung tödlicher Gewalt, wenn man bedenkt, dass sie an der polizeilich registrierten Gewaltkriminalität etwa 0,1 Prozent ausmacht (Tötungsdelikte ohne fahrlässige Tötung, BKA 2008: 268291).

Tabelle 17: Anteile tödlicher Delikte an der Berichterstattung über Gewaltkriminalität

\begin{tabular}{|l|r|r|r|r|r|r|r|r|r|r|}
\hline & \multicolumn{2}{|l|}{$\begin{array}{l}\text { Nachrichten } \\
\text { öffentlich- } \\
\text { rechtlich }\end{array}$} & \multicolumn{2}{l|}{$\begin{array}{l}\text { Nachrichten } \\
\text { privat }\end{array}$} & $\begin{array}{l}\text { Boulevard- } \\
\text { magazine } \\
\text { öffentlich- } \\
\text { rechtlich }\end{array}$ & \multicolumn{2}{l|}{$\begin{array}{l}\text { Boulevard- } \\
\text { magazine } \\
\text { privat }\end{array}$} & \multicolumn{2}{|l|}{ Gesamt } \\
\hline & $\mathrm{N}$ & $\%$ & $\mathrm{~N}$ & $\%$ & $\mathrm{~N}$ & $\%$ & $\mathrm{~N}$ & $\%$ & $\mathrm{~N}$ & $\%$ \\
\hline Tödlich & 5 & 62,5 & 61 & 82,4 & 66 & 69,5 & 55 & 67,1 & 187 & 72,2 \\
\hline $\begin{array}{l}\text { Nicht } \\
\text { tödlich }\end{array}$ & 3 & 37,5 & 13 & 17,6 & 29 & 30,5 & 27 & 32,9 & 72 & 27,8 \\
\hline Gesamt & 8 & 100,0 & 74 & 100,0 & 95 & 100,0 & 82 & 100,0 & 259 & 100,0 \\
\hline
\end{tabular}

$\mathrm{N}=259$ aus 264 Fernsehbeiträgen zu Gewaltkriminalität im Inland, die sich auf konkrete Delikte beziehen.

Über Sexualmorde wird im Untersuchungszeitraum mehr als 6.000 -mal so viel ${ }^{18}$, über Körperverletzungen dagegen nur ein Zehntel so viel berichtet, wie es den

18 Wegen der geringen Fallzahl - im Jahr 2007 registrierte die Polizei elf Sexualmorde (BKA 2008: 268-291, Tabellenanhang: 1-2) - kann dieser Wert erheblich schwanken. In den vier ausgewählten Wochen geschah kein Fall, in die Berichterstattung flossen zwei 
statistischen Anteilen entspricht. Dies beweist nicht, wie stark die Berichterstattung von dem abweicht, was wirklich ist. Verglichen werden lediglich zwei Konstrukte. Gleichwohl lässt sich damit - zumal die Polizei zu den wichtigsten Informationsquellen gehört, am häufigsten in den Beiträgen zu Wort kommt und es bis auf wenige Ausnahmen keine Berichterstattung aus dem Dunkelfeld gibt - das journalistische Auswahlmuster quer durch alle Sendergruppen und Fernsehformate ausmachen: Die Programmverantwortlichen greifen am häufigsten die Delikte auf, die gravierende Folgen haben, aber nach Erkenntnis der Polizei für den einzelnen besonders unwahrscheinlich sind.

Tabelle 18: Straftaten im Vergleich ihrer Anteile an der polizeilich erfassten und der im Fernsehen berichteten Gewaltkriminalität

\begin{tabular}{|l|r|r|r|r|r|}
\hline Delikt & \multicolumn{1}{|c|}{ PKS n } & \multicolumn{1}{c|}{ PKS \% } & \multicolumn{1}{c|}{ TV n } & \multicolumn{1}{c|}{ TV \% } & Faktor \\
\hline Sexualmorde & 11 & 0,001 & 23 & 8,9 & 6.450 \\
\hline Sonstige Tötungsdelikte* & 807 & 0,1 & 164 & 63,3 & 627 \\
\hline Sexualdelikte & 53.233 & 6,7 & 16 & 6,2 & 0,9 \\
\hline $\begin{array}{l}\text { Körperverletzungen } \\
\text { ohne Raub }\end{array}$ & 523.504 & 65,5 & 20 & 7,7 & 0,1 \\
\hline Sonstige Gewaltdelikte & 221.557 & 27,7 & 36 & 13,9 & 0,5 \\
\hline Gesamt & 799.112 & 100,0 & 259 & 100,0 & \\
\hline
\end{tabular}

$\mathrm{N} 1=799.112$ vollendete Gewaltdelikte im Jahr 2007 einschließlich aller Körperverletzungen laut Polizeilicher Kriminalstatistik (PKS, nach BKA 2008: 268291, Tabellenanhang: 1-2).

N2 = 259 Fernsehbeiträge, die sich auf einzelne Gewaltdelikte im Inland beziehen.

* Tötungsdelikte ohne Sexualmorde und ohne fahrlässige Tötung.

\subsubsection{Entgrenzung des Schreckens}

Die interviewten Fernsehjournalistinnen und Fernsehjournalisten berichten, dass eine hohe statistische Reichweite von Delikten keineswegs zu einer stärkeren Berichterstattung führt, sondern gegenüber deren Folgenschwere unerheblich ist (s.o.). $\mathrm{Zu}$ unterscheiden ist danach die statistische Reichweite, die etwas über das Risiko aussagt, dass Menschen tatsächlich Opfer einer Straftat werden, von der gefühlten Reichweite, wonach sich Menschen von einer Straftat betroffen oder

zurückliegende Fälle ein. Dass der ermittelte Faktor gleichwohl so hoch ist, belegt die herausragende Gewichtung dieses Delikts. 
bedroht fühlen. Lediglich die in öffentlich-rechtlichen Nachrichtenredaktionen Beschäftigten betonen einen eigenständigen Stellenwert von Statistiken gegenüber der als „Virulenz“ bezeichneten subjektiven Bedeutung (vgl. Kap. 5.4.3.2).

Das persönliche Risiko, einem Sexualmord zum Opfer zu fallen, steht der Polizeilichen Kriminalstatistik zufolge pro Jahr eins zu sieben Millionen. Gewaltsam getötet wird im Schnitt ein, Opfer eines Sexualdelikts werden 17, eine Körperverletzung erleiden 706 von 100.000 Menschen (gerundete Zahlen nach BKA 2008: 57). Ginge es also innerhalb des Themenspektrums Gewaltkriminalität um die tatsächliche Reichweite einzelner Delikte (ungeachtet der Tatsache, dass auch die Zahlen der Polizei subjektiven Faktoren unterliegen und nicht das Dunkelfeld verdeckter Straftaten erfassen), würde über Sexualmorde sehr selten, über Körperverletzungen häufig berichtet. Erwartungsgemäß ist das Gegenteil der Fall.

Wie sich das Befürchtete abwenden ließe, wird kaum thematisiert: Verbrechensverhütung spielt in der Kriminalitätsberichterstattung eine verschwindend geringe Rolle. In sechs Beiträgen geht es explizit um eine Verbrechensverhütung durch staatliche Einrichtungen, beispielsweise eine mögliche präventive Wirkung einer Datei von Sexualstraftätern. Weitere sechs Beiträge greifen die Verbrechensverhütung durch Einzelne auf - darunter lediglich zwei Beiträge, die konkrete Empfehlungen in jeweils einem Originalton geben. So empfiehlt ein Kriminalpsychologe Eltern, mit ihren Kindern darüber zu reden, ,dass man es den Menschen nicht ansehen kann, ob sie gute oder schlechte Absichten haben" (hallo deutschland, ZDF 5.3.2007). Und zu kinderpornografischen Inhalten im Internet spricht ein Jugendschützer von technischen Schutzmaßnahmen (heute, ZDF 8.5.2007).

Die befragten Journalistinnen und Journalisten beschreiben, wie sie eine soziale Übereinstimmung zwischen ihrem Publikum und den Opfern von Kriminalität konstruieren, um eine Emotionalisierung zu verstärken. Sie sprechen etwa von „zielgruppiger" Recherche, mit der Verbrechensopfer vor allem aus der Zielgruppe bis 49 Jahren ausgewählt werden. Diese Auswahlstrategie lässt sich inhaltsanalytisch bestätigen. Dafür wurde das Alter der Opfer in den untersuchten Beiträgen erfasst. Tatsächlich ist in der Berichterstattung kaum ein Verbrechensopfer über 49 Jahre alt (3,4 Prozent), auch nicht in den Boulevardmagazinen von ARD und ZDF, deren Publikumsschnitt bei Mitte 60 liegt (SevenOneMedia 2006). Bei den öffentlich-rechtlichen Sendern sind nur 18,1 Prozent der Opfer älter als 29 Jahre, bei den Privatsendern 9,1 Prozent (gesamt 12,3 Prozent) ${ }^{19}$.

Die Befragten erläutern als weitere Ableitung ihrer Wirkungsabsicht, die gefühlte Reichweite zu erhöhen und damit den Schrecken zu entgrenzen, so dass sich die Berichterstattung auf Deutsche konzentriert. Dem liegt das Bild eines implizit deutschen Publikums zugrunde, das an Nichtdeutschen kaum Anteil nimmt. Daher wurden in 264 Fernsehbeiträgen über Gewaltkriminalität im Inland explizite

19 In die Analyse gingen die Angaben zu 203 Personen ein, zu denen Altersangaben gemacht wurden, von insgesamt 345 Verbrechensopfern, über die im Untersuchungszeitraum berichtet wurde. 
Hinweise gesucht, die sich unmittelbar auf die Nationalität bzw. Ethnie der Opfer beziehen bzw. sich eindeutig aus dem Kontext erschließen (z.B. Tochter einer Afrikanerin), nicht aber aus Vermutungen, beispielsweise aufgrund von Namen. Berücksichtigt wird auch ausländische Herkunft, wenn zumindest ein Elternteil ausdrücklich als ausländisch bezeichnet wird.

Dabei zeigt sich: Von ausländischen Opfern ist kaum die Rede. Ihr Anteil an der Kriminalitätsberichterstattung beträgt 3,2 Prozent und ist damit stark unterproportional. Nach dem 2. Periodischen Sicherheitsbericht unterliegen Ausländer und Ausländerinnen einem überdurchschnittlichen Risiko, Opfer einer Gewalttat zu werden (Bundesministerien der Justiz und des Innern 2006: 414). Exakte Zahlen für nichtdeutsche Gewaltopfer führt die Polizeiliche Kriminalstatistik zwar nicht auf (BKA 2008). Doch einer Fragebogenerhebung der kriminologischen Forschungsstelle der bayerischen Polizei zufolge sind 26,7 Prozent aller Gewaltopfer ausländisch (Bayerisches Landeskriminalamt 1995: 172). Untersucht wurden Gewaltdelikte aller Art, also Straftaten gegen das Leben, gegen die sexuelle Selbstbestimmung sowie Rohheitsdelikte und Straftaten gegen die persönliche Freiheit (Bayerisches Landeskriminalamt 1995: 170). Werden diese Ergebnisse aus der Analyse von Gewaltdelikten an die Berichterstattung angelegt, wird die alltägliche Gewalt gegenüber Menschen ausländischer Herkunft nur zu einem Bruchteil medial erfasst. Dieses Desinteresse wird keineswegs durch eine besondere Aufmerksamkeit für fremdenfeindliche Übergriffe aufgehoben. Über derartige Gewaltdelikte berichteten die analysierten Fernsehformate im Untersuchungszeitraum kein einziges Mal.

Tabelle 19: Gewaltopfer ausländischer Herkunft nach Sendern und Formaten

\begin{tabular}{|l|r|r|r|r|r|r|r|r|r|r|}
\hline & \multicolumn{2}{|l|}{$\begin{array}{l}\text { Nachrichten } \\
\text { offentlich- } \\
\text { rechtlich }\end{array}$} & \multicolumn{2}{l|}{$\begin{array}{l}\text { Nachrichten } \\
\text { privat }\end{array}$} & $\begin{array}{l}\text { Boulevard- } \\
\text { magazine } \\
\text { offentlich- } \\
\text { rechtlich }\end{array}$ & \multicolumn{2}{l|}{$\begin{array}{l}\text { Boulevard- } \\
\text { magazine } \\
\text { privat }\end{array}$} & \multicolumn{2}{|l|}{ Gesamt } \\
\cline { 2 - 12 } & $\mathrm{N}$ & $\%$ & $\mathrm{~N}$ & $\%$ & $\mathrm{~N}$ & $\%$ & $\mathrm{~N}$ & $\%$ & $\mathrm{~N}$ & $\%$ \\
\hline $\begin{array}{l}\text { Gewalt- } \\
\text { opfer ausl. } \\
\text { Herkunft }\end{array}$ & 0 & 0 & 5 & 5,0 & 1 & 0,8 & 5 & 4,5 & 11 & 3,2 \\
\hline $\begin{array}{l}\text { Gewaltop- } \\
\text { fer gesamt }\end{array}$ & 10 & 100,0 & 101 & 100,0 & 122 & 100,0 & 112 & 100,0 & 345 & 100,0 \\
\hline
\end{tabular}

$\mathrm{N}=345$ Gewaltopfer in 264 Fernsehbeiträgen über Gewaltkriminalität im Inland.

Die interviewten Fernsehjournalistinnen und Fernsehjournalisten nennen das Verbrechensopfer als zentrale Figur, dessen - möglichst idealtypische - Merkmale für die Auswahl von Fällen vorrangig sind, während die Eigenschaften der Tatverdächtigen einen geringeren Ausschlag geben. Dies gilt umso mehr, als in der aktuellen Berichterstattung häufig Eigenschaften der Opfer bereits bekannt sind, während sich noch kein Tatverdacht gegen eine bestimmte Person richtet. Daher lässt die Befragung erwarten, dass sich die Präferenz für Deutsche vor allem auf die 
Auswahl der Opfer auswirkt. Die Programmanalyse bestätigt diese Annahme.

32 Tatverdächtige, über die im Untersuchungszeitraum berichtet wird, werden mit Hinweisen auf ihren ausländischen Hintergrund versehen, sei es durch Angabe ihrer Nationalität, ihrer fremden Ethnie oder durch Umschreibungen wie „Verdächtige südländischen Typs“. Ihr Anteil an der Gesamtheit der Beschuldigten und Verurteilten beträgt 12,5 Prozent. Die Polizeiliche Kriminalstatistik gibt die Anteile nichtdeutscher Tatverdächtiger mit 28,3 Prozent bei Tötungsdelikten und 23 Prozent bei gefährlichen und schweren Körperverletzungen an (BKA 2008: 108). Gemessen daran ist der Anteil der ausländischen Tatverdächtigen an der Kriminalitätsberichterstattung weit unterdurchschnittlich.

Tabelle 20: Tatverdächtige ausländischer Herkunft nach Sendern und Formaten

\begin{tabular}{|c|c|c|c|c|c|c|c|c|c|c|}
\hline & \multicolumn{2}{|c|}{$\begin{array}{l}\text { Nachrichten } \\
\text { öffentlich- } \\
\text { rechtlich }\end{array}$} & \multicolumn{2}{|c|}{$\begin{array}{l}\text { Nachrichten } \\
\text { privat }\end{array}$} & \multicolumn{2}{|c|}{$\begin{array}{l}\text { Boulevard- } \\
\text { magazine } \\
\text { öffentlich- } \\
\text { rechtlich }\end{array}$} & \multicolumn{2}{|c|}{$\begin{array}{l}\text { Boulevard- } \\
\text { magazine } \\
\text { privat }\end{array}$} & \multicolumn{2}{|c|}{ Gesamt } \\
\hline & $\mathrm{N}$ & $\%$ & $\mathrm{~N}$ & $\%$ & $\mathrm{~N}$ & $\%$ & $\mathrm{~N}$ & $\%$ & $\mathrm{~N}$ & $\%$ \\
\hline $\begin{array}{l}\text { Tatverdäch- } \\
\text { tige ausl. } \\
\text { Herkunft }\end{array}$ & 1 & 20,0 & 12 & 16,0 & 6 & 6,5 & 13 & 15,3 & 32 & 12,5 \\
\hline $\begin{array}{l}\text { Tatverdächti- } \\
\text { ge, Täter/in- } \\
\text { nen gesamt }\end{array}$ & 5 & 100,0 & 75 & 100,0 & 92 & 100,0 & 85 & 100,0 & 257 & 100,0 \\
\hline
\end{tabular}

$\mathrm{N}=257$ Tatverdächtige bzw. Täter/innen in 264 Fernsehbeiträgen über Gewaltkriminalität im Inland.

Mit der Ausblendung von Ausländerinnen und Ausländern vor allem als Gewaltopfer ergibt sich ein diskriminierender Effekt: In der Berichterstattung treten explizit Nichtdeutsche fast viermal so häufig als Tatverdächtige wie als Opfer von Gewalttaten in Erscheinung. Die Polizeistatistiken dagegen - soweit sie vergleichbar sind weisen jeweils etwa gleich hohe Anteile auf. Nicht bestätigt zeigt sich die Aussage von Journalistinnen und Journalisten, dass kaum berichtet wird, wenn sowohl Tatverdächtige wie Opfer ausländisch sind. Wird im Untersuchungszeitraum über ausländische Gewaltopfer berichtet, sind in der Mehrzahl dieser Fälle auch die Tatverdächtigen explizit ausländisch. An diesem Punkt besteht Forschungsbedarf, um das besondere mediale Desinteresse am ausländischen Opfer und die entsprechende Verzerrung des Bildes der Tatverdächtigen weiter zu erkunden. Eine vertiefte Analyse, die sich auf mehr Fälle stützen kann, steht noch aus. 
Die befragten Journalistinnen und Journalisten bekunden die Annahme, dass sich ihr Publikum vor allem für die einzelnen in Gewaltkriminalität verwickelten Menschen interessiert. Danach geht es in erster Linie darum, deren Gewalterfahrungen und Empfindungen zu vermitteln.

Über Kriminalität zu berichten bedeutet den Befragten zufolge daher vor allem, über Einzelfälle und damit einzelne Menschen zu berichten. Die Fokussierung auf den Einzelfall lässt sich mit der Programmanalyse klar bestätigen. 95,4 Prozent aller untersuchten Fernsehbeiträge beleuchten konkrete Gewaltereignisse. 2,7 Prozent aller Beiträge - in Nachrichten des Privatfernsehens und in Boulevardmagazinen erörtern Kriminalitätsdebatten beispielsweise über Strafverschärfungen oder die Einführung von halböffentlichen Täterdateien und stützen sich vignettenhaft auf einzelne Taten. Lediglich 1,9 Prozent aller Beiträge - allesamt in privaten oder öffentlich-rechtlichen Nachrichten - beziehen sich auf kein einzelnes Delikt, sondern auf Akte der Exekutive oder Legislative, beispielsweise die Vorstellung der polizeilichen Kriminalstatistik oder einen Bundestagsbeschluss zur Strafverschärfung.

Tabelle 21: Beitragsanlässe von Fernsehberichten über Gewaltkriminalität

\begin{tabular}{|l|r|r|}
\hline & $\mathrm{N}$ & \multicolumn{1}{c|}{$\%$} \\
\hline Beiträge über konkrete Fälle & 252 & 95,4 \\
\hline Beiträge allgemeiner Art mit Fallbeispielen & 7 & 2,7 \\
\hline Beiträge allgemeiner Art ohne Fallbeispiele & 5 & 1,9 \\
\hline Beiträge gesamt & 264 & 100 \\
\hline
\end{tabular}

$\mathrm{N}=264$ Fernsehbeiträge zu Gewaltkriminalität im Inland.

Um Mitgefühl mit den Opfern und Furcht vor der Gewalt zu wecken, müssen den Befragten zufolge die unmittelbar und mittelbar Betroffenen von Gewalt selbst Gestalt gewinnen. Daher wird den Äußerungen der Opferseite eine Schlüsselrolle zugewiesen, um das Publikum emotional zu erreichen. Dies bildet sich in der Programmanalyse nur bedingt ab. So kommt in 75 von 264 Beiträgen (28,4 Prozent) die Opferseite zu Wort, sei es durch die Opfer selbst, nahe Angehörige oder ihr weiteres Umfeld einschließlich Anwältinnen und Anwälten. Seltener, in 50 Beiträgen (18,9 Prozent), ist die Tatverdächtigenseite mit Interviewpassagen vertreten. In 14,8 Prozent der Beiträge ist ausschließlich die Opferseite, in nur 5,3 Prozent der Beiträge ist ausschließlich die Tatverdächtigenseite präsent. 
Tabelle 22: Originaltöne von Opferseite und Tatverdächtigenseite

\begin{tabular}{|l|r|r|r|r|r|r|}
\hline & \multicolumn{2}{|l|}{$\begin{array}{l}\text { Opferseite im } \\
\text { O-Ton }\end{array}$} & \multicolumn{2}{l|}{$\begin{array}{l}\text { Opferseite nicht } \\
\text { im O-Ton }\end{array}$} & \multicolumn{2}{l|}{ Gesamt } \\
\cline { 2 - 7 } & \multicolumn{1}{c|}{$\mathrm{n}$} & \multicolumn{1}{c|}{$\%$} & \multicolumn{1}{c|}{$\mathrm{n}$} & \multicolumn{1}{c|}{$\%$} & \multicolumn{1}{c|}{$\mathrm{n}$} & \multicolumn{1}{c|}{$\%$} \\
\hline $\begin{array}{l}\text { Tatverdächtigenseite } \\
\text { im O-Ton }\end{array}$ & 36 & 13,6 & 14 & 5,3 & 50 & 18,9 \\
\hline $\begin{array}{l}\text { Tatverdächtigenseite } \\
\text { nicht im O-Ton }\end{array}$ & 39 & 14,8 & 175 & 66,3 & 214 & 81,1 \\
\hline Beiträge gesamt & 75 & 28,4 & 189 & 71,6 & 264 & $\begin{array}{r}100, \\
0\end{array}$ \\
\hline
\end{tabular}

$\mathrm{N}=264$ Fernsehbeiträge zu Gewaltkriminalität im Inland. Opferseite: Mindestens eine Person - Opfer, deren Angehörige, Anwältin/Anwalt bzw. Umfeld, entsprechend bei Tatverdächtigen bzw. Verurteilten.

Um eine starke Personalisierung zu erreichen, halten die interviewten Journalistinnen und Journalisten für wirksam, vor allem die Menschen, die unmittelbar betroffen sind, dazu zu bewegen, möglichst authentisch über die emotionale Wucht der Gewalt zu sprechen. So kommt mit 42 Opfern fast jedes dritte überlebende Opfer zu Wort. Seltener gelingt die Annäherung an die nahen Angehörigen, nämlich bei 31 von 345 Opfern, über die berichtet wurde (9,0 Prozent). Deutlich heben sich die öffentlich-rechtlichen Nachrichten ab - in keinem Beitrag erscheint die Opferseite mit Äußerungen. Für ein „Witwenschütteln“ im engen, buchstäblichen Sinne ${ }^{20}$ - also ein Interview mit der Ehefrau eines Todesopfers - fand sich im Untersuchungszeitraum kein einziges Beispiel. Wenn sich Angehörige von Gewaltopfern äußern, sind dies mehrheitlich Mütter.

20 „Witwenschütteln“ wird im Journalismus allgemein der Kontakt zu Angehörigen von Gewaltopfern genannt, in der Regel, um Informationen und Bildmaterial zu erhalten (vgl. Adolf-Grimme-Institut 2002, Koelbl 2001: 129f., als Praxisbericht: Dombrowski 2008: 128137). 
Tabelle 23: Originaltöne von Opfern und ihrem Umfeld nach Sendern und Formaten

\begin{tabular}{|l|r|r|r|r|r|r|r|r|r|r|}
\hline & \multicolumn{2}{|l|}{$\begin{array}{l}\text { Nachrichten } \\
\text { öfentlich- } \\
\text { rechtlich }\end{array}$} & \multicolumn{2}{l|}{$\begin{array}{l}\text { Nachrichten } \\
\text { privat }\end{array}$} & \multicolumn{2}{l|}{$\begin{array}{l}\text { Boulevard- } \\
\text { magazine } \\
\text { offentlich- } \\
\text { rechtlich }\end{array}$} & \multicolumn{2}{l|}{$\begin{array}{l}\text { Boulevard- } \\
\text { magazine } \\
\text { privat }\end{array}$} & \multicolumn{2}{l|}{ Gesamt } \\
\hline & $\mathrm{N}$ & $\%$ & $\mathrm{~N}$ & $\%$ & $\mathrm{~N}$ & $\%$ & $\mathrm{~N}$ & $\%$ & $\mathrm{~N}$ & $\%$ \\
\hline Opfer-O-Ton & 0 & 0 & 8 & 7,9 & 17 & 13,9 & 17 & 15,2 & 42 & 12,2 \\
\hline Angehörige & 0 & 0 & 2 & 2,0 & 15 & 12,3 & 14 & 12,5 & 31 & 9,0 \\
\hline $\begin{array}{l}\text { Weiteres } \\
\text { Umfeld }\end{array}$ & 0 & 0 & 8 & 7,9 & 23 & 18,9 & 17 & 15,2 & 48 & 13,9 \\
\hline $\begin{array}{l}\text { Anwälte / } \\
\text { Anwältinnen }\end{array}$ & 0 & 0 & 1 & 1,0 & 3 & 2,5 & 3 & 2,7 & 7 & 2,0 \\
\hline $\begin{array}{l}\text { Keine } \\
\text { O-Töne }\end{array}$ & 10 & 100,0 & 84 & 83,2 & 71 & 58,2 & 70 & 62,5 & 235 & 68,1 \\
\hline $\begin{array}{l}\text { Zahl Opfer } \\
\text { gesamt }\end{array}$ & 10 & 100,0 & 101 & 100,0 & 122 & 100,0 & 112 & 100,0 & 345 & 100,0 \\
\hline
\end{tabular}

$\mathrm{N}=345$ Opfer aus 264 Fernsehbeiträgen zu Gewaltkriminalität im Inland.

Die interviewten Journalistinnen und Journalisten umreißen die Rollen von Tatverdächtigen und Opfern als unterschiedlich wichtig für die Emotionalisierung des Publikums und betonen zugleich, dass sie eine formale Symmetrie anstreben. Danach sollen beide Seiten vertreten sein, aber sich deutlich unterscheiden. Wie die Programmanalyse zeigt, treten Tatverdächtige und Täter/innen sowie ihre Angehörigen mit Äußerungen nicht einmal halb so oft vor die Kamera wie die Opferseite. In Boulevardmagazinen privater Sender sind Beschuldigte besonders häufig vertreten. Insgesamt gesehen, sprechen häufiger als bei den Opfern Anwälte und Anwältinnen für Verdächtige und Beschuldigte. Dies wird zum Teil juristische Gründe haben, schließlich könnten sich Personen unter Tatverdacht selbst belasten. Auch dürfte die Verfügbarkeit eine Rolle spielen, etwa die Tatsache, dass nur 203 von 257 Tatverdächtigen bzw. Täter oder Täterinnen bekannt und diejenigen, die schwerer Gewalttaten beschuldigt werden, in Haft und damit kaum erreichbar sind. 
Tabelle 24: Originaltöne von Tatverdächtigen bzw. Täter/innen und ihrem Umfeld nach Sendern und Formaten

\begin{tabular}{|c|c|c|c|c|c|c|c|c|c|c|}
\hline & \multicolumn{2}{|c|}{$\begin{array}{l}\text { Nachrichten } \\
\text { öffentlich- } \\
\text { rechtlich }\end{array}$} & \multicolumn{2}{|c|}{$\begin{array}{l}\text { Nachrichten } \\
\text { privat }\end{array}$} & \multicolumn{2}{|c|}{$\begin{array}{l}\text { Boulevardma } \\
\text { gazine } \\
\text { öffentlich- } \\
\text { rechtlich }\end{array}$} & \multicolumn{2}{|c|}{$\begin{array}{l}\text { Boulevard- } \\
\text { magazine } \\
\text { privat }\end{array}$} & \multicolumn{2}{|c|}{ Gesamt } \\
\hline & $\mathrm{N}$ & $\%$ & $\mathrm{~N}$ & $\%$ & $\mathrm{~N}$ & $\%$ & $\mathrm{~N}$ & $\%$ & $\mathrm{~N}$ & $\%$ \\
\hline $\begin{array}{l}\text { Tatverdäch- } \\
\text { tige / Täter / } \\
\text {-innen O-Ton }\end{array}$ & 0 & 0,0 & 0 & 0,0 & 3 & 4,2 & 13 & 18,8 & 16 & 6,2 \\
\hline Angehörige & 0 & 0,0 & 1 & 1,3 & 6 & 6,5 & 8 & 9,4 & 15 & 5,8 \\
\hline $\begin{array}{l}\text { Weiteres } \\
\text { Umfeld }\end{array}$ & 0 & 0,0 & 1 & 1,3 & 9 & 9,8 & 18 & 21,2 & 28 & 10,9 \\
\hline $\begin{array}{l}\text { Anwälte / } \\
\text { Anwältinnen }\end{array}$ & 1 & 20,0 & 2 & 2,7 & 10 & 10,9 & 3 & 3,5 & 16 & 6,2 \\
\hline $\begin{array}{l}\text { Tatverdäch- } \\
\text { tige/Täter/in- } \\
\text { nen gesamt }\end{array}$ & 5 & 100,0 & 75 & 100,0 & 92 & 100,0 & 85 & 100,0 & 257 & 100,0 \\
\hline
\end{tabular}

$\mathrm{N}=257$ Tatverdächtige bzw. Täter/innen aus 264 Fernsehbeiträgen zu Gewaltkriminalität im Inland

Trotz des Plädoyers der Fernsehjournalistinnen und Fernsehjournalisten, vor allem die Betroffenen selbst und weniger die professionell Involvierten vor die Kamera zu bekommen, ist die Polizei am stärksten vertreten - in 97 von 264 Beiträgen (36,7 Prozent). Unbeteiligte, meist aus der Nachbarschaft, äußern sich in 58 Beiträgen (22,0 Prozent). 36 Berichte (13,6 Prozent) enthalten Originaltöne aus der Justiz. Am deutlichsten unterscheiden sich die Formate darin, dass politisch Verantwortliche in Boulevardmagazinen nur in 4 von 177 Beiträgen (2,3 Prozent), in den öffentlich-rechtlichen Nachrichten anteilig am häufigsten (in 2 von 9 Beiträgen) das Wort ergreifen. In privaten Boulevardmagazinen ist der Anteil von Stimmen aus Politik und Justiz besonders gering. 
Tabelle 25: Äußerungen weiterer Personen nach Sendern und Formaten

\begin{tabular}{|c|c|c|c|c|c|c|c|c|c|c|}
\hline & \multicolumn{2}{|c|}{$\begin{array}{l}\text { Nachrichten } \\
\text { öffentlich- } \\
\text { rechtlich }\end{array}$} & \multicolumn{2}{|c|}{$\begin{array}{l}\text { Nachrichten } \\
\text { privat }\end{array}$} & \multicolumn{2}{|c|}{$\begin{array}{l}\text { Boulevard- } \\
\text { magazine } \\
\text { öffentlich- } \\
\text { rechtlich }\end{array}$} & \multicolumn{2}{|c|}{$\begin{array}{l}\text { Boulevard- } \\
\text { magazine } \\
\text { privat }\end{array}$} & \multicolumn{2}{|c|}{ Gesamt } \\
\hline & $\mathrm{N}$ & $\%$ & $\mathrm{~N}$ & $\%$ & $\mathrm{~N}$ & $\%$ & $\mathrm{~N}$ & $\%$ & $\mathrm{~N}$ & $\%$ \\
\hline Polizei & 3 & 33,3 & 36 & 46,2 & 39 & 41,1 & 19 & 23,2 & 97 & 36,7 \\
\hline Justiz & 2 & 22,2 & 8 & 10,3 & 21 & 22,1 & 5 & 6,1 & 36 & 13,6 \\
\hline $\begin{array}{l}\text { Politik, } \\
\text { Behörden }\end{array}$ & 2 & 22,2 & 8 & 10,3 & 1 & 1,1 & 3 & 3,6 & 14 & 5,3 \\
\hline Experten & 0 & 0,0 & 2 & 2,6 & 4 & 4,2 & 3 & 3,7 & 9 & 3,4 \\
\hline $\begin{array}{l}\text { Andere } \\
\text { Personen }\end{array}$ & 0 & 0,0 & 12 & 15,4 & 30 & 31,6 & 16 & 19,5 & 58 & 22,0 \\
\hline $\begin{array}{l}\text { Beiträge } \\
\text { gesamt }\end{array}$ & 9 & 100,0 & 78 & 00,0 & 95 & 100,0 & 82 & 100,0 & 264 & 100,0 \\
\hline
\end{tabular}

$\mathrm{N}=264$ Fernsehbeiträge zu Gewaltkriminalität im Inland. Andere Personen: Personen, die weder Opfer- noch Tatverdächtigenseite zugerechnet werden können, meist Nachbarschaft bzw. Straßenumfragen.

\subsubsection{Idealisierung des Opfers}

Im Folgenden wird der Frage nachgegangen, inwieweit die Berichterstattung polarisiert, auf wen sich dies bezieht und welche Merkmale dabei im Vordergrund stehen. In ihren Annahmen über ihr Publikum führen die Interviewten aus, dass die Konstruktion von Eindeutigkeit dazu beiträgt, die Zuschauenden in besonderer Weise zu bewegen und damit letztlich deren Sehbeteiligung zu erhöhen. Daraus leiten sie Muster der Auswahl und Thematisierung bestimmter Ereignisse und der daran beteiligten Personen ab. Diese Strategien der Polarisierung beziehen sich in erster Linie auf Verbrechensopfer und ihre Angehörigen. Vor allem vom Verbrechensopfer werden idealtypische Eigenschaften erwartet, insbesondere, dass das Opfer sympathisch, schwach und unschuldig erscheint. Daraus folgern die Befragten, dass beispielsweise Gewalt innerhalb krimineller Milieus wegen ungenügender Trennschärfe zwischen Beschuldigten und Opfern nicht publikumsaffin ist (s.o.).

Tatsächlich tauchen Gewalttaten an Prostituierten in keinem der untersuchten Fernsehberichte auf. Nicht absolut zu bestätigen ist dagegen die Einschätzung, dass die Berichterstattung über einen Mord im Drogenmilieu ,journalistisch tot“ ist, wie eine Redakteurin vermutet (Kap. 5.3.3.4). Über den Mord an einem 14jährigen Mädchen und ihre Verstrickung in das Drogenmilieu wird im Untersuchungszeitraum siebenmal berichtet. Dabei wird allerdings betont, dass das Opfer so genannte 
weiche illegale Drogen konsumiert hat, und als junges Mädchen erfüllt es wiederum andere idealtypische Eigenschaften, wie im Folgenden dargelegt wird.

Die Eigenschaften des idealen Opfers sehen die Befragten grundsätzlich im kindlichen Opfer erfüllt. „Wenn es um Kinder geht, gerät man sofort in eine Haltung, nahezu jeder Mensch“, zeigt sich ein Redakteur überzeugt (Kap. 5.3.3.4). Begründet wird dies mit äußeren Merkmalen wie dem Kindchenschema und dem gleichsam automatischen Mitleid mit schwachen und kleinen Opfern. Diese Deutung der Publikumsreaktionen schlägt sich in der teils geradezu mechanischen Auswahl von Opfern nach ihrem Alter nieder.

Dieses Auswahlmuster bildet sich in der Inhaltsanalyse klar ab: 41,9 Prozent aller Opfer, deren Alter in den untersuchten Fernsehbeiträgen bekannt wird, sind Kinder, vor allem zwischen 6 und 13 Jahren. Die Polizeiliche Kriminalstatistik (BKA 2008: Tabellenanhang, Tabelle 91) weist einen sehr viel niedrigeren Kinderanteil unter den Opfern aller Gewaltdelikte von nur 8,5 Prozent aus. Wird die statistische Altersverteilung entsprechend den Anteilen der Delikte an der Berichterstattung von Nachrichten und Boulevardmagazinen im Untersuchungszeitraum gewichtet, lassen sich die Merkmale der tatsächlich berichteten Delikte berechnen. Danach wird vor allem die Gewalt an Kindern zwischen 6 und 13 Jahren mit Faktor 5,0 überproportional, spiegelbildlich die Gewalt an Menschen über 60 Jahren mit dem Faktor 0,1 unterproportional stark berichtet. Diese Verzerrung wird im unmittelbaren Vergleich der Opfergruppen noch deutlicher: Im Vergleich zur Kriminalstatistik werden Gewalttaten, denen Kinder zwischen 6 und 13 Jahren zum Opfer fallen, 43-mal so oft berichtet wie Gewaltdelikte mit Opfern über 60 Jahren $^{21}$.

Bei Tötungsdelikten werden die Fokussierung auf kindliche und die Ausblendung älterer Opfer noch deutlicher: Bei gleicher Zahl polizeibekannter Fälle wird über Opfer tödlicher Gewalt zwischen 6 und 13 Jahren fast 70-mal so oft berichtet wie über Todesopfer älter als 60 Jahre. 
Tabelle 26: Alter der Opfer von Gewaltdelikten in der Fernsehberichterstattung im Vergleich zur Polizeilichen Kriminalstatistik nach Sendern und Formaten

\begin{tabular}{|c|c|c|c|c|c|c|c|c|c|c|c|c|c|}
\hline \multirow[b]{2}{*}{ Alter } & \multicolumn{2}{|c|}{$\begin{array}{l}\text { Nachrichten } \\
\text { öffentlich- } \\
\text { rechtl. }\end{array}$} & \multicolumn{2}{|c|}{$\begin{array}{l}\text { Nachrichten } \\
\text { privat }\end{array}$} & \multicolumn{2}{|c|}{$\begin{array}{l}\text { Boulevard- } \\
\text { magazine } \\
\text { öff.-rechtl. }\end{array}$} & \multicolumn{2}{|c|}{$\begin{array}{l}\text { Boulevard- } \\
\text { magazine } \\
\text { privat }\end{array}$} & \multicolumn{2}{|c|}{ Gesamt } & \multirow{2}{*}{\begin{tabular}{|c|} 
Faktor \\
F
\end{tabular}} & \multirow{2}{*}{$\begin{array}{l}\begin{array}{l}\text { PKS } \\
\text { gew.* }\end{array} \\
\%\end{array}$} & \multirow{2}{*}{$\begin{array}{r}\text { PKS } \\
\%\end{array}$} \\
\hline & $\mathrm{n}$ & $\%$ & $\mathrm{n}$ & $\%$ & $\mathrm{n}$ & $\%$ & $\mathrm{n}$ & $\%$ & $\mathrm{n}$ & $\%$ & & & \\
\hline $\begin{array}{l}\text { Kleinkinder } \\
0 \text { bis } 5\end{array}$ & 0 & 0,0 & 6 & 9,7 & 11 & 16,4 & 16 & 22,8 & 33 & 16,3 & 2,9 & 5,5 & 1,0 \\
\hline $\begin{array}{l}\text { Kinder } \\
6 \text { bis } 13\end{array}$ & 1 & 25,0 & 17 & 27,4 & 16 & 23,9 & 18 & 25,7 & 52 & 25,6 & 5,0 & 5,1 & 7,6 \\
\hline $\begin{array}{l}\text { Jugendliche } \\
14 \text { bis } 17\end{array}$ & 0 & 0,0 & 5 & 8,1 & 9 & 13,4 & 9 & 12,9 & 23 & 11,3 & 1,8 & 6,1 & 13,1 \\
\hline $\begin{array}{l}\text { Heranwach- } \\
\text { sende } 18-20\end{array}$ & 1 & 25,0 & 5 & 8,1 & 7 & 10,5 & 7 & 10,0 & 20 & 9,9 & 1,8 & 5,3 & 12,2 \\
\hline $\begin{array}{l}\text { Erwachsene } \\
21 \text { bis } 59\end{array}$ & 2 & 50,0 & 29 & 46,8 & 21 & 31,3 & 17 & 24,3 & 69 & 34,0 & 0,6 & 52,9 & 60,9 \\
\hline $\begin{array}{l}\text { Ältere } \\
\text { über } 60\end{array}$ & 0 & 0,0 & 0 & 0,0 & 3 & 4,5 & 3 & 4,3 & 6 & 2,9 & 0,1 & 25,1 & 5,2 \\
\hline Gesamt & 4 & 100,0 & 62 & 100,0 & 67 & 100,0 & 70 & 100,0 & 203 & 100,0 & & 100,0 & 100,0 \\
\hline
\end{tabular}

N1= 203 von 345 Opfern, soweit das Alter genannt wird, aus 264 Fernsehbeiträgen über Gewaltkriminalität im Inland.

N2 = PKS (Polizeiliche Kriminalstatistik) für 2007 (BKA 2008: Tabellenanhang, Tabelle 91).

* = PKS-Daten gewichtet nach Anteilen an der TV-Berichterstattung im Untersuchungszeitraum.

Wenn die Befragten erläutern, mit welchen Merkmalen sie das idealisierte Opfer darstellen, heben sie implizit vielfach auf das weibliche Opfer ab. Inhaltsanalytisch ist zu bestätigen, dass die Gewalt an Frauen und Mädchen überdurchschnittlich starke Beachtung findet. Dies ergibt sich zum Teil bereits aus der Auswahl der Delikte - Sexualdelikte, die vor allem Mädchen und Frauen treffen, werden stark betont. Um die eigentliche Auswahl der Opfer zu beleuchten, wird daher wiederum die Geschlechterverteilung laut Polizeilicher Kriminalstatistik (PKS) nach der Häufigkeit der jeweiligen Delikte in der Berichterstattung gewichtet. Laut PKS (BKA 2008: Tabellenanhang, Tabelle 91) sind 39,7 Prozent der Gewaltopfer weiblich, bei entsprechender Gewichtung steigt ihr Anteil auf 44,4 Prozent. In der Berichterstattung liegt der Anteil weiblicher Opfer weitaus höher, und zwar bei 66,0 Prozent. Daraus lässt sich ein deutliches Auswahlmuster bestätigen: Das medial bevorzugte Opfer ist weiblich. Dieses Muster zieht sich durch alle Formate. 
Tabelle 27: Geschlecht der Opfer von Gewaltdelikten in der Fernsehberichterstattung im Vergleich zur Polizeilichen Kriminalstatistik nach Sendern und Formaten

\begin{tabular}{|c|c|c|c|c|c|c|c|c|c|c|c|c|}
\hline \multirow[b]{2}{*}{ Geschlecht } & \multicolumn{2}{|c|}{$\begin{array}{l}\text { Nachrichten } \\
\text { öffentlich- } \\
\text { rechtlich }\end{array}$} & \multicolumn{2}{|c|}{$\begin{array}{l}\text { Nachrichten } \\
\text { privat }\end{array}$} & \multicolumn{2}{|c|}{$\begin{array}{l}\text { Boulevard- } \\
\text { magazine } \\
\text { öffentlich- } \\
\text { rechtlich }\end{array}$} & \multicolumn{2}{|c|}{$\begin{array}{l}\text { Boulevard- } \\
\text { magazine } \\
\text { privat }\end{array}$} & \multicolumn{2}{|c|}{ TV gesamt } & \multirow{2}{*}{\begin{tabular}{c|}
$\begin{array}{l}\text { PKS } \\
\text { gew.* }\end{array}$ \\
$\%$
\end{tabular}} & \multirow{2}{*}{$\begin{array}{r}\text { PKS } \\
\\
\%\end{array}$} \\
\hline & $\mathrm{N}$ & $\%$ & $\mathrm{~N}$ & $\%$ & $\mathrm{~N}$ & $\%$ & $\mathrm{~N}$ & $\%$ & $\mathrm{~N}$ & $\%$ & & \\
\hline Männer & 3 & 30,0 & 29 & 30,5 & 39 & 34,2 & 41 & 37,3 & 112 & 34,0 & 55,6 & 60,3 \\
\hline Frauen & 7 & 70,0 & 66 & 69,5 & 75 & 65,8 & 69 & 62,7 & 217 & 66,0 & 44,4 & 39,7 \\
\hline Gesamt & 10 & 100,0 & 95 & 100,0 & 114 & 100,0 & 110 & 100,0 & 329 & 100,0 & 100,0 & 100,0 \\
\hline
\end{tabular}

N1= 329 von 345 Opfern, soweit das Geschlecht genannt wird, aus 264 Fernsehbeiträgen über Gewaltkriminalität im Inland.

N2 = PKS (Polizeiliche Kriminalstatistik) für 2007 (BKA 2008: Tabellenanhang, Tabelle 91).

* = PKS-Daten gewichtet nach Anteilen an der TV-Berichterstattung im Untersuchungszeitraum.

Die interviewten Fernsehjournalistinnen und Fernsehjournalisten offenbaren Strategien der Polarisierung, um Opfer zu idealisieren. Keineswegs aber geht es ihnen darum, so betonen sie, spiegelbildlich Tatverdächtige, Täter bzw. Täterininnen als Schreckensgestalten darzustellen. Das dämonisierte Böse ist vielmehr unpersönlich. Es gilt als tabu, Tatverdächtige herabzuwürdigen. Inhaltsanalytisch lässt sich belegen, dass in keinem einzigen der untersuchten Nachrichten- und Magazinbeiträge über Gewaltkriminalität in Deutschland Begriffe wie „Bestie“ oder „Monster“ verwendet werden. Wertende Formulierungen sind zwar zahlreich negative Deutungen wie ,grausam“ oder „brutal“ tauchen 403-mal in den untersuchten Beiträgen auf. Doch soweit Negativbegriffe verwendet werden, beziehen sie sich in aller Regel auf das Tatgeschehen, nicht auf die Handelnden selbst.

$\mathrm{Zu}$ den häufigsten Begriffen gehört die Brutalität (42 Textstellen). In der großen Mehrzahl wird von der Brutalität der Tat gesprochen, etwa so: „Ein brutaler Polizeimord am helllichten Tag, mitten in der Stadt." (hallo deutschland, ZDF 26. April 2007) Nur in drei Textpassagen richtet sich der Vorwurf unmittelbar an Personen, beispielsweise: „Sie sorgte damals dafür, dass der brutale Familienvater auszog.“ (RTL explosiv, 25.4.2007) Grausamkeit wird 30-mal thematisiert, doch wird nur einmal von grausamen Tätern gesprochen. Um schreckliche Details, einen schrecklichen Fund oder die schreckliche Bluttat geht es 29-mal - nie aber werden Menschen selbst als schrecklich charakterisiert. 


\subsubsection{Zusammenfassung}

Die Nachrichten der Privatsender berichten über Gewaltkriminalität im Inland mit einem Anteil von 6,4 Prozent rund fünfmal so umfangreich wie die öffentlichrechtlichen Nachrichten mit einem Anteil von 1,3 Prozent. Bei den untersuchten Boulevardmagazinen dagegen berichten die öffentlich-rechtlichen Formate mit durchschnittlich 15,4 Prozent mehr als doppelt so viel über Gewaltkriminalität im Inland wie die privaten Magazine mit 6,9 Prozent. Um Techniken der Visualisierung zu erkunden, bedarf es einer vertieften Bildanalyse, die ihm Rahmen dieser Forschungsarbeit nicht möglich war. Die übrigen vier Muster journalistischer Auswahl und Thematisierung, die sich aus der Befragung herauskristallisiert haben, lassen sich inhaltsanalytisch bestätigen:

1. Dramatisierung der Gewalt: 72,2 Prozent aller untersuchten Fernsehbeiträge thematisieren tödliche Gewalt. Über Tötungsdelikte wird damit anteilig an der Gewaltberichterstattung mehr als 600-mal so viel berichtet wie es dem Anteil an der polizeilich registrierten Gewaltkriminalität entspricht. Sexuelle Gewalt wird besonders stark thematisiert - Sexualmorde anteilig etwa zehnmal so häufig wie sonstige Tötungsdelikte, nichttödliche sexuelle Gewalt etwa achtmal so oft wie Körperverletzungen.

2. Entgrenzung des Schreckens: Die statistische Reichweite ist für die Auswahl von Delikten unerheblich. Von größerer Bedeutung ist die subjektive Reichweite. So wird der impliziten Annahme, dass die Zielgruppe meist deutsch ist, mit dem stark unterproportionalen Anteil ausländischer Opfer von 3,2 Prozent Rechnung getragen. Dieses Auswahlmuster wird weniger intensiv auf Tatverdächtige angelegt, deren Anteil 12,5 Prozent beträgt.

3. Personalisierung des Leids: Kriminalitätsberichterstattung stellt zu 95,4 Prozent das einzelne Gewaltereignis in den Mittelpunkt. Der journalistische Anspruch, die unmittelbar Beteiligten zu Wort kommen zu lassen, wird in der Mehrzahl der Berichte nicht eingelöst. Nur in 28,4 Prozent der Beiträge äußert sich die Opferseite, und weniger häufig (18,9 Prozent) die Tatverdächtigenseite. Beiträge mit Äußerungen ausschließlich der Opferseite sind mit 14,8 Prozent fast dreimal so häufig wie Beiträge, in denen sich allein die Tatverdächtigenseite (5,3 Prozent) äußert. Die am häufigsten auftretenden Angehörigen sind die Mütter von Gewaltopfern. Häufiger als unmittelbar Betroffene ist die Polizei mit Äußerungen vertreten. Mit einem Anteil von 36,7 Prozent an allen Beiträgen ist sie mit großem Abstand am häufigsten Quelle von Interviewaussagen.

4. Idealisierung des Opfers: Die Polarisierung der Berichterstattung über Gewaltkriminalität zeigt sich in der Auswahl von aus journalistischer Sicht idealtypischen Opfern. Als ideales Opfer gilt das kindliche Opfer. 41,9 Prozent aller Opfer, deren Alter in den untersuchten Fernsehbeiträgen bekannt wird, sind Kinder. 
Werden Kinder zwischen 6 und 13 Jahren Opfer von Gewalt, wird darüber bei gleicher Zahl polizeibekannter Fälle 43-mal so oft berichtet wie über Delikte mit Opfern über 60 Jahren. Bevorzugt wird die Gewalt an weiblichen Opfern thematisiert, ihr Anteil an den analysierten Fernsehformaten beträgt 66,0 Prozent und ist damit, gemessen an der statistischen Zusammensetzung der berichteten Fälle, anderthalbmal so hoch wie der Anteil männlicher Gewaltopfer. Der Idealisierung des Opfers steht die Darstellung der Tatverdächtigen nicht spiegelbildlich gegenüber. In keinem der untersuchten Beiträge werden sie als „Bestie“, „Monster“ oder in ähnlicher Weise bezeichnet. Das Böse bleibt eher unpersönlich. Negative Wertungen wie „brutal“ oder „grausam“ beziehen sich nahezu durchgängig auf die Tat und nicht die Handelnden. 